\title{
Excavaciones en la segunda muralla-sector Puente Lurín. Correlación estratigráfica de los estilos cerámicos durante el Horizonte Tardío en el santuario Pachacamac
}

Fouilles de la deuxième muraille-Pont de Lurín. Corrélation stratigraphique des styles de céramique lors de l'Horizon Récent au sanctuaire de Pachacamac Excavations in the Second Wall - Puente Lurin. Stratigraphic correlation of the ceramic styles during the Late Horizon in the Pachacamac santuary

Jesús A. Ramos Giraldo y Ponciano Paredes Botoni

\section{(2) OpenEdition Journals}

\section{Edición electrónica}

URL: http://journals.openedition.org/bifea/2173

DOI: $10.4000 /$ bifea. 2173

ISSN: 2076-5827

Editor

Institut Français d'Études Andines

Edición impresa

Fecha de publicación: 1 abril 2010

Paginación: 105-166

ISSN: 0303-7495

Referencia electrónica

Jesús A. Ramos Giraldo y Ponciano Paredes Botoni, « Excavaciones en la segunda muralla-sector Puente Lurín. Correlación estratigráfica de los estilos cerámicos durante el Horizonte Tardío en el santuario Pachacamac », Bulletin de l'Institut français d'études andines [En línea], 39 (1) | 2010,

Publicado el 01 octubre 2010, consultado el 07 noviembre 2020. URL : http://journals.openedition.org/ bifea/2173; DOI : https://doi.org/10.4000/bifea.2173

\section{(c) (†) $\ominus$}

Les contenus du Bulletin de l'Institut français d'études andines sont mis à disposition selon les termes de la licence Creative Commons Attribution - Pas d'Utilisation Commerciale - Pas de Modification 4.0 International. 


\title{
Excavaciones en la segunda muralla-sector Puente Lurín \\ Correlación estratigráfica de los estilos cerámicos durante el Horizonte Tardío en el santuario Pachacamac
}

\author{
Jesús A. Ramos Giraldo* \\ Ponciano Paredes Botoni*
}

\begin{abstract}
Resumen
El santuario de Pachacamac plantea la idea de un urbanismo de corte religioso en función de una urbe amurallada por sectores y conforma un eje de calles alrededor de las cuales se distribuye un conjunto de complejos arquitectónicos denominados «Pirámides con Rampa». Eso permite que el crecimiento urbano esté delimitado por anchos muros macizos que cumplirían la función de «murallas» que comienzan en el núcleo y van abarcando paulatinamente los sectores externos. En tal sentido, Ponciano Paredes estableció un ordenamiento cronológico de las murallas e identificó 3 de ellas que corresponderían a los diferentes períodos que se desarrollaron en el santuario. La segunda muralla, según Paredes, correspondería al período Intermedio Tardío, momento de gran auge de las «Pirámides con Rampa». Sin embargo las excavaciones realizadas en 1991 y el análisis de la cerámica recuperada en el sector «Segunda Muralla-Puente Lurín» permiten demostrar que esta muralla se construyó durante el Horizonte Tardío, etapa en que los incas ordenaron la traza cuatripartita y su relación con las principales calles y caminos epimurales que articulaban los diversos sectores del santuario.
\end{abstract}

Palabras claves: segunda muralla, santuario, Horizonte Tardío, Puente Lurín, cerámica, Inca

* Arqueólogo del Instituto Nacional de Cultura. Av. Javier Prado n. ${ }^{\circ}$ 2465, San Borja. E-mail: pachajesus@hotmail.com

**Arqueólogo Consultor. Email: ponparbot@gmail.com 
Fouilles de la deuxième muraille-Pont de Lurín. Corrélation stratigraphique des styles de céramique lors de l'Horizon Récent au sanctuaire de Pachacamac

\section{Résumé}

Le sanctuaire de Pachacamac suggère l'idée d'un urbanisme à caractère religieux dans le cadre d'une ville traversée de remparts qui délimitent autant de secteurs et de rues. Alentour se trouvent des complexes architecturaux qualifiés de «Pyramides à rampe ». La croissance urbaine est donc contrainte par d'epais murs qui auraient une fonction de " remparts ». Ceux-ci commencent au centre du site et occupent progressivement les secteurs périphériques. Ponciano Paredes a établi la chronologie des murailles, rapportant trois d'entre elles aux différentes périodes que le sanctuaire a connues. Selon Parees, la deuxième muraille devrait correspondre à la période de l'Intermédiaire Récent, moment de l'apogée des « Pyramides à rampe ». Cependant les fouilles réalisées en 1991 et l'analyse des poteries récupérées dans le secteur de la Deuxième Muraille-Pont Lurin nous démontrent que ce rempart fut construit au cours de l'Horizon Récent, étape où les Incas ont mis en place le tracé quadripartite, en relation avec les principales rues et chemins entre les murs qui articulaient les différents secteurs et quartiers du Sanctuaire.

Mots clés : deuxième muraille, sanctuaire, Horizon Récent, Pont Lurin, poterie, Inca

\section{Excavations in the Second Wall - Puente Lurin. Stratigraphic} correlation of the ceramic styles during the Late Horizon in the Pachacamac santuary

\section{Abstract} The excavations conducted in 1991 were the first to be carried out at the second wall of the Puente this, crucial information about the stratigraphic sequence of the construction and several changes that the second wall suffered in a short period of time could be found as well as the association between pottery styles whose developments dated back to the Late Horizon times in this sector of the city The main purpose of this investigation is to identify the different pottery styles that gathered in this ceremonial center, and also determine as accurate by as possible, how contemporaneously styles are related that come from the valleys of Rimac, Chillon and some others near the site. Furthermore, the cultures that developed in those valleys shared stylistic characteristics along transverse and longitudinal routes, and of we attempt to do a revision of pottery styles that were located at the lower valleys mentioned, in order to build a framework regional knowledge.

Key words: Second wall, sanctuary, Late Horizon, Puente Lurín, ceramic, Inca

\section{INTRODUCCIÓN}

El centro ceremonial de Pachacamac se encuentra a $31 \mathrm{~km}$ al sur de Lima, en el distrito de Lurín. El área del presente estudio se ubica hacia el lado Este, muy cerca de la actual población conocida como Puente Lurín o Asentamiento Humano (AAHH) Julio C. Tello (fig. 1).

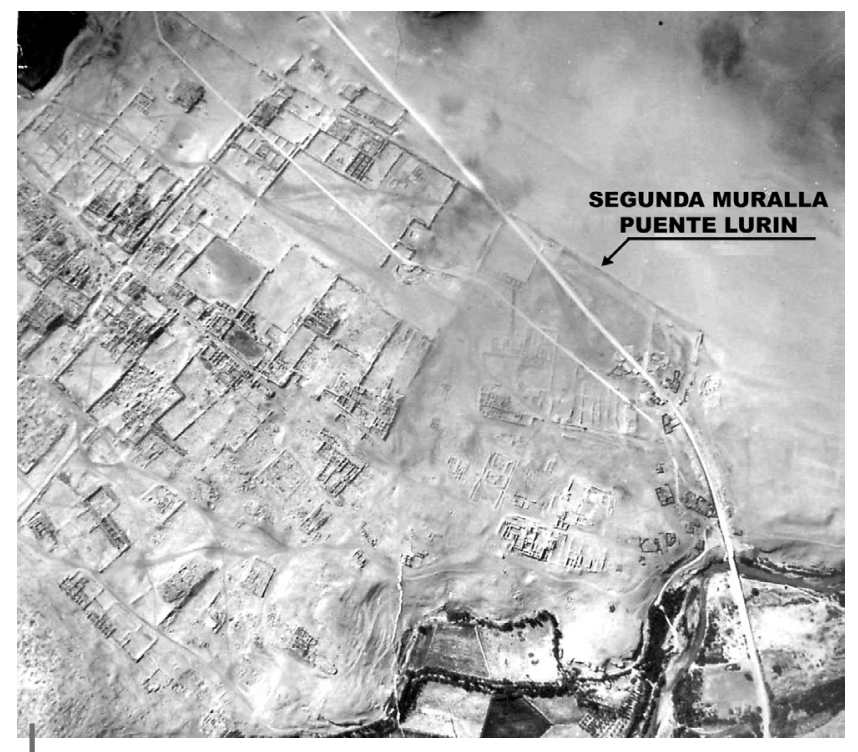

Figura 1 - Ubicación de la segunda muralla-Puente Lurín

La Segunda Muralla se encuentra en la parte central de la zona monumental y estaría directamente relacionada con el sector de las «Pirámides con Rampa» y con la fase tardía de auge constructivo de las mismas hacia la periferia del centro ceremonial. Su presencia indicaría la existencia de un control en el flujo de gente que participaba en el calendario anual de peregrinaciones, romerías y servicios necrológicos (Paredes 1991a: 381). Paredes (1991b) situa cronológicamente la segunda muralla entre los años 1000-1532 d. C., pero las primeras excavaciones realizadas en 1991 nos permiten precisar que la segunda muralla se construyó en el Horizonte Tardío.

De acuerdo a su trazo, la segunda muralla debería encerrar todas las «Pirámides con Rampa», pero los trabajos de campo demuestran que, fuera de esta muralla también se han identificado dos «Pirámides» aisladas. Junto con la calle Norte-Sur, que se orienta a su vez con la Portada de la Costa insertada en la tercera muralla, la segunda muralla se convierte en el eje ordenador de la ciudad, integrando calles y caminos epimurales.

En su construcción se emplearon adobes unidos con argamasa de barro y, como sobrecimiento, la mampostería de piedra pizarra que llega hasta una altura promedio de $1 \mathrm{~m}$ calculada a partir de la actual superficie.

Según el plano elaborado por Uhle (1903), la segunda muralla era una sola construcción. En el primer tercio del siglo XX fue cortada para construir la antigua carretera panamericana sur, razón por la cual hoy en día se encuentra partida en 
dos secciones: segunda muralla de la zona monumental y segunda muralla del sector Puente Lurín (fig. 2).

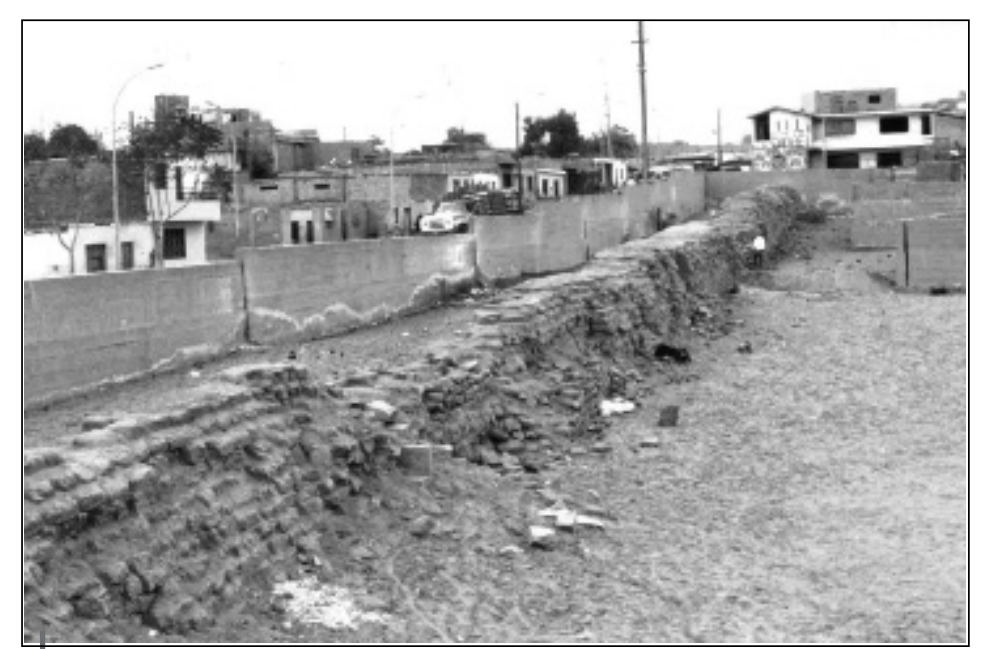

Figura 2 - Vista de la segunda muralla-Puente Lurín antes de iniciar los trabajos de excavación

Producida esta división, la segunda muralla del Puente Lurín alcanza 190 m de largo y $3 \mathrm{~m}$ de ancho y tiene una dirección este-oeste. En el paramento sur se aprecian 8 pequeños cuartos que pudieron cumplir la función de depósitos, en cuyo extremo este existe una plataforma muy destruida. A pesar de que en esta zona la segunda muralla se encuentra protegida por un muro de concreto, su estado de conservación es muy deteriorado, produciéndose desplomes en grandes tramos; además sus bases están muy erosionadas, lo cual afecta la estabilidad integral de la misma.

Las excavaciones realizadas en 1991 son los primeros trabajos efectuados en la segunda muralla del Sector Puente Lurín-ZAM Pachacamac. La coordinación realizada entre el Dr. Arturo Jiménez, Director del Museo de Sitio de Pachacamac, y la dirigencia del $\mathrm{AAHH}$ «Julio C. Tello»-Puente Lurín, permitió que personal del Museo de Sitio de Pachacamac llevara a cabo el trabajo de monitoreo arqueológico permanente durante la ejecución de las obras de instalación de redes de servicios básicos. Para lograr eso fue necesario realizar excavaciones arqueológicas para demostrar el potencial subyacente, pues se requería dar paso a las tuberías de la red de desagüe y cortar esta muralla.

Se efectuaron 4 unidades de excavación ubicadas a ambos paramentos (fig. 3) cuyos resultados proporcionaron una importante información sobre la secuencia estratigráfica de la construcción y remodelaciones que sufrió la segunda muralla en un corto período de tiempo, así como las asociaciones y contactos de los estilos alfareros que se desarrollaron durante el Horizonte Tardío en este sector de la ciudad sagrada. Por eso el tema principal de ese trabajo está centrado en la identificación de los estilos alfareros del centro ceremonial en particular, y la determinación, con la mayor aproximación posible, de las relaciones de contemporaneidad con los valles del Rímac, Chillón y demás valles vecinos. Asimismo se trata de hacer una revisión de los estilos alfareros que florecieron para la parte baja de estos valles, de manera que se tenga un conocimiento regional, puesto que las culturas que se desarrollaron en estos valles compartieron características estilísticas en recorridos longitudinales y transversales.

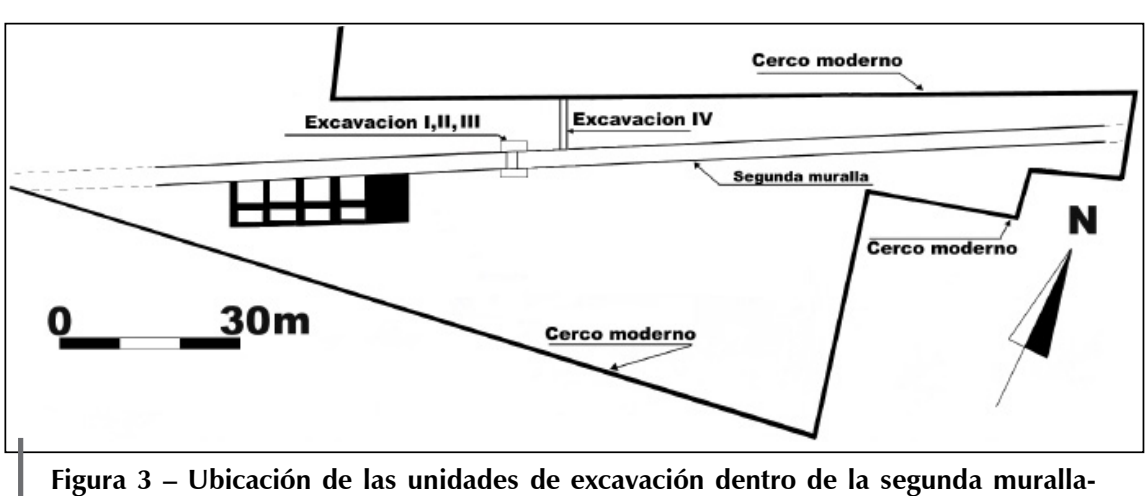

Figura 3 - Ubicación de las unidades de excavación dentro de la segunda murallaPuente Lurín

\section{ANTECEDENTES}

La orientación de nuestra investigación tomó en cuenta trabajos específicos de investigadores que han profundizado el tema de los estilos cerámicos desarrollados en el santuario, encontrando que la información es muy escasa, ya que siempre se trata sobre la monumentalidad del centro ceremonial, mas no sobre quiénes habitaron y construyeron esos edificios, así como su relación entre ellos y los valles vecinos.

Los primeros trabajos corresponden a Max Uhle (1903) quien identifica muestras del estilo «Tiahuanaco», planteando que no fueron producidos en Pachacamac. Luego aísla un estilo que denomina «Epigonal», englobando a entierros asociados con cerámica definitivamente pre Inca y que pueden fecharse en la parte final del Horizonte Medio (900-1000 d. C.).

Excavando debajo de las terrazas del Templo de Pachacamaco Pintado, pero encima del cementerio antiguo, Uhle encuentra un grupo de tumbas con cerámicas menos artísticas. Consisten principalmente en cántaros largos de cuerpo redondeado, de base plana y cuellos cilíndricos cortos; también identifica copas, platos con borde en la parte inferior a manera de una base, jarras y finalmente algunos vasos con pequeños cuellos (Uhle, 1903). Todo esto le lleva a manifestar que las formas de las vasijas son totalmente diferentes a las del período temprano.

La característica principal de estas vasijas es la superficie poco pulida con colores blanquecino con rojo y figuras negras. Corresponden a los estilos que Kroeber (1926) denominó «Epigonal» y «Tricolor Geométrico de Chancay» y Strong (1925) 
llamó «Ancón Tardío l», y que estarían fechados entre 900 y 1100 d. C. Además algunas vasijas son identificadas gracias a una decoración modelada, característica del estilo Chimú difundido o de influencia Chimú, que pertenecerían a la parte final del Intermedio Tardío. En un nivel superior, Uhle reportó otro lote de tumbas que incluían cerámica de los estilos Inca Imperial y costeños del Horizonte Tardío (1440-1533 d. C.). En consecuencia, los trabajos realizados por Uhle permitieron tener un conocimiento general de la cerámica, principalmente funeraria.

En 1941, Strong y Corbett excavan en los basurales del Templo del Sol. Realizan una gran trinchera muy cerca de la entrada del frente este con un área de $104 \mathrm{~m}^{2}$ alcanzando una profundidad máxima de $13 \mathrm{~m}$. Los estilos cerámicos recuperados son: «Interlocking» que incluyen algunos tiestos decorados denominándolos tipos «Blanco sobre Rojo», «Pachacamac Negativo», «Blanco y Negro sobre Rojo», «lnca Asociado» e «Inca» (Strong et al., 1943: 62). La ocupación Inca incluye tiestos de fino acabado y destacan los aríbalos y platos con mangos; también se presentan restos de remodelaciones arquitectónicas (enlucidos de color rojo, caña y totora), y materiales orgánicos, vegetal y animal, que formaban parte de la dieta alimenticia así como otras evidencias de la vida cotidiana. Los autores las interpretan como indicadores de un grupo de la nobleza Inca, probablemente los sacerdotes que vivían en las terrazas del Templo del Sol con sus sirvientes.

Entre 1980 y 1982, Ponciano Paredes excava en la «Pirámide con Rampa» n. ${ }^{\circ}$ 2. En su informe de campo, Paredes (1988) da un mayor énfasis al aspecto arquitectónico. Describe cada ambiente que ha excavado, y ensaya asignarle función a cada uno. Para inferir la función utiliza la ubicación y morfología de las habitaciones.

Años más tarde, Franco $(1993 ; 1998)$ publica los resultados de las investigaciones, donde identifica tres momentos constructivos para la «pirámide». Las excavaciones realizadas muestran que los pisos conservan las evidencias de una fuerte actividad ceremonial. Además la concentración de cientos de tiestos de vasijas quebradas sobre los diferentes niveles de pisos hasta la época incaica, confirmarían que en este sector se realizaban rituales masivos (Franco, 1998: 63-64) y que el patio era el lugar de concentración de las actividades ceremoniales y comunitarias.

La secuencia alfarera que establece se basa en una tipología con registro estratigráfico recuperado en la «Pirámide con Rampa» n. ${ }^{\circ} 2$ y en otros sitios de Pachacamac (Franco, 1993). Al tratar de correlacionar la etapa de ocupación más temprana con la cerámica, señala que no descubrió restos de cerámica que pueden identificar a los primeros ocupantes, a excepción de un fragmento de cerámica incrustado en un adobe, pintada de color negro y rojo oscuro, que por su tratamiento correspondería al Horizonte Medio (Franco, 1993). El tipo «IncisoPunzonado Acabado» fue encontrado en la capa más profunda del patio principal. El autor precisa que se halló asociado en la capa XV con numerosos fragmentos de cerámica de uso exclusivamente utilitario o doméstico, con pintura amarillo pálido y sin pintura, de textura tosca con decoración de figuras geométricas incisas rellenas con punzonado. Sus formas corresponden a cuellos recto-divergentes (Franco, 1993).
El segundo momento constructivo se asocia a construcciones de adobes diferentes a los anteriores. La cerámica del segundo momento está representada por cántaros cara-gollete pintados con colores marrón oscuro sobre amarillo pálido, vasijas abiertas o escudillas de paredes rojizas, pulidas, vasijas cerradas con cuerpo aquillado pintadas de color amarillo pálido o blanco en el tercio superior y rojo oscuro en el cuerpo inferior. Se suman algunos tiestos de ollas de uso doméstico trabajadas con cerámica negra y elementos decorativos en relieve de serpientes con incisos, círculos impresos y una cara-gollete alta de lados divergentes con tratamiento inciso y ojos alados. También se reconocen pequeños fragmentos pintados de color rojo, negro y blanco, donde negro y blanco aparecen unidos siempre, en líneas delgadas sobre el fondo rojo oscuro (Franco, 1993).

El tercer momento estaría relacionado con la presencia Inca en Pachacamac, momento en que continúan produciéndose los mismos tipos identificados; sin embargo surgen nuevos, vinculados a la alfarería de los incas. La cerámica asociada mencionada, corresponde a los estilos Ishmay Pachacamac e Inca relacionada a basurales encontrados en los patios. Lamentablemente Franco no detalla estos contextos, dando lugar a especulaciones.

Revisando los trabajos de Franco $(1993 ;$ 1998) se aprecia que no mantiene una correlación entre sus datos estratigráficos y sus conclusiones. Al respecto, creemos que las 3 fases o momentos propuestos por Franco para la «Pirámide con Rampa» n. ${ }^{\circ} 2$ deben ser revisados a la luz de un análisis más concienzudo del material cerámico recuperado. No se puede aceptar que se elabore una secuencia alfarera a partir de la presencia de un tiesto incrustado en un adobe, relacionado con el Horizone Medio solo por su tratamiento.

También reporta 3 muestras del tipo «Inciso-Punzonado Acabado» que nosotros identificamos como «Punzonado en Zona». Franco (1998: 60) manifiesta que este tipo aparece en los niveles más tempranos de la «Pirámide» n. ${ }^{\circ} 2$ y que habría sido utilizado por sus constructores. Sin embargo, años antes, Franco (1993) señala que no ha sido posible hallar cerámica que pueda identificar a los primeros ocupantes de la «pirámide», ya que el tipo «Inciso-Punzonado Acabado» fue recuperado en un nivel de relleno constructivo. A pesar de eso, realiza toda una caracterización y comparación atribuyéndole una correspondencia cronológica a la época 3 del Horizonte Medio.

Para el segundo momento, manifiesta haber recuperado tiestos con elementos decorativos en relieve de serpientes con incisos y círculos impresos. Según comparaciones la presencia del motivo de la serpiente fue introducida por los incas a su llegada a la costa central, por lo que este motivo estaría relacionado al Horizonte Tardío.

Franco (1993) también identifica el tipo «Marrón Oscuro/Amarillo Pálido», como parte de la segunda fase. Refiere que su acabado es áspero al tacto, las tonalidades marrón oscuro son variados: marrón oscuro 10YR 4/3, aceituna pálido 5 y 6/3, aceituna grisáceo oscuro 5 y $3 / 2$ y marrón oscuro bien cargado 7,5YR 5/6. El color amarillo pálido se presenta en 5 y 8/3-8/4. Algunas veces hay en el interior un engobe de color pardo 7,5YR 5/4. Otros no tienen engobe y el color de la superficie es un rojo claro 2,5 YR 6/6-6/8. Durante el Horizonte Tardío, el tipo 
«Marrón Oscuro/Amarillo Pálido» continúa presente en los niveles estratigráficos asociados con cerámica incaica (Franco, 1993); sin embargo, existen vasijas con diferencias menores en la forma. Según nuestras comparaciones, Franco (1993) considera dentro del tipo «Marrón Oscuro/Amarillo Pálido» a la cerámica Marrón sobre Crema y el estilo Puerto Viejo - tipo Negro sobre Blanco-, cuando todo pertenece al estilo Puerto Viejo y dataría del Horizonte Tardío. También describe una vasija cerrada como cara-cuello, evertida; el rostro diseñado tiene un color marrón oscuro sobre blanco 5 y $8 / 1$. Se caracteriza también por tener el contorno del borde interior pintado entre blanco y amarillo pálido (Franco 1993). Sin embargo la considera dentro del tipo «Marrón Oscuro/Amarillo Pálido». Formaría parte del tipo Cara-Gollete del estilo Puerto Viejo.

En el grupo «Inca Asociado» considera que existen muchos estilos en asociación con cerámica incaica o viceversa (Franco, 1993), pero refiere que es todavía un poco difícil establecer una clasificación por tipos, puesto que se cuenta con un reducido número de fragmentos de cada tipo. Sin embargo, Franco logra identificar tentativamente 4 tipos: entre ellos, el tipo «Negro, Amarillo Pálido»o «Blanco sobre Engobe Rojo» serían parte del tipo Cara-Gollete. La cerámica que Franco describe como tipo «Negro, Amarillo Pálido» o «Blanco sobre Engobe Rojo» está conformada por la del tipo «Cara-Cuello» larga; los rasgos de la cara están delineados con color negro, el fondo de los ojos y la boca amarillo pálido, ambos colores están sobre un fondo con engobe rojo oscuro (Franco, 1993: Figs. 68, 69). Reporta un reducido número (describe 2 fragmentos); este tipo formaría parte del estilo Puerto Viejo-«Cara-Gollete».

Con lo expuesto, estamos apreciando que se tendrían que afinar las 3 fases propuestas por Franco para la «Pirámide con Rampa» $\mathrm{n}{ }^{\circ} 2$; el material recuperado y asignado a la segunda fase formaría parte del Horizonte Tardío. Franco (1998: 47) también define al tipo «Engobe Rojizo Bruñido y Sin Bruñir». Según las comparaciones hechas, este tipo correspondería al «Marrón Micáceo», reportado en la «Pirámide con Rampa» n. ${ }^{\circ} 1$ y en varias excavaciones dentro del centro ceremonial, así como en Puente Lurín y en todo el valle de Lurín; siempre está asociado a materiales del Horizonte Tardío (Feltham, 1983; Paredes \& Ramos, 1994: 347; Eeckhout \& Ramos, 1995; Eeckhout, 1999a: 40). El tipo «Marrón Micáceo» también ha sido reconocido en la «Pirámide con Rampa» n. $^{\circ} 3$. Eeckhout (1999b: 56) lo denomina «Lurín Brun Lisse». En el sitio 26, ubicado en la margen izquierda de la quebrada Cruz de Hueso —Pampa de San Bartolo—, se ha reportado la asociación del tipo «Marrón Micáceo» con cerámica Inca, pero junto a ellos se recuperaron restos de textiles de la época colonial (Ramos \& Paredes, 2002: 50). El tipo «Marrón Micáceo» continuó utilizándose en los primeros años de la Conquista, las formas no cambiaron, razón por la cual es fácil identificarlo. Para 1991 Shimada realiza una revisión bibliográfica de los trabajos realizados en Pachacamac. Cuando trata de los estilos cerámicos del período Intermedio Tardío señala que aún son imprecisos. Para el valle de Lurín, manifiesta que el estilo Tri-Color Geométrico es transformado dentro del Ichimay Blanco sobre Rojo, y explica que era el estilo para el tiempo en que el Señorío de Ichimay gobernaba el valle (Shimada, 1991: XXVII). Sin embargo, no muestra ni describe las formas propias del supuesto estilo, llegando incluso a manifestar que era contemporáneo al Negro sobre Blanco del estilo Chancay Tardío.

Desde 1993 hasta 1999 Eeckhout estuvo realizando trabajos de excavación en la «Pirámide con Rampa» n. ${ }^{\circ} 3$. Luego de varios años aún no han logrado resolver la problemática de la función, ni la secuencia alfarera. Eeckhout (1999a: 170 no acepta el modelo de «Embajadas religiosas» por estar directamente inspirado por las fuentes etnohistóricas. Por el contrario, propone un planteamiento muy particular y parecido al de la escuela norteamericana para Chan Chan. Plantea que en Pachacamac cada una de las «pirámides» se construye y se ocupa durante un período bastante corto, correspondiendo a la duración de un reino, que las «pirámides» son aparentemente sucesivas y cada una se construye una vez que la anterior es abandonada (Eeckhout, 1999a: 209).

Para la clasificación de la cerámica recuperada en la «Pirámide con Rampa» n. ${ }^{\circ} 3$, elabora su propia tipología y para ello utiliza la estratigrafía y las fechas absolutas. En la Unidad 1, los fechados de radiocarbono han permitido determinar que la ocupación se remonta al siglo X y continúa hasta el XV; en otros sectores de la «pirámide», los fechados corresponden a los siglos XV y XVI (Eeckhout, 1999a: 183). Utilizando la cronología empleada por Menzel para el valle de Ica, la muestra de cerámica recolectada en 1995 abarca íntegramente el período Intermedio Tardío y el Horizonte Tardío (Eeckhout, 1999a: 184). Sin embargo hasta la fecha, Eeckhout no ha descrito el material cerámico a pesar de varias temporadas de excavación realizadas. En los diversos artículos publicados solo proporciona información de la arquitectura y la religiosidad del sitio.

De acuerdo a lo que hemos podido apreciar personalmente, en la colección de cerámica recuperada se distinguen los estilos Lambayeque y Chimú propio de la costa norte; también se identifican el estilo Puerto Viejo, un grupo de muestras de cerámica del tipo «Marrón Micáceo» que estamos denominando «Estilo Lurín» y otros alfares clásicos de la zona. Pero es necesario que Eeckhout presente la información estratigráfica para poder correlacionar la asociación que presenta estos materiales.

Como parte de su trabajo de investigación de pre bachillerato, Rocío Aramburu y Marco Machacuay presentan una monografía «Talleres Inca de Producción no agrícola en Pachacamac», redactada en base a los trabajos de excavación realizados en los alrededores de la tercera muralla, entre los años 1994 y 1995 (Aramburu \& Machacuay, 1996)

La excavación en el sector II muestra dos ocupaciones. La ocupación 1 correspondería a la ocupación final Ishmay en los inicios del Horizonte Tardío. No encuentran estructuras elaboradas anteriores a la arquitectura Inca. La ocupación 2 se relaciona con la presencia Inca; las excavaciones hallan un conjunto de 4 recintos rectangulares orientados al noroeste y una zona de depósitos. Estos recintos están divididos funcionalmente (depósitos, cocinas) y tienen los accesos restringidos, presentan elementos constructivos más definidos (pisos, cimientos) y materiales imperecederos en su mayor parte (Aramburu \& Machacuay, 1996: 26-27). 
Cuando realizan el análisis de la cerámica recuperada, refieren haber identificado 26 alfares. Además, basándose en la decoración, los acabados y las formas de los fragmentos, diferencian la cerámica en los siguientes grupos: «Inca Imperial», «Inca Asociado», «lchma y Foráneos» (Aramburu \& Machacuay, 1996: 47). En el grupo «Inca Asociado» identifican el subgrupo «Cara-Gollete». Describen esta cerámica como correspondiente a cántaros de mediana proporción y formas ovoides en cuyo cuello se han modelado los rasgos humanos faciales (Aramburu \& Machacuay, 1996: 50). Sin embargo, estos investigadores no logran realizar una comparación con la cerámica de Puerto Viejo.

Para el grupo «Foráneo», determinan la existencia de cerámica «Chancay» y «Chimú»; sin embargo no presentan los dibujos o, si los presentan, no mencionan a qué grupo pertenecen. Al parecer los autores no dan mucha importancia a la identificación de los estilo alfareros, puesto que su objetivo era identificar los talleres de trabajo en el sector de Pachacamac.

El año 2000, Cornejo presenta una síntesis de su tesis doctoral donde discute cómo la administración Ishmay fue incorporada como provincia Inca en términos políticos, religiosos y sociales (Cornejo, 2000: 149). Cuando se refiere al estilo Ishmay, dice que no ha sido adecuadamente descrito. Sin embargo, propone que vendría del Horizonte Medio y quizás estaría relacionado con el estilo Pachacamac propuesto por Menzel (Cornejo, 2000: 166). Tentativamente divide el estilo en dos tipos: «cerámica decorada ceremonial» y «cerámica doméstica». Para Cornejo la cerámica ceremonial sería parte del estilo llamado Pachacamac pero no lo define; utiliza como argumento que nadie es claro en definir este tipo. En cambio, describe la cerámica doméstica como decorada con bandas anchas de color blanco, serpientes aplicadas en el cuerpo o gollete de manera opuesta y representando formas de frutos; algunas veces se encuentra asociada a cerámica ceremonial Inca provincial e Ishmay ceremonial (Cornejo, 2000: 166). Por lo descrito, Cornejo considera como estilo Ishmay varios tipos de cerámica sin considerar sus contextos de procedencia, por ejemplo: la cerámica doméstica decorada con serpientes aplicadas correspondería al tipo «Marrón Micáceo».

En 2004, Feltham \& Eeckhout publican un artículo sobre el estilo Ychsma Tardío en base al material recuperado en la «Pirámide con Rampa» n. ${ }^{\circ} 3$. En primer lugar, sitúan el estilo Ychsma Tardío desde finales del siglo XIV hasta las primeras décadas de la Colonia. Luego de un estudio morfológico de los materiales cerámicos, identifican 6 clases: los platos, los cuencos, las jarras, los frascos y botellas, las tinajas y tinajones y las vasijas en miniatura (Feltham \& Eeckhout, 2004: 658).

Al describir cada clase identificada, manifiestan que no hubieron platos en el Ychsma Tardío; los cuencos fueron la forma más frecuente (Feltham \& Eeckhout, 2004: 658). Los autores describen los cuencos con cuerpo carenado, engobe rojo y una capa de pintura blanca en la parte superior. Un diseño de pequeños rectángulos con un punto al interior, o de triángulos, o de peces, está pintado sobre esta capa; esta forma fue la más frecuente en el Ychsma Tardío.

A partir de tiestos y ceramios enteros los autores realizan una descripción morfológica de las vasijas lo que sirve para sustentar su estilo Ychsma Tardío. Sin embargo se olvidan de correlacionar las formas y estilos identificados en otras zonas y engloban todo el material recuperado dentro de un mismo estilo, cayendo en errores a obviar los trabajos anteriores1. Por ejemplo, la descripción y las figuras presentadas por Feltham \& Eeckhout (2004: Figs. 17 y 18), que llaman cuenco del «Ychsma Tardío», corresponderían a lo que proponemos identificar como estilo Puerto Viejo - tipo Negro sobre Crema-. Además presentan muchas vasijas oriundas del valle de Lurín que llaman Ychsma Tardío, olvidándose que el supuesto señorío de Ishmay mencionado en los documentos etnohistóricos, está conformado por varios curacazgos que son independientes política y económicamente 2 y que, por lo tanto, tiene una producción artesanal autónoma.

A partir de sus excavaciones en el sitio arqueológico Pueblo Viejo-Pucará, Makowski \& Vega Centeno (2004) realizan un estudio sobre los estilos regionales en la costa central durante el Horizonte Tardío. Makowski \& Vega Centeno (2004 687), señalan que para hacer una profunda revisión de conceptos clasificatorios y un seguimiento sistemático de la distribución de talleres con sus tradiciones tecnológicas previamente definidas, se requiere de un esfuerzo mancomunado de varios proyectos. Para eso, utilizan muy acertadamente las clasificaciones presentes en los períodos tardíos donde resalta que algunas tienen un origen local, otras son sin duda de procedencia foránea y otras parecen haberse formado gracias a la asimilación selectiva de algunos procedimientos de acabado e imitación de diseños decorativos que se originaron fuera de ambas cuencas.

Utilizando este criterio, el análisis de una muestra de 3456 fragmentos diagnósticos seleccionados les permite definir 16 alfares y varios estilos: «Ychsma» local del valle bajo, la cerámica marrón del valle alto, «Puerto Viejo» de la costa, estilo influenciado por la Costa Norte, incluyendo el «Chimú-Inca», y el «Inca Provincial». Por la descripción que hacen de la cerámica marrón, parece corresponder, por el alfar, a la tradición serrana, así como por las formas características (cántaros

A lo largo de los años, la cerámica del estilo Puerto Viejo recuperada en Pachacamac ha sido denominada de diferente manera. En el siguiente cuadro se realiza una comparación entre los denominada de diferente manera.
principales investigadores del tema:

\begin{tabular}{|c|c|c|c|c|c|}
\hline Franco (1993) & $\begin{array}{l}\text { Makowski \& Vega } \\
\text { Centeno (2004) }\end{array}$ & $\begin{array}{l}\text { Feltham \& Eec- } \\
\text { khout (2004) }\end{array}$ & $\begin{array}{l}\text { Vallejo } \\
(2004)\end{array}$ & Bueno (1982) & $\begin{array}{c}\text { Paredes \& Franco } \\
(1987-1988)\end{array}$ \\
\hline $\begin{array}{l}\text { Negro, Amarillo } \\
\text { pálido o blanco } \\
\text { sobre engobe } \\
\text { rojo. } \\
\text { Marrón oscuro } \\
\text { sobre amarillo } \\
\text { pálido }\end{array}$ & Puerto Viejo & Ychsma tardío & $\begin{array}{l}\text { Ychsma tar- } \\
\text { dío A y B }\end{array}$ & $\begin{array}{l}\text { Ichima Cara } \\
\text { Gollete. } \\
\text { Ichimay Negro } \\
\text { sobre blanco }\end{array}$ & Ichma Bícromo \\
\hline
\end{tabular}

2 Los documentos etnohistóricos señalan que el valle bajo de Lurín durante la época inca estaba conformado por los curacazgos de: Ishmay, Manchay, Quilcay y Caringa que eran señoríos naturales, y que también eran políticamente autónomos con organización dual. Al existir la autonomía política, los asentamientos podían ser diferentes en el plano arquitectónico, porque cada dominio étnico tenía su propia unidad administrativa de ubicación central. 
con labios reforzados interna y externamente; cántaros con cuello compuesto, ollas, pequeñas botellas, platos, etc.) y por el acabado marrón llano. Su única decoración consiste en el uso de pintura roja poscocción y en algunos casos, en las serpientes aplicadas (Makowski \& Vega Centeno, 2004: 700). Este grupo de cerámica corresponde a lo que nosotros hemos identificado en Pachacamac como tipo «Marrón Micáceo» y que denominamos en este trabajo «Estilo Lurín»3.

Planteamos que el alfar dominante del «Estilo Lurín» tiene su origen en uno de los dos alfares predominantes a partir del Horizonte Blanco sobre Rojo y que abundan en los complejos cerámicos de la Tablada de Lurín y de las Lomas de Valle de Lurín, en donde abundan también las serpientes aplicadas en el cuerpo de las ollas y cántaros. La cantera de donde proviene la materia prima de estos alfares es de colinas metamorfizadas del batolito de la costa. Por su lado, las canteras de arcilla se obtienen de los mantos de llapana o ihuancos que existen en las quebradas de lomas y que se ubican en las intercuencas que flanquean a los valles de la costa central.

Al tomar como corpus principal los materiales recuperados en las excavaciones realizadas por el Dr. Arturo Jiménez en el sitio arqueológico de Huallamarca, valle bajo del Rímac, Guerrero trata de caracterizar los estilos cerámicos que se desarrollaron en la costa central durante los períodos tardíos (Guerrero, 2004: 157). A pesar de que aún no existe una definición consistente y consensual y tampoco se conocen los rasgos distintivos del desarrollo temporal del estilo Ishmay, acepta el término Ishmay, tal como lo definió Bazán (1990), como el nombre de estilo local del valle de Lima (Bazán, 1990: 17). Según Guerrero (2004: 164), el estilo Ishmay está surgiendo a fines de las épocas 2-3 del Horizonte Medio. Cuando realiza la descripción de la cerámica de los períodos Intermedio Tardío y Horizonte Tardío, no solo trata de los motivos decorativos, sino también de las formas, ya que cuenta con ceramios enteros recuperados en los entierros de los sitios arqueológicos de Huallamarca, Rinconada Alta y Armatambo.

Cuando trata de identificar las vasijas propias del Intermedio Tardío, sólo describe las propias de los inicios de este período, tales como los cántaros cara-gollete con los rasgos faciales y las extremidades representadas en relieve; en algunos casos se registra decoración punteada en zona (casi siempre triángulos) delimitada

${ }^{3}$ Los investigadores que han identificado el estilo Lurín, le asignan diferentes nombres que corresponden mayormente a la técnica de acabado; en tal sentido tendríamos lo siguiente:

\begin{tabular}{|c|c|c|c|}
\hline Ramos \& Paredes (1992) & Franco (1993) & Eeckhout (1999b) & Makowski \& Vega Centeno (2004) \\
\hline Marrón Micáceo & $\begin{array}{c}\text { Engobe Rojizo } \\
\text { Bruñido y Sin } \\
\text { Bruñir }\end{array}$ & Lurín Brun Lisse & Cerámica Marrón \\
\hline
\end{tabular}

con incisiones (Guerrero, 2004: 167). Para nosotros esta vasija pertenece al tipo «Punteado en Zona» y corresponde a las épocas 2 y 3 del Intermedio Tardío.

Cuando describe la cerámica del Horizonte Tardío, Guerrero (2004: 168) presenta una mayor diversificación de estilos, e identifica los estilos Chimú, Chimú-Inca, Ica, Lambayeque y Puerto Viejo. Llama la atención que, a pesar de que la cerámica procedente de Armatambo, Huallamarca y Rinconada Alta pertenece a la misma época, existen grandes diferencias que Guerrero (2004: 171) atribuye al origen Inca de los asentamientos de Armatambo y Rinconada Alta. Sin embargo, uno olvida que cada asentamiento fue independiente política y económicamente, y en tal sentido, cada uno debió tener su propia producción local de alfares en el momento de la conquista Inca. Es el caso especial de Armatambo que, junto con Pachacamac y el Bajo Lurín, conformaron un Hunu con el Señorío de Surco en el Rímac (Cornejo, 2000:150). En este sentido, una capital de Hunu debió tener una mayor presencia de grupos locales y foráneos. No está nada claro el panorama de los estilos de cerámica que se desarrollaron a extramuros de la Segunda Muralla del Santuario Arqueológico Pachacamac para los últimos 500 años previos a la llegada de los españoles. Por eso el próposito del presente trabajo es aportar evidencias e hipótesis para el mejor estudio del tema.

\section{PROCEDENCIA DE LA MUESTRA}

En este trabajo se ha tomado en cuenta la cerámica de la excavación IV (una de las cuatro excavaciones realizadas en la segunda muralla del Puente Lurín). Esta excavación alcanzó un área de 7,50 m², con una profundidad de 1,60 m, excavándose solo el paramento norte de la muralla (fig. 4). Durante el proceso de excavación se aplicó el decapado (fig. 5), lo que nos permitió identificar 73 niveles culturales (fig. 6) y siete bolsones con contenido cultural.

\section{RESULTADO DE LOS ANÁLISIS DE LA CERÁMICA}

La cerámica trabajada procede de las excavaciones sistemáticas; por eso disponemos exclusivamente de fragmentos. Este carácter de selección determina el tipo de análisis tipológico, basado ante todo en los fragmentos de los bordes y de otras partes características de las vasijas. Su análisis nos permite conocer el contexto del conjunto de vasijas utilizadas por los moradores de este componente arquitectónico investigado.

La cronología relativa divide el desarrollo local en fases o períodos cortos de tiempo, y se basa en las variaciones estilísticas observadas en la cerámica que procede de las capas estratigráficas de los sitios excavados. Entonces, uno de los propósitos del análisis es definir la fase o fases representadas en los materiales acumulados en la Segunda Muralla-Puente Lurín. En la clasificación y descripción, hemos establecido una fase, a la cual corresponde determinado tipo de cerámica. Esta secuencia se basa en las excavaciones estratigráficas 

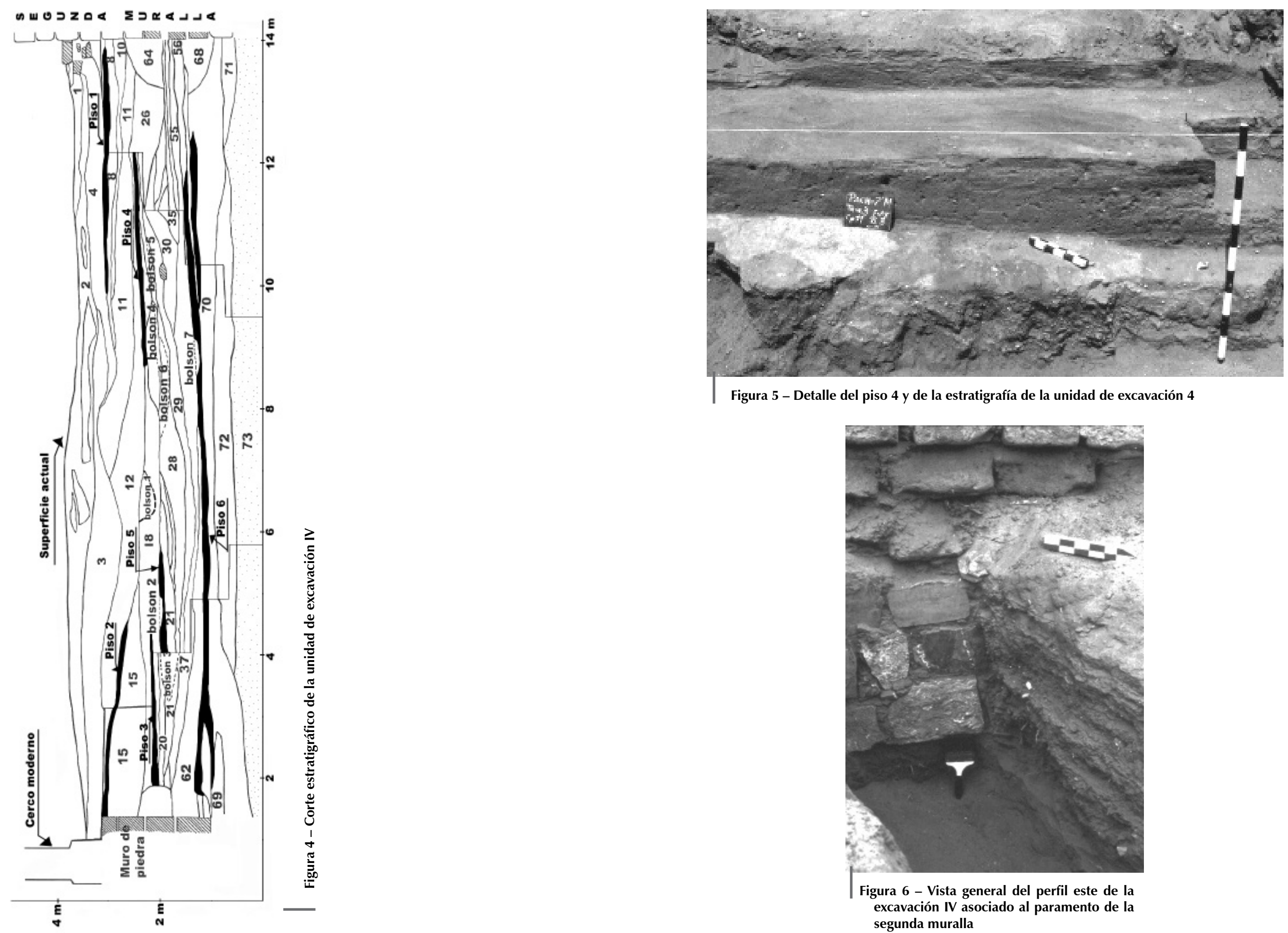

Figura 5 - Detalle del piso 4 y de la estratigrafía de la unidad de excavación 4

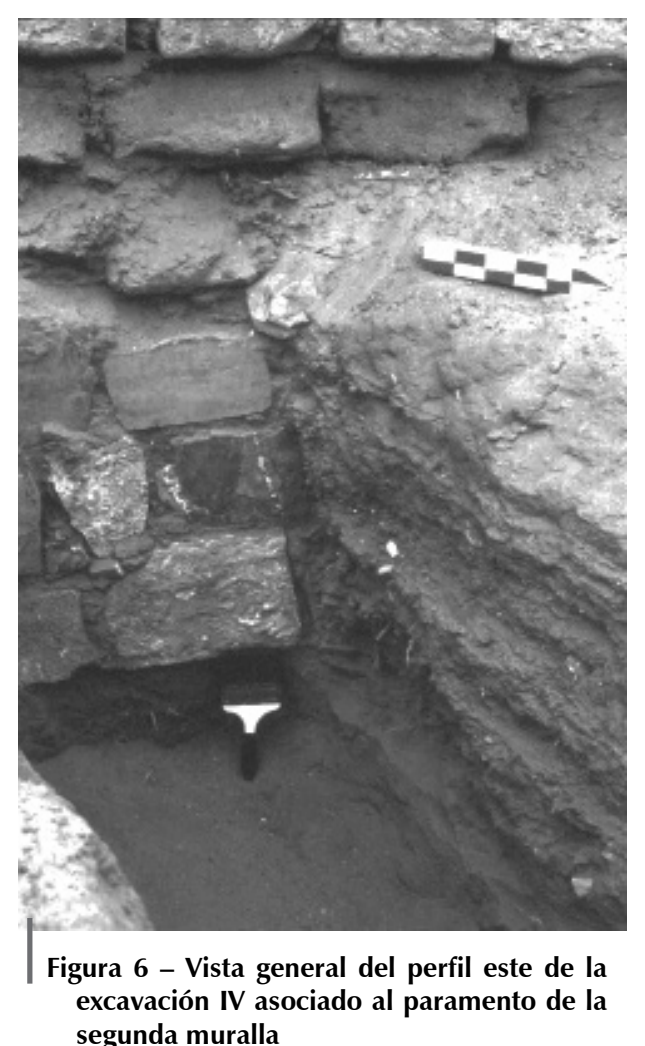


de la Unidad IV4. En el material analizado se distinguen claramente 4 estilos: «Inca Local», «Lurín», «Puerto Viejo» e «lshmay-Pachacamac»5. En este último estilo hemos agrupado 10 tipos de cerámica considerando el tratamiento de la superficie, decoración y forma.

Al considerar que los procesos de descripción de los tipos de pasta tienen un significado muy importante para todo el análisis, se procede a continuación:

\section{1. Descripción de los tipos de pasta}

En la colección de cerámica analizada se observan 7 tipos de pastas. Se distinguen especialmente los tiestos con la pasta clara de grano mediano; su temperante dominante consiste en partículas blanco lechosas y transparentes de grano grueso a mediano, de forma angulosa y distribuida en forma uniforme.

Los análisis se efectuaron solo en los tiestos diagnósticos6, puesto que son los más fáciles de comparar estilísticamente.

A continuación se describe los tipos de pastas correspondientes:

\section{Pasta A}

Temperante: contiene partículas blancas transparentes y lechosas, además de partículas de color gris oscuro, de formas angulosas. Algunos fragmentos presentan además partículas de color marrón en poca cantidad, de forma redondeada. También se observan pocas láminas de mica.

Textura: De consistencia compacta a semicompacta.

Color: Desigual. Hay tiestos que presentan la pasta de color claro uniforme (5YR 5/6 rojo amarillento, 5YR 4/4 marrón rojizo, 5YR 5/6 rojo, 2,5YR 5/6 rojo), algunos presentan el núcleo y/o uno de los extremos de color gris (5YR 3/1 gris muy oscuro).

Cocción: Por oxidación completa a incompleta.

4 La cerámica de esta unidad fue más numerosa pues se trabajó con 1203 tiestos solo considerando el material diagnóstico. Es por eso que se decidió estudiar el conjunto del material. El resultado de las otras unidades será tratado en un trabajo posterior.

5egún los documentos etnohistóricos, los valles bajos de Lurín y Rímac pertenecían al Señorío de Ishmay (Rostworowski, 1978). Es por eso que los investigadores consideran dentro del estilo Ishmay a toda la cerámica de estos valles sin identificar los estilos propios de cada curacazgo. Para fines de este trabajo, estamos considerando con el estilo Ishmay-Pachacamac a la cerámica encontrada solo en el santuario de Pachacamac.

El análisis de la cerámica fue realizado solo con los bordes, cuerpos decorados, asas y bases, dejando de lado los tiestos de cuerpo simple. Por problemas administrativos con el INC, no hubo tiempo para realizar tomas fotográticas de los tiestos $\mathrm{y}$ a la fecha es imposible retomar esta tarea por la remodelación que se viene realizando en los depósitos del Museo de Sitio de Pachacamac

\section{Pasta B}

Temperante: compuesto por partículas blanco lechoso de formas angulosas e irregulares, con presencia de mica. En poca proporción se presentan partículas de color oscuro y opacas; son de formas angulosas y a veces algo redondeadas.

Textura: de consistencia semicompacta.

Color: desigual. Se encuentran tiestos que presentan la pasta de color claro uniforme (5YR 5/6 rojo amarillento, 5YR 4/4 marrón rojizo, 5YR 5/6 rojo, 2,5YR $5 / 6$ rojo); algunos presentan el núcleo y/o uno de los extremos de color gris (5YR $3 / 1$ gris muy oscuro)

Cocción: por oxidación completa a incompleta.

\section{Pasta C}

Temperante: se caracteriza por presentar una mayor cantidad de partículas de grano grueso de color blanco lechoso, de formas angulosas o subredondeadas, distribuidas homogéneamente; en menor proporción se encuentran inclusiones blancas transparentes, de formas angulosas. Hay presencia de escasas partículas de color gris. También se observan láminas doradas (mica) que afloran en ambas superficies.

Textura: de consistencia compacta a semicompacta.

Color: desigual. Constituido por tiestos con la pasta de color claro uniforme (5YR 5/6 rojo amarillento, 5YR 4/4 marrón rojizo, 5YR 5/6 rojo, 2,5YR 5/6 rojo), en poca proporción algunos fragmentos muestran el núcleo y uno de los extremos de color gris.

Cocción: oxidación completa a incompleta.

\section{Pasta D}

Temperante: esta pasta presenta como característica elementos líticos de color negro oscuro en proporción mayor a los de color blanco. Estos elementos negro oscuro son de tamaño mediano en general, de forma angulosa e irregular. La distribución es homogénea en toda la sección. Hay pocas partículas de mica.

Textura: de grano mediano y pequeño, compacto y de fractura irregular.

Color: varía entre los colores 5YR 5/6 (rojo), 2,5YR 5/6 (rojo). Algunos elementos presentan el núcleo de color gris.

Cocción: en general por oxidación completa, algunos por oxidación incompleta.

\section{Pasta E}

Temperante: este tipo se caracteriza por contener en la misma proporción partículas blancas transparentes y lechosas. Además existen feldespatos en poca proporción, variando su tamaño de grandes a medianos, de forma angulosa.

Textura: granulosa, compacta, en algunos casos es porosa. La fractura es irregular. Las partículas están distribuidas de forma homogénea. 
Color: los tiestos presentan diversas tonalidades de grises, en algunos casos el núcleo varía entre 5YR 4/4 (marrón rojizo), 5YR 4/6 (marrón rojizo) y 5YR 5/6 (rojizo amarillento).

Cocción: oxidación completa y parcial, y pocos por reducción.

\section{Pasta F}

Temperante: de grano grueso, visible a simple vista. Hay abundantes granos de piedra de formas angulosas e irregulares y presencia de pocas partículas de color blanco lechoso, variando su tamaño de mediano a pequeño, de forma angulosa. Textura: granulosa, compacta, en algunos casos es porosa; se notan los desprendimientos por capas. Asimismo, en algunos tiestos se observan bolsones de aire. La fractura es irregular.

Color: varía entre marrón rojizo (5YR 4/4) y rojo amarillento (5YR 4/6).

Cocción: por oxidación completa e incompleta. El núcleo es gris oscuro.

\section{2. Descripción por tipos de cerámica}

Para conocer el modo o forma de elaboración de la cerámica por una población, es necesario distinguir y definir un estilo, lo que permite compartir aspectos de identidad cultural en la alfarería, si se considera el acabado, la forma o la decoración, elementos que facilitan diferenciarlos unos de otros. Si alguno de estos aspectos cambia o evoluciona, se va a producir un cambio cualitativo lento o rápido en el curso del tiempo.

Antes de identificar el verdadero cambio de estilo, se clasifican los materiales conforme a características de acabado de la superficie, temperantes o cocción. Para Ford (1962) un tipo de cerámica es el producto de una combinación de modos de manufactura y de decoración utilizados durante un lapso de tiempo más o menos corto. Por eso, una vez transcurrido ese tiempo, los tipos de cerámica van a desaparecer para ir apareciendo otros nuevos con antecedentes sacados del anterior. En consecuencia, el tipo puede perdurar a través del tiempo a pesar que lleguen elementos innovadores a la región.

El tipo no solo se construye agrupando objetos iguales entre sí a partir de un orden derivado de la suma de sus atributos físicos (índice de popularidad de algunos rasgos, o en otros casos, estrictamente segregativos). Por el contrario, consideramos que los tipos están agrupados en relación directa con su base contextual; eso quiere decir que a mayor relación entre un tipo y las asociaciones de un contexto, es mayor la proximidad a la realidad en el pasado (Lumbreras, 1981: 69). La idea consiste entonces en agrupar objetos en base a determinados rasgos específicos por contexto, y luego ver si se repiten tales rasgos en otros contextos. La recurrencia de los rasgos específicos tipifica el tipo. Entonces, un tipo es la organización de los materiales arqueológicos mediante grupos de objetos que por ser iguales entre sí reflejan, por recurrencia, la concentración o el resultado material de una manera de satisfacer una necesidad. Reúne objetos que cumplen una misma función, utilizan la misma técnica de fabricación y tienen además los mismos atributos de forma y acabado (Lumbreras, 1983: 3).

En síntesis, no solamente estamos definiendo un tipo como una forma de organizar los materiales cerámicos, en donde no solo consideramos el acabado o tratamiento de la superficie, sino también estamos vinculando los atributos recurrentes sin que necesariamente impliquen etapas cronológicas. Al mantener este criterio, clasificamos el material cerámico, logrando conciliar tipo y función?.

La muestra de cerámica de la Segunda Muralla-Puente Lurín tiene un patrón bastante regular en su elaboración, la manufactura es enrollada y modelada, con temperantes predominantes de partículas blanco lechoso con una distribución uniforme, de consistencia compacta a semicompacta; la cocción es mayormente defectuosa, el tratamiento de la superficie predominante es el alisado y existe el pulido en algunos casos. Las vasijas cerradas predominan entre las formas. La decoración es pintada antes de la cocción teniendo como colores básicos el crema, negro y rojo. Los motivos decorativos son básicamente geométricos y consisten en juego de bandas, líneas horizontales y verticales que delimitan campos; también se utilizan diseños en forma de cuadrados.

A continuación presentamos la descripción tipológica de la fragmentería cerámica procedente de la Segunda Muralla-Puente Lurín.

\section{2. 1. Pachacamac-Crema sobre Rojo}

Lo conforman las pastas A, B, D y F. Las vasijas poseen una banda pintada en el sector superior del labio, en el exterior del cuello y en el cuerpo. Los diseños son trazados con pintura crema, con una aplicación previa de engobe rojo. Los trazos son irregulares, no solo en el espesor de la pintura y color, sino en la dirección del diseño.

Las formas que predominan son las vasijas cerradas; destacan las siguientes:

1. Olla:

Ollas sin cuello, de paredes curvas y bordes convergentes que presentan un reborde corto proyectado en el exterior a manera de «pestaña». El labio es redondeado y el diámetro de boca es de $18 \mathrm{~cm}$ (fig. 7a).

Ollas con cuello corto que presentan el borde engrosado en el exterior para dar una apariencia curvo convexa. La altura del cuello (desde el punto de constricción máxima hasta la boca de la vasija) es de $21 \mathrm{~mm}$. Los diámetros de estas vasijas varían de 8 a $10 \mathrm{~cm}$ (fig. 7b, 7c, 7d).

Ollas de cuello compuesto y de labio redondeado. Los diámetros de estas vasijas varían de 10 a $16 \mathrm{~cm}$ (fig. 7e, 7f).

7 Si bien se agruparon los tiestos teniendo en cuenta sus características físicas, no hemos olvidado que forma y función. 
Ollas de cuello divergente y doblado hacia el exterior en el sector del labio. La altura del cuello es de $5 \mathrm{~cm}$. El grosor de los bordes alcanza $2 \mathrm{~cm}$ y se mantiene constante hasta la unión con el cuerpo. El diámetro del cuello mide $16 \mathrm{~cm}$ (fig. $7 \mathrm{~g}$ ).

Ollas de cuello recto divergente hacia el exterior. Generalmente, el cuello tiene entre 30 y $40 \mathrm{~mm}$ de altura. Los labios son redondeados, aguzados y semiplanos con 8 a $10 \mathrm{~mm}$ de grosor que se incrementa hasta $12 \mathrm{~mm}$ en la unión con el cuerpo. El diámetro de estas vasijas alcanza entre 20 y $24 \mathrm{~cm}$ (fig. 8a, 8b, 8c, $8 \mathrm{~d}, 8 \mathrm{e})$

Ollas de cuello corto y divergente hacia el exterior. La altura del cuello (desde el punto de constricción máxima hasta la boca de la vasija) va de 5 a $20 \mathrm{~mm}$. Los diámetros de estas vasijas varían de 14 a $26 \mathrm{~cm}$. Los bordes tienen un grosor promedio de 7,5 mm y los labios son aguzados y redondeados. Las paredes de cuerpo son más delgadas conforme se distancian del cuello (fig. 9a, 9b, 9c, 9d).

Ollas con un biselamiento exterior plano del borde, lo que origina un incipiente cuello con una altura de $5 \mathrm{~mm}$. El diámetro de la boca es de $20 \mathrm{~cm}$ (fig. 9e).
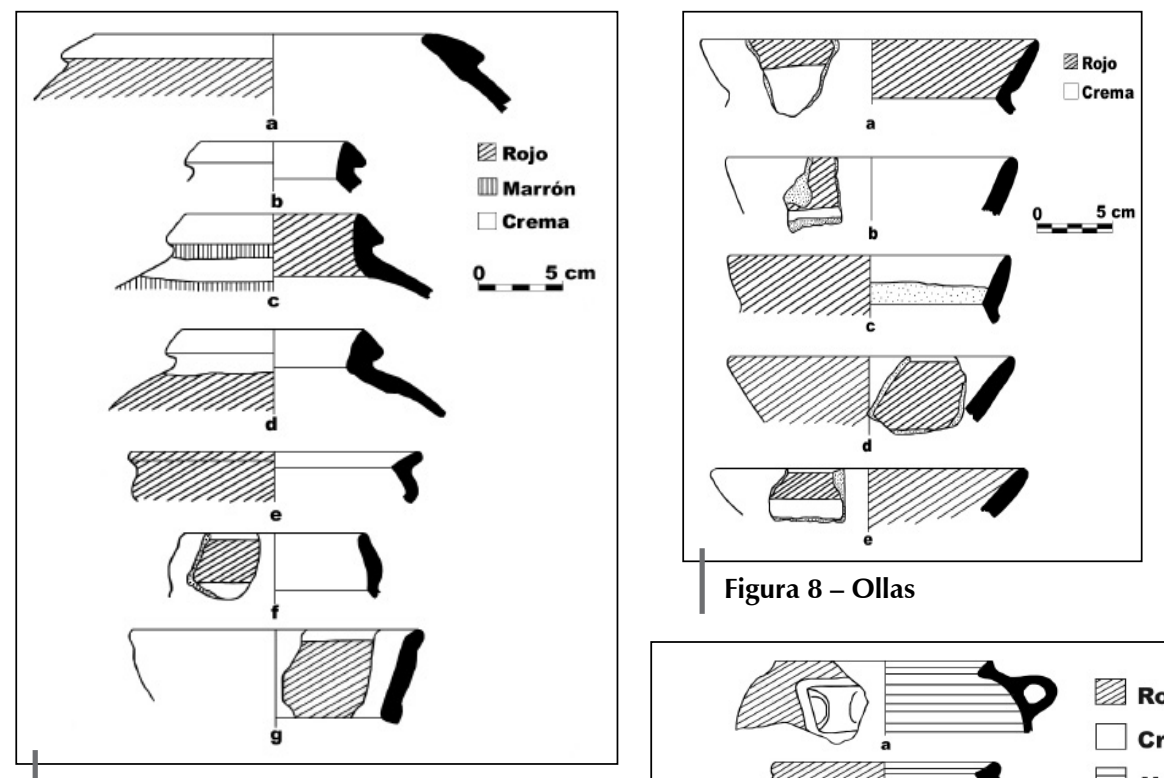

Figura 7 - Ollas

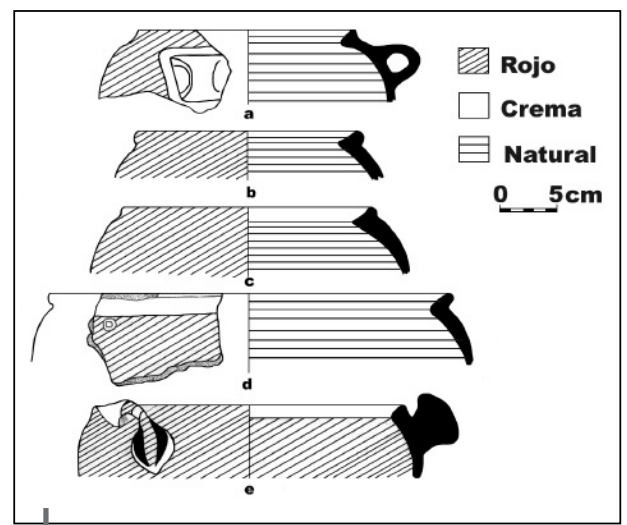

Figura 9 - Ollas

\section{Cántaro:}

Cántaros de paredes rectas que convergen a medida que se acercan al cuello. E diámetro de la boca es de $10 \mathrm{~cm}$. El labio es redondeado y la pared del cuello tiene $8 \mathrm{~mm}$ de grosor (fig. 10a).

Cántaros de lados curvo cóncavos que convergen a medida que se acercan al cuello. Tienen el labio redondeado. El diámetro de la boca es de $13 \mathrm{~cm}$ (fig. 10b).

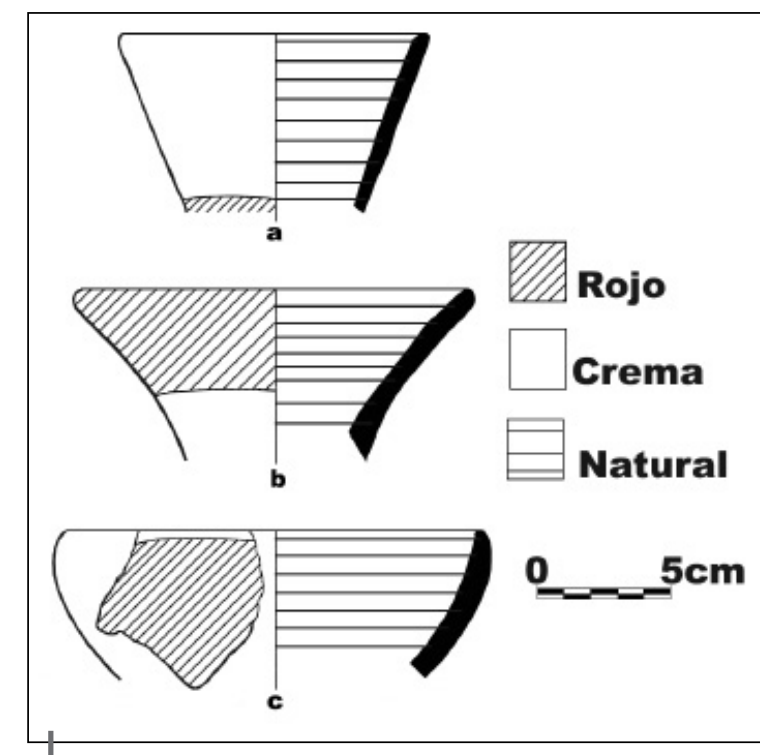

Figura 10 - Cántaros y cuenco

Entre la vasija abierta, destaca un cuenco de lados curvo convexos que se inclinan hacia el interior en el borde. En esta forma no se recuperaron vasijas enteras, pero por los fragmentos podemos inferir que las bases son redondeadas y no tienen punto terminal. Las paredes tienen $10 \mathrm{~mm}$ de espesor y poseen un ligero engrosamiento en la sección media. El labio es aguzado. El diámetro de la boca de esta vasija es de $14 \mathrm{~cm}$ (fig. 10c). Las asas que se han recuperado son planas y se presentan tanto en posición horizontal como vertical. Casi siempre están ubicadas en la sección media del cuerpo. Se presentan pintadas de rojo y la unión del cuerpo con el asa es de color crema en una banda. Hay 22 fragmentos diagnósticos de ese tipo, lo que representa el 1,83 \% del total de la muestra.

\section{2. 2. Pachacamac-Banda Crema}

Está conformado por las pastas A, B, D y F. Los tiestos presentan una capa de engobe crema sobre la superficie externa, el cuello y el labio; en algunos casos 
se extiende en una banda hasta el interior. La superficie interna tiene un alisado regular tosco y la externa un alisado regular con huellas de restregado.

Predominan las vasijas cerradas y destacan las siguientes formas:

1. Cántaro: por la forma de los cuellos se distinguen los siguientes grupos:

Cántaros de cuello divergente inclinado hacia el exterior en el sector de la boca y de labio redondeado. El diámetro de boca de estas vasijas varía de 10 a $12 \mathrm{~cm}$ (fig. 11a, 11b)

Cántaros de cuello divergente hacia el exterior y de labio recto. El diámetro de la boca es de $27 \mathrm{~cm}$ (fig. 11c).

Cántaros de cuello recto o casi recto con ligera inclinación al interior en el sector del borde. El labio es recto (fig. 11d, 11f) y redondeado (fig. 11e). Los diámetros de boca varían de 15 a $19 \mathrm{~cm}$.

Cántaros de cuello compuesto. La altura (desde el punto de construcción máxima hasta la boca de la vasija) varía de 30 a $40 \mathrm{~mm}$. El diámetro de estas vasijas es de $12 \mathrm{~cm}$ (fig. 11g, 11h).

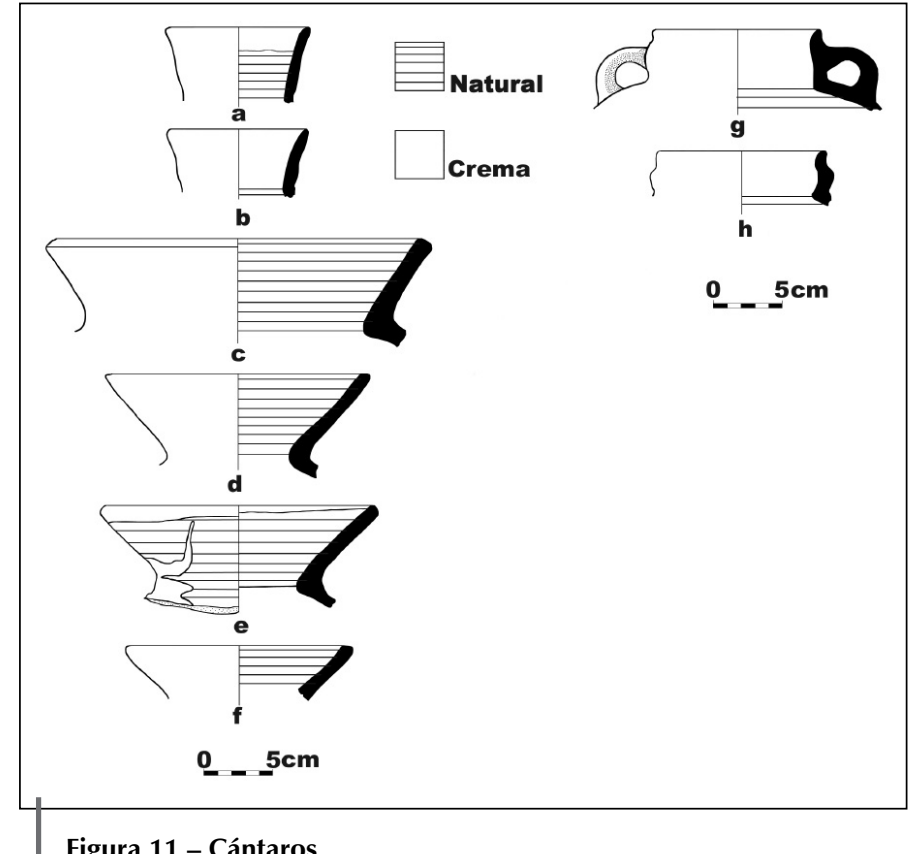

2. Botella:

Destaca un fragmento de cuello recto (fig. 12a) y uno con ligera inclinación al exterior en el sector de la boca (fig. 12b). Corresponden a botellas con un gollete único. La boca de los golletes varía de 4 a $7 \mathrm{~cm}$ de diámetro. Presentan los labios redondeados.

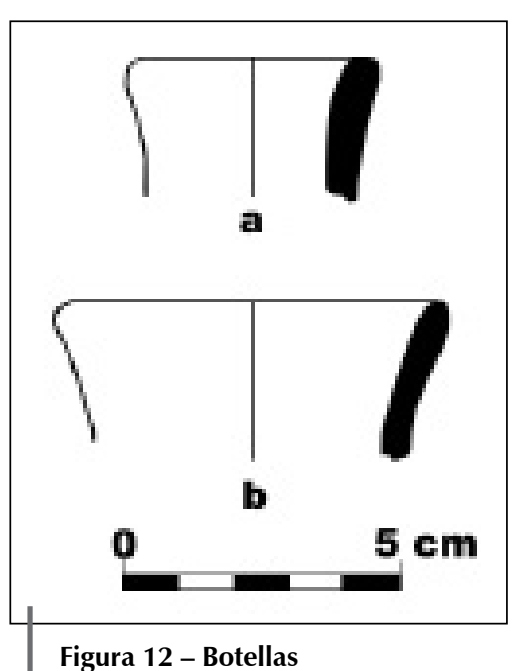

3. Olla: al considerar la forma del cuello, dividimos las ollas de la siguiente manera:

Ollas sin cuello de paredes curvas y bordes convergentes, que presentan un reborde proyectado al exterior a manera de «pestaña». El labio es redondeado y el diámetro de boca va de 19 a $26 \mathrm{~cm}$ (fig. 13).

Ollas de cuello compuesto y labio redondeado y aguzado. El diámetro de boca va de 10 a $22 \mathrm{~cm}$ (fig. 14a, 14b, 14c, 14d).

Ollas de cuello recto reforzado al exterior y labio aguzado. El diámetro de boca es de $16 \mathrm{~cm}$ (fig. 14e).

Ollas de cuello corto divergente en el exterior. La altura del cuello (desde el punto de constricción máxima hasta la boca de la vasija) varía entre 7 y $12 \mathrm{~mm}$. Los diámetros de la vasija varían de 12 a $18 \mathrm{~cm}$ en la boca. Presenta labios redondeados y aguzados (fig. 15a, 15b, 15c, 15d)

Ollas de cuello incipiente y labio recto. El diámetro de boca es de $18 \mathrm{~cm}$ (fig. 15e).

Ollas de cuello recto divergente al exterior, de labio redondeado, recto y aguzado. Los diámetros de la boca varían de 12 a $28 \mathrm{~cm}$ (fig. 16a, 16b, 16c, 16d, 16e).

Ollas de cuello recto y labio aguzado al exterior. El diámetro de boca es de $12 \mathrm{~cm}$ (fig. 17a).

Entre las vasijas abiertas se identifica la presencia de:

\section{Cuenco:}

Cuencos de lados curvo convexos que se inclinan hacia el interior en el borde, lo que produce una forma ligeramente cerrada. Las bases son redondeadas y no tienen punto terminal. Los labios son redondeados. Existe variación en los tamaños: los diámetros de boca pueden tener $14 \mathrm{~cm}$ como mínimo y $18 \mathrm{~cm}$ como máximo (fig. 17b, 17c).

Cuencos de lados curvo convexos con la inclinación muy pronunciada hacia el interior. No hallamos cuencos completos; sin embargo, a juzgar por los fragmentos de cuerpo, las bases no están marcadas por un punto terminal abrupto, sino que son redondeadas, o quizás tienen algún aplanamiento. La boca cerrada tiene $16 \mathrm{~cm}$ de diámetro y el labio es aguzado (fig. 17d).

Se cuentan 121 fragmentos diagnósticos de este tipo, lo que corresponde al $10,06 \%$ del total de la muestra.

\section{2. 3 . Pachacamac-Engobe Marrón}

Lo conforman las pastas A, B y D. Los tiestos se caracterizan por la aplicación de una capa de engobe sobre la superficie externa del cuerpo y el labio (se extiende 

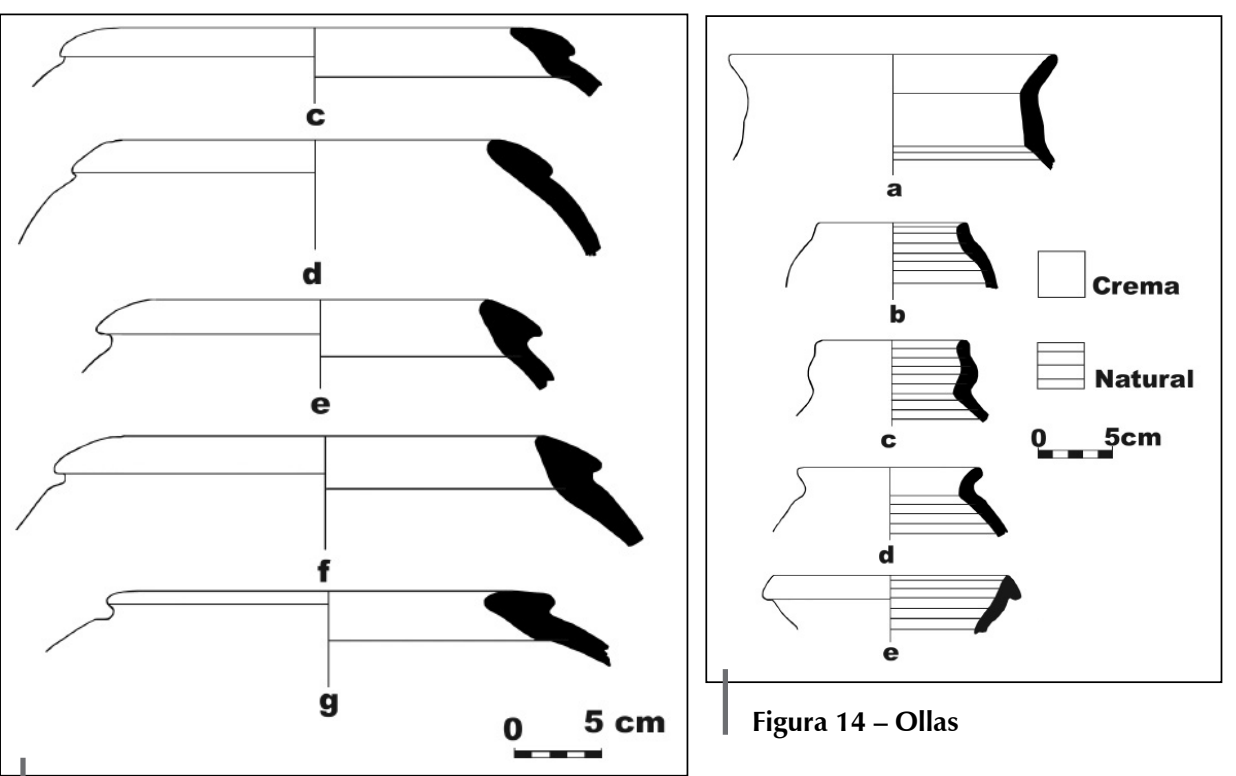

Figura 13 - Ollas con pestañas
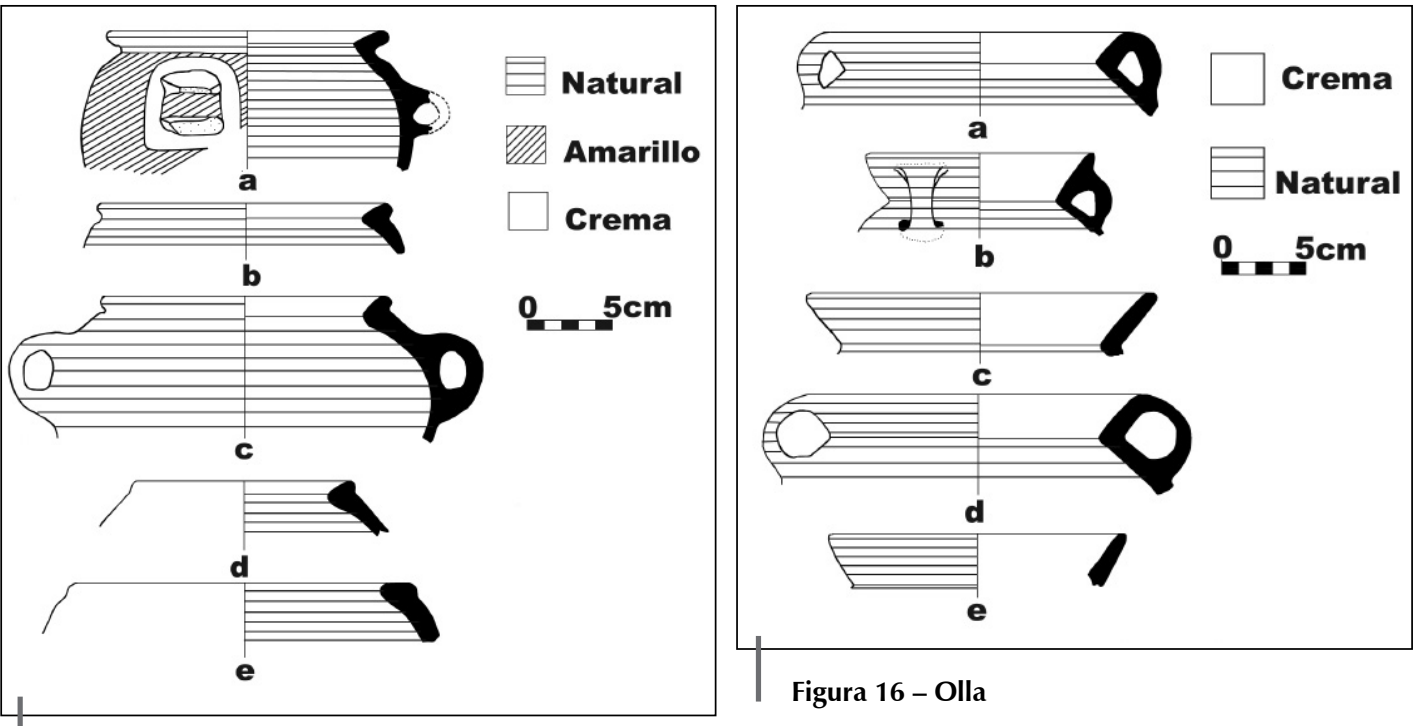

Figura 15 - Ollas

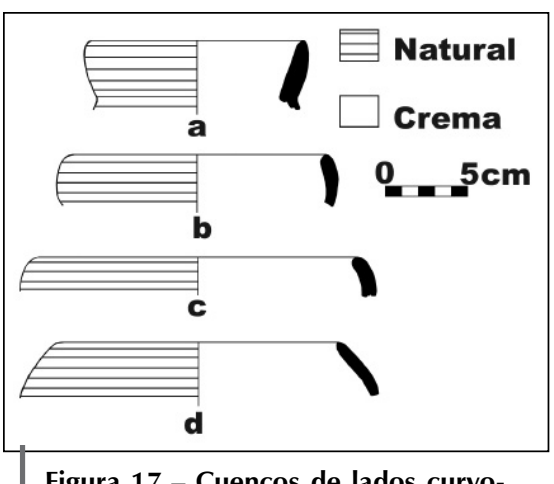

Figura 17 - Cuencos de lados curvo-

convexos en una banda hasta el interior). La superficie interna está tratada con un alisado de regular a uniforma, la externa con una regular.

Las formas que predominan son las vasijas cerradas y destacan las siguientes:

1. Cántaro:

Cántaros de cuello divergente con paredes engrosadas hacia el exterior en el sector del borde. Los labios son adelgazados y redondeados. El diámetro de boca varía de 13 a $21 \mathrm{~cm}$ (fig. 18a, 18b, 18c, 18d, 18e, 18f)

Cántaros de cuello expandido y labio plano. El diámetro de boca varía de 12 a $22 \mathrm{~cm}$.

Cántaros de cuello recto con inclinación hacia el exterior en el sector del borde. El labio plano es redondeado. Los diámetros de boca varían de 16 a $24 \mathrm{~cm}$.

Cántaros de cuello divergente y labio adelgazado. El diámetro de boca es de $16 \mathrm{~cm}$.

Cántaros de cuello curvo convexo con el borde inclinado hacia el interior. El labio es redondeado y el diámetro de boca alcanza $22 \mathrm{~cm}$.

Cántaros de cuello divergente con ligera inclinación hacia el exterior en el sector del borde (fig. 18g). El labio es plano y los diámetros de boca varían de 12 a $21 \mathrm{~cm}$

La decoración es en bulto, mediante la técnica del aplicado. Las facciones se logran aplicando tiras para formar los ojos y la nariz. Los ojos son almendrados y la nariz respingada; la boca está en relieve con incisión (fig. 18e, 18g).

2. Botella con gollete recto y corto con representación del rostro de un personaje. Los ojos se aplican en forma de granos de café y la boca consiste en una incisión en forma de media luna. En la frente se ve una tira aplicada. El diámetro es de $6 \mathrm{~cm}$ en la boca (fig. 19a)

3. Olla:

Ollas de cuello corto divergente hacia el exterior. La altura del cuello (desde el punto de constricción máxima hasta la boca de la vasija) es de $10 \mathrm{~mm}$ (fig. 19b, 19c)

Ollas de cuello divergente con el borde que presenta un engrosamiento exterio produciendo un labio con reborde. Los cuellos varían de 24 a $34 \mathrm{~mm}$ de altura. Ceneralmente, estas ollas tienen de 7 a $9 \mathrm{~mm}$ de grosor en el borde disminuye hasta 4 ó 6 mm cerca de la unión con el cuerpo (fig. 19d, 19e, 19f). Ollas de cuello incipiente cuya altura alcanza $5 \mathrm{~mm}$. El labio es aguzado. El diámetro es de $14 \mathrm{~cm}$ en la boca.

Ollas de cuello corto divergente y alto. El labio es redondeado. El diámetro de la boca va de $11 \mathrm{~cm}$ a $20 \mathrm{~cm}$. La gran mayoría presenta un asa que une el cuerpo con el labio y generalmente es cintada en posición horizontal. 

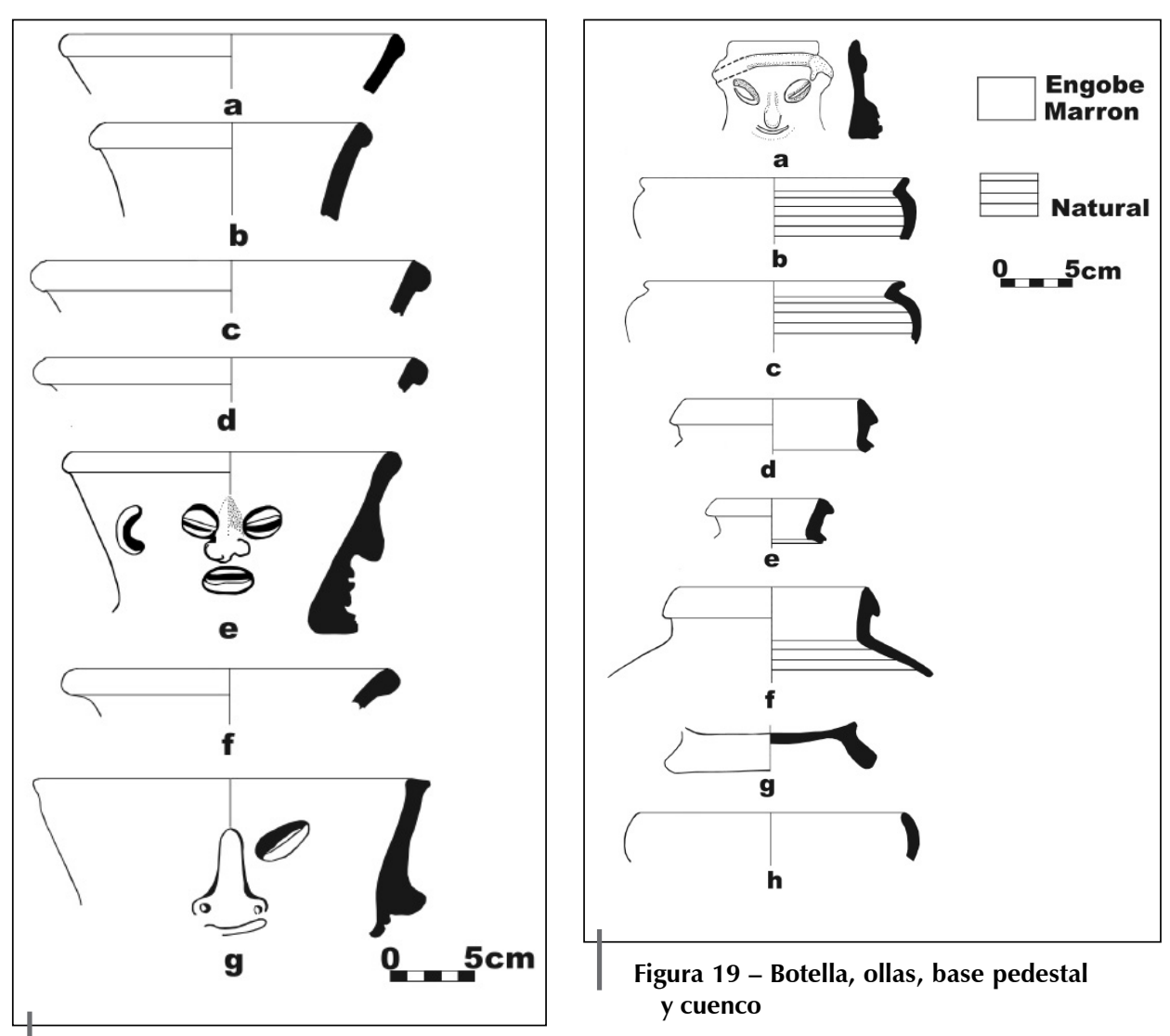

Figura 18 - Cántaros

4. Base pedestal:

El exterior del pedestal es alisado con un material flexible que deja marcas finas. El interior, en cambio, se presenta áspero. El lado superior tiene restos de carbón (fig. 19g).

5. Cuerpo decorado:

Consiste en una tira de aplicado. Sobre la parte superior se ven, a modo de decoración, dos círculos estampados y cercanos. Es probable que se han utilizado cañitas y dejado como huellas los círculos de $10 \mathrm{~mm}$ de diámetro, estampados con las mismas profundidades.

6. Cuenco:

Cuencos de paredes curvo convexo que se inclinan hacia el interior por el borde, lo que produce una forma ligeramente cerrada. No hallamos cuencos completos; sin embargo, a juzgar por los fragmentos de cuerpo, las bases no están marcadas por un punto terminal abrupto, sino que son redondedas, o quizás tienen algún aplanamiento. El labio es redondeado y el diámetro alcanza $18 \mathrm{~cm}$ en la boca (fig. 19h).

Tenemos un total de 63 fragmentos diagnóstico, lo que corresponde al 5,24 \% del total de la muestra.

\section{2. 4. Pachacamac-Crema sobre Naranja}

Lo conforman las pastas B y D. Exteriormente la superficie está pulida de manera uniforme y se ve cubierta por una capa de engobe naranja, sobre la cual se encuentran diseños geométricos de color crema. Interiormente la superficie está lisada toscamente con huellas aisladas de restregado.

Las formas que predominan son:

1. Cántaro:

Cántaros de cuello expandido de 14 a $20 \mathrm{~cm}$ de diámetro en la boca y con labio redondeado y plano (fig. 20a, 20b, 20c, 20d, 20e, 20f, 20g).

2. Botella de gollete recto de $6 \mathrm{~cm}$ de diámetro en la boca y con labio aguzado (fig. 21a).

3. Olla:

Ollas de cuello divergente de 16 a $20 \mathrm{~cm}$ de diámetro de boca, con labio redondeado y plano (fig. 21b, 21c, 21d, 21e).

Ollas de cuello corto evertido. La altura de los cuellos varía de 7 a $14 \mathrm{~mm}$, con labio redondeado (fig. 21f, 21g, 21h).

Tenemos un total de 16 fragmentos diagnósticos, que representa el 1,33\% del total de la muestra.

\section{2. 5. Pachacamac-Negro Pulido}

Lo conforman las pastas B y E. La superficie exterior es pulida uniformemente hasta alcanzar brillantez $y$, al parecer, se agrega una capa de engobe negro. En el interior, los fragmentos están alisados, se observan pulidos en forma aislada.

Predominan formas de vasijas cerradas. Destacan las siguientes:

1. Olla:

Ollas de cuellos divergentes de 16 a $22 \mathrm{~cm}$ de diámetro de boca. La altura de los cuellos varía de 12 a $25 \mathrm{~mm}$. Presentan labio redondeado (fig. 22a, 22b, 22c 22d, 22e).

Ollas de cuello incipiente engrosado en el sector del borde. La altura del cuello varía de 6 a $9 \mathrm{~mm}$. El labio es adelgazado. El diámetro de la boca varía de 18 a $24 \mathrm{~cm}$ (figs. 22f, 22g, 23a).

Ollas de cuello corto evertido y cuerpo globular. La altura del cuello varía de 10 a $15 \mathrm{~mm}$ y el diámetro de 18 a $20 \mathrm{~cm}$; presenta el labio redondeado (fig. 23b, 23c, 23d).

Ollas de cuello divergente de 16 a $20 \mathrm{~cm}$ de diámetro de boca, con labio aguzado (fig. 23e, 23f). 

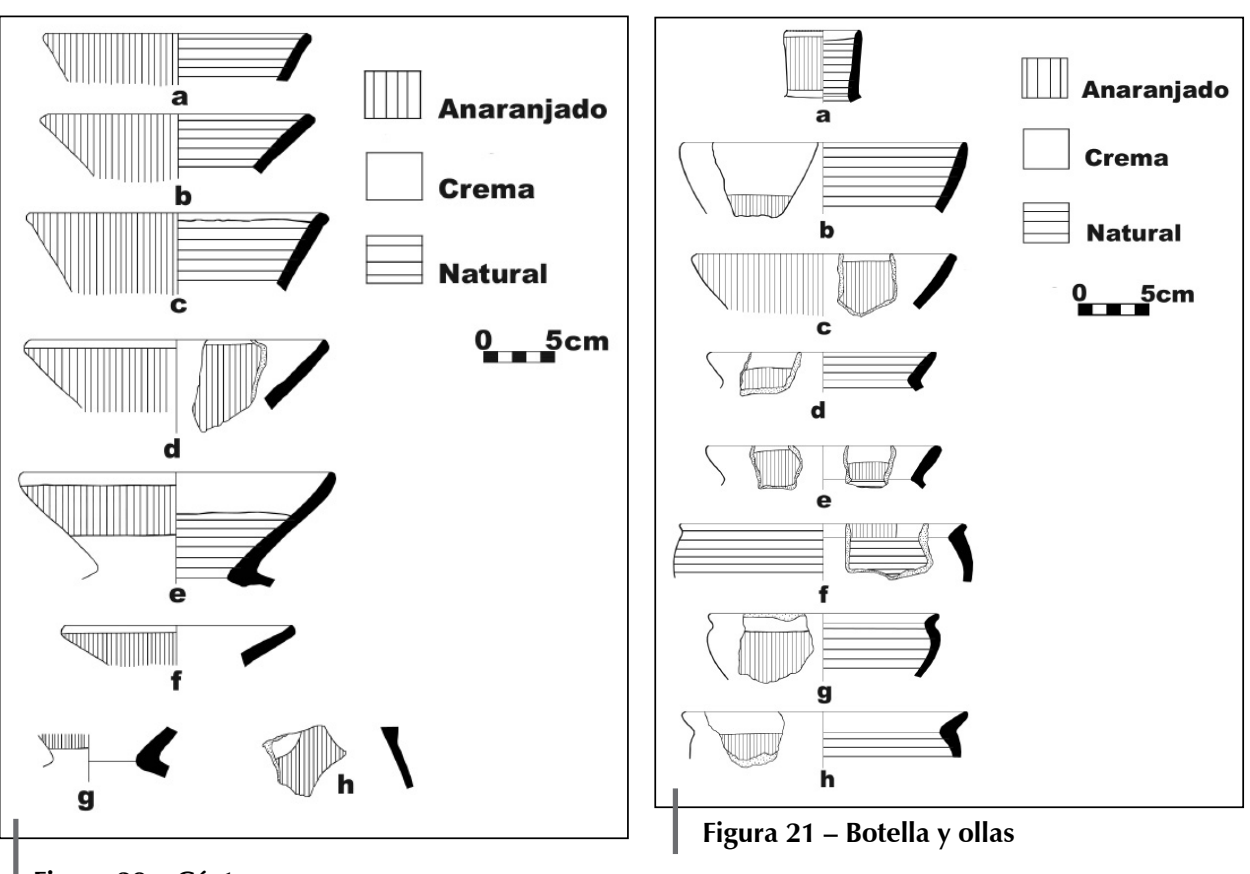

Figura 20 - Cántaro

Ollas de cuello divergente y cuerpo globular, con labio redondeado (fig. 24a). La decoración es escultórica y consiste en un sapo aplicado sobre el diámetro mayor del cuerpo, de tal forma que apoya sus extremidades anteriores sobre el labio de las ollas. La ejecución de los sapos son burdas, con rasgos pocos claros hechos con incisiones en el caso de los dedos, y orificios punzonados de las fosas nasales (figs. 22d, 23e, 23f)

2. Botella:

Botellas de gollete recto doblado en el exterior en el sector del borde. El labio es redondeado y adelgazado. El diámetro de boca varía de 5 a 6 cm (fig. 24b, 24c).

Botellas de gollete divergente de $4 \mathrm{~cm}$ de diámetro de boca con labio adelgazado (fig. 24d).

3. Cántaro:

Cántaros de cuello divergente engrosado en el exterior en el sector del borde. El labio es adelgazado. El diámetro varía de 18 a $19 \mathrm{~cm}$ en la boca (figs. 25a 25b, 25c).

Cántaros de cuello divergente de 15 a $25 \mathrm{~cm}$ de diámetro de boca con labio plano (fig. 25d, 25e, 25f).

Cántaros de cuello recto doblado en el exterior en el sector del borde. El labio es adelgazado y redondeado. El diámetro varía de 10 a 16 cm en la boca (fig. 25g).
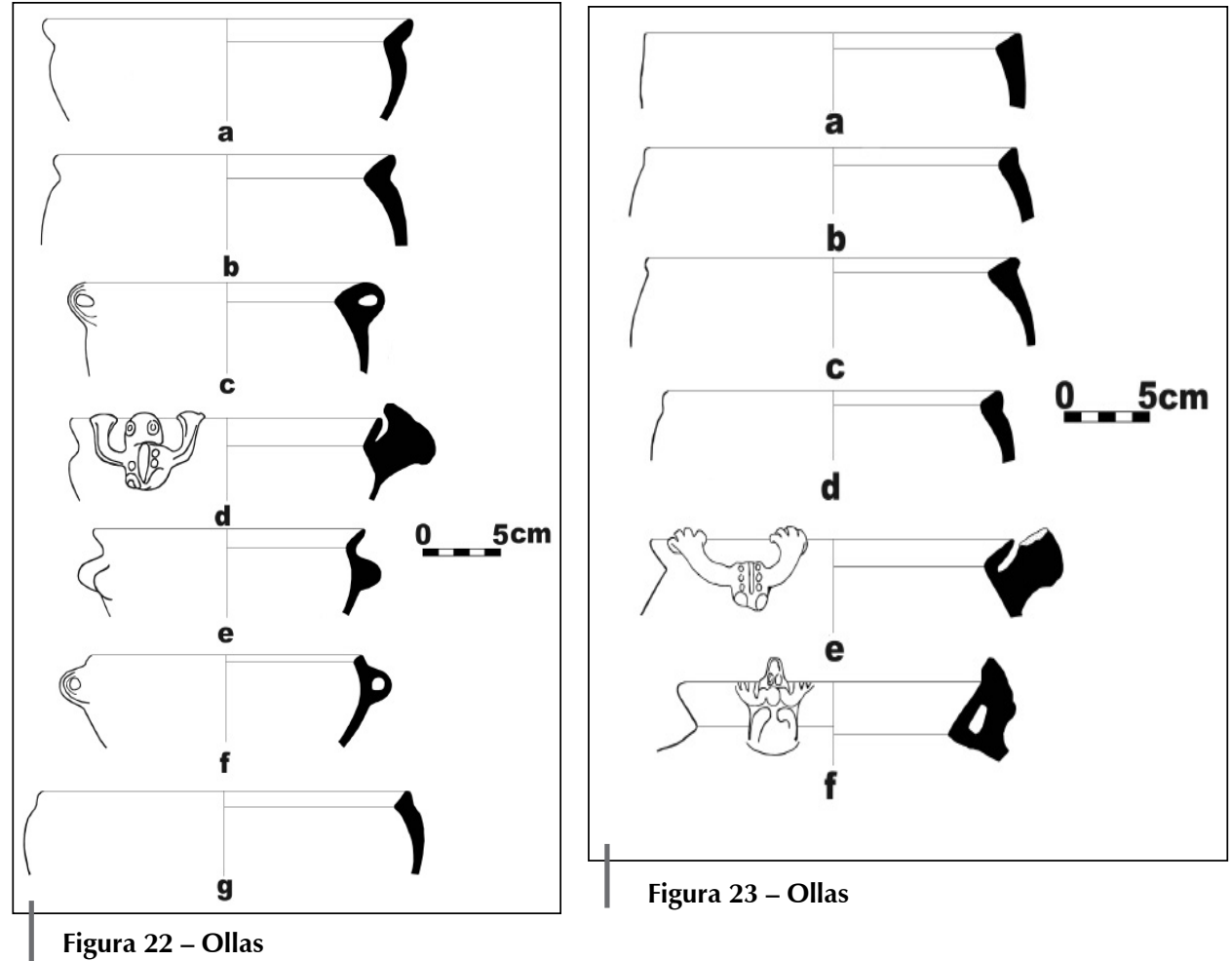

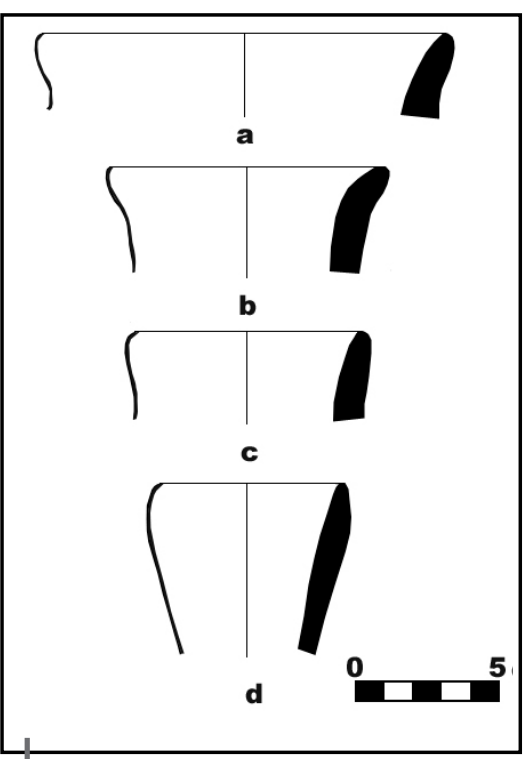

Figura 24 - Olla y botellas
4. Plato:

Platos de paredes extendidas de 20 a $22 \mathrm{~cm}$ de diámetro de boca, con labio redondeado (fig. 26a, 26b).

Platos de paredes extendidas inclinadas hacia el interior en el sector del borde. El labio es plano y el diámetro de boca mide $18 \mathrm{~cm}$ (fig. 26c).

5. Cuenco:

Cuencos de paredes rectas, con carena en el ecuador. El labio es plano, redondeado y adelgazado. El diámetro de boca varía de 16 a $22 \mathrm{~cm}$ (fig. 26d, 26e). Cuencos de paredes convergentes carenadas en el ecuador. El labio es redondeado y adelgazado. El diámetro varía de 10 a $24 \mathrm{~cm}$ en la boca (fig. 26f, 26g).

Cuenco ligeramente cerrado, de lados rectos. Se recupera un solo fragmento. Las paredes se engrosan gradualmente en el borde y el labio es plano. El diámetro es de $16 \mathrm{~cm}$ en la boca (fig. 26h). 

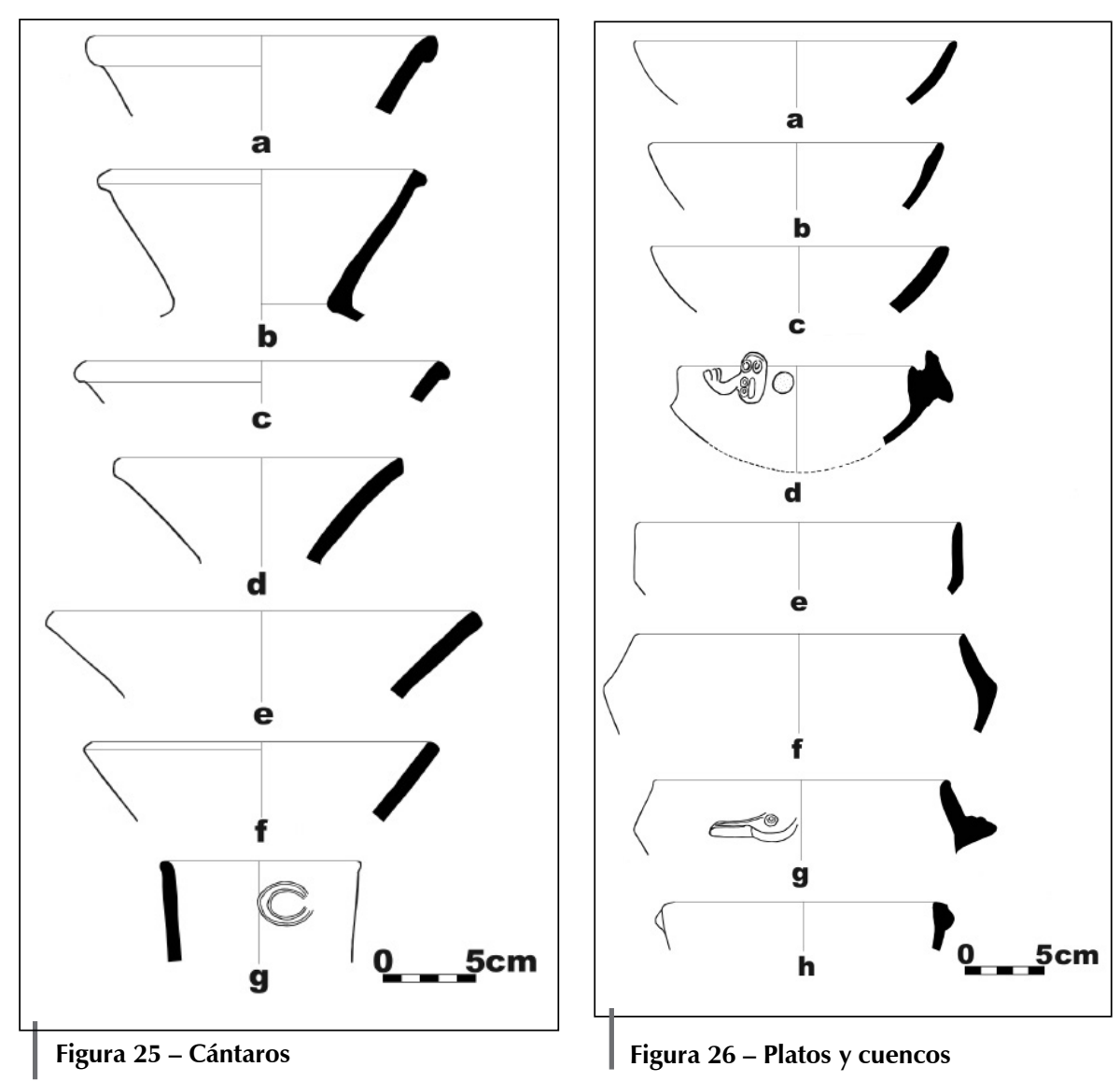

Cuencos de paredes marcadamente curvas con labio redondeado. El diámetro de la boca oscila entre 13 y $20 \mathrm{~cm}$ (fig. 27a, 27b, 27c, 27d).

Cuencos de paredes curvo convexas que se inclinan hacia el interior en el sector del borde, lo que produce una forma ligeramente cerrada. Las bases son redondeadas. Por lo general, los labios son redondeados y aguzados. Existe una considerable variación en los tamaños. Los diámetros de boca oscilan entre 14 y $22 \mathrm{~cm}$ (fig. 27e, 27f, 27g, 27h).

Cuencos poco profundos, no cerrados, con paredes curvo convexas. La base es redondeada así como los labios. El diámetro de la boca varía de 18 a 26 cm (figs. 28a, 28b).

Cuencos cuyas paredes inferiores enseñan una marcada convexidad y las paredes superiores son casi verticales. Son de labio redondeado y adelgazado en el interior. Los diámetros de boca van de 18 a 24 cm (fig. 28c, 28d, 28e, 28f, 28g).

Cuencos pequeños con $8 \mathrm{~cm}$ de diámetro de boca y labio aguzado (fig. 28h).

Esta muestra cuenta con 102 fragmentos diagnósticos, lo que representa el 8,48 \% del total de la muestra.

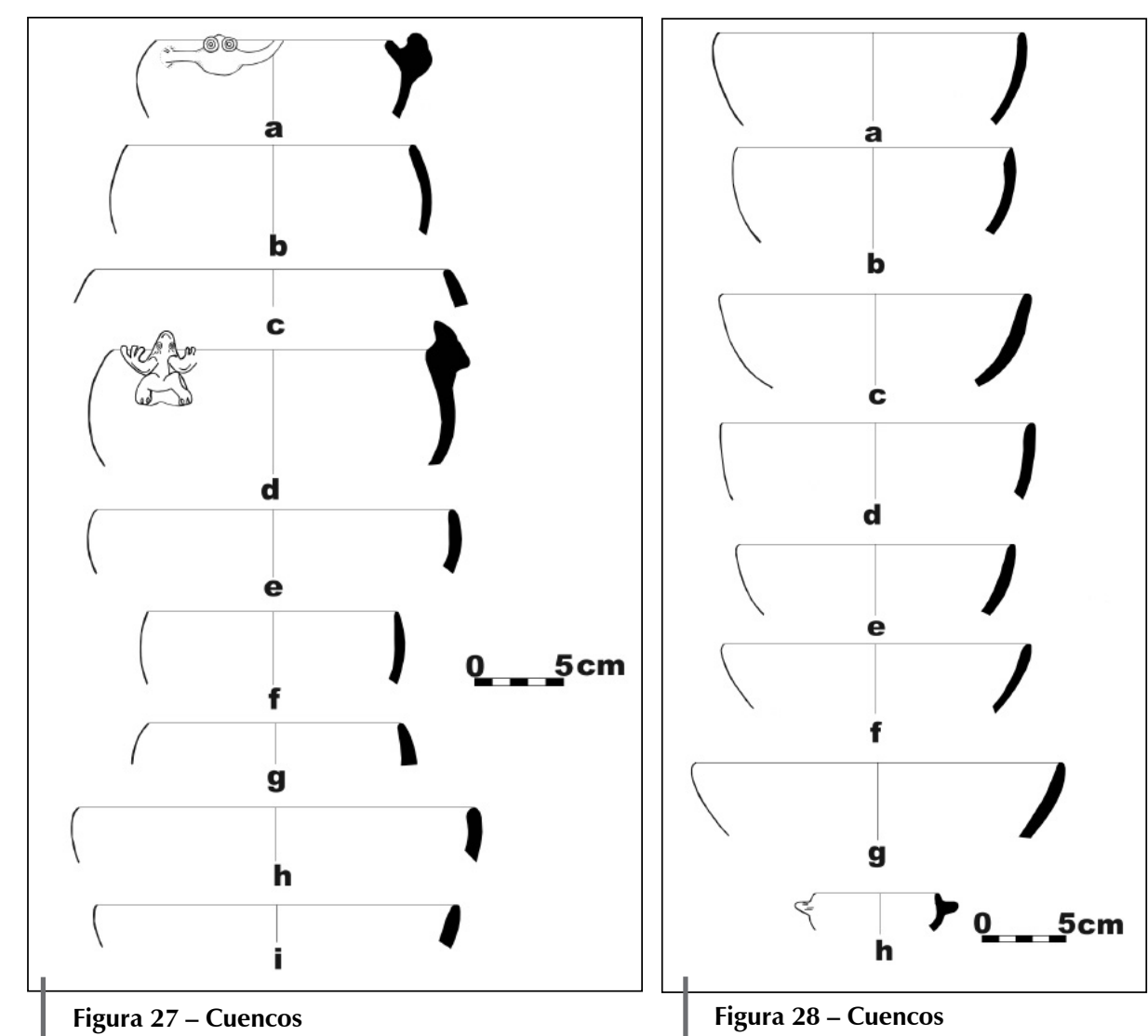

\section{2. 6. Pachacamac-Engobe Rojo}

Lo conforman las pastas A, B y D. Los tiestos se caracterizan por llevar una capa de engobe rojo, en particular en la superficie externa. Ambos lados de los tiestos están alisado de manera uniforme, aunque muchos presentan una apariencia irregular en la superficie interna.

Se han identificado las siguientes formas:

1. Cántaro:

Cántaros de cuello divergente con inclinación hacia el exterior en el sector del borde. El labio es redondeado y plano. El diámetro varía de 10 a $18 \mathrm{~cm}$ en la boca (fig. 29a, 29b, 29c).

Cántaros con cuello corto y vertical. La altura del cuello es de $40 \mathrm{~mm}$. El diámetro es de $18 \mathrm{~cm}$ (fig. 29d).

Cántaros de cuello divergente inclinado al interior en el sector del borde. El labio es plano y redondeado. El diámetro de boca es de 12 a $22 \mathrm{~cm}$ (fig. 29e, 29f, 29g). 
2. Botella de $4 \mathrm{~cm}$ de diámetro en la boca, posee un gollete curvo cóncavo que se abocina de manera pronunciada hacia el exterior cerca del borde; el labio es redondeado. Presenta restos del asa que sale del sector medio del gollete para unirse probablemente con el cuerpo (fig. 30a).

3. Olla:

Ollas de cuello divergente engrosado al exterior en el labio de 10 a $20 \mathrm{~cm}$ de diámetro en la boca. El labio es aguzado, plano y redondeado (fig. 30b, 30c, 30d, 30e, 30f, 30g).

Ollas de cuello convergente de 7 a $12 \mathrm{~cm}$ de diámetro en la boca, los tiestos están reforzados al exterior en el sector de la boca (fig. 30h, 30i).

Ollas de cuello corto divergente en el exterior. El cuello varía de 6 a $12 \mathrm{~mm}$ de altura. El labio es aguzado y redondeado. El diámetro varía de 12 a $22 \mathrm{~cm}$ en la boca (fig. 31a, 31b, 31c).

Ollas de cuello recto doblado en el exterior en el sector del borde. Presenta el labio plano y alcanza los $20 \mathrm{~cm}$ de diámetro de boca (fig. 31d).

Ollas sin cuello de paredes convergentes y paredes rectas que se inclinan ligeramente hacia el interior (fig. 31e). El labio es redondeado y plano. El diámetro de boca varía de 9 a $14 \mathrm{~cm}$.

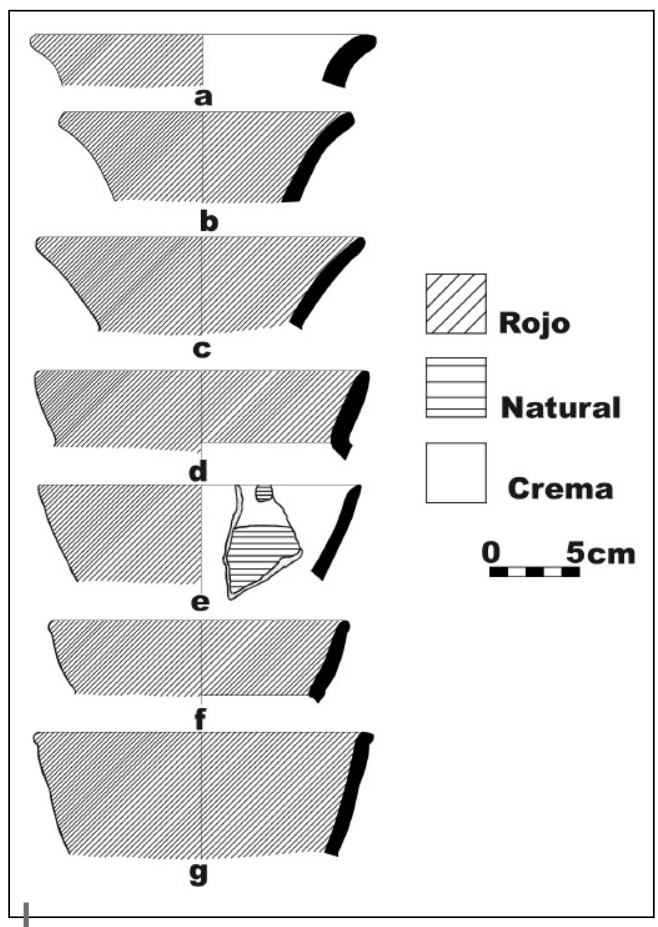

Figura 29 - Cántaros

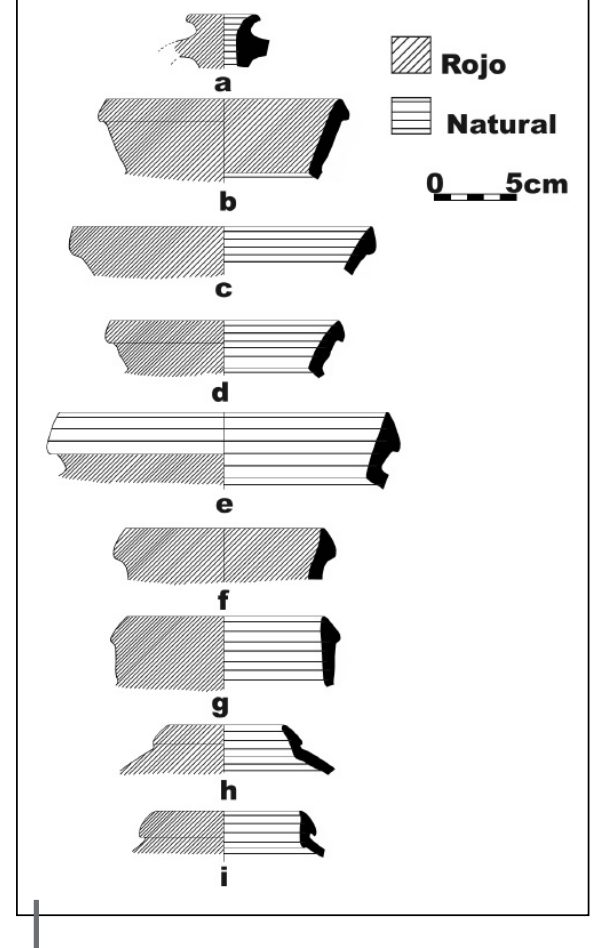

Figura 30 - Botella y ollas
Ollas de cuello divergente en el exterior. La altura del cuello (desde el punto de constricción máxima hasta la boca de la vasija) varía de 18 a $39 \mathrm{~mm}$. El labio es plano y redondeado. El diámetro varía de 14 a $20 \mathrm{~cm}$ en la boca (fig. $31 \mathrm{f}, 31 \mathrm{~g}$ 31h, 31i).

Ollas de cuello recto de 8 a $20 \mathrm{~cm}$ de diámetro. El labio es plano.

Ollas de cuello compuesto de $12 \mathrm{~cm}$ de diámetro. El labio es redondeado.

Existe un fragmento de cuello donde aparece el rostro de una persona rechoncha, llamada también «mofletuda».

Existen 51 fragmentos diagnósticos que representan el 4,24\% del total de la muestra.

\section{2. 7. Pachacamac-Naranja Pulido}

Lo conforman las pastas A B y D. Los tiestos se caracterizan por llevar una capa de engobe naranja, en particular en la superficie externa. Ambos lados de los

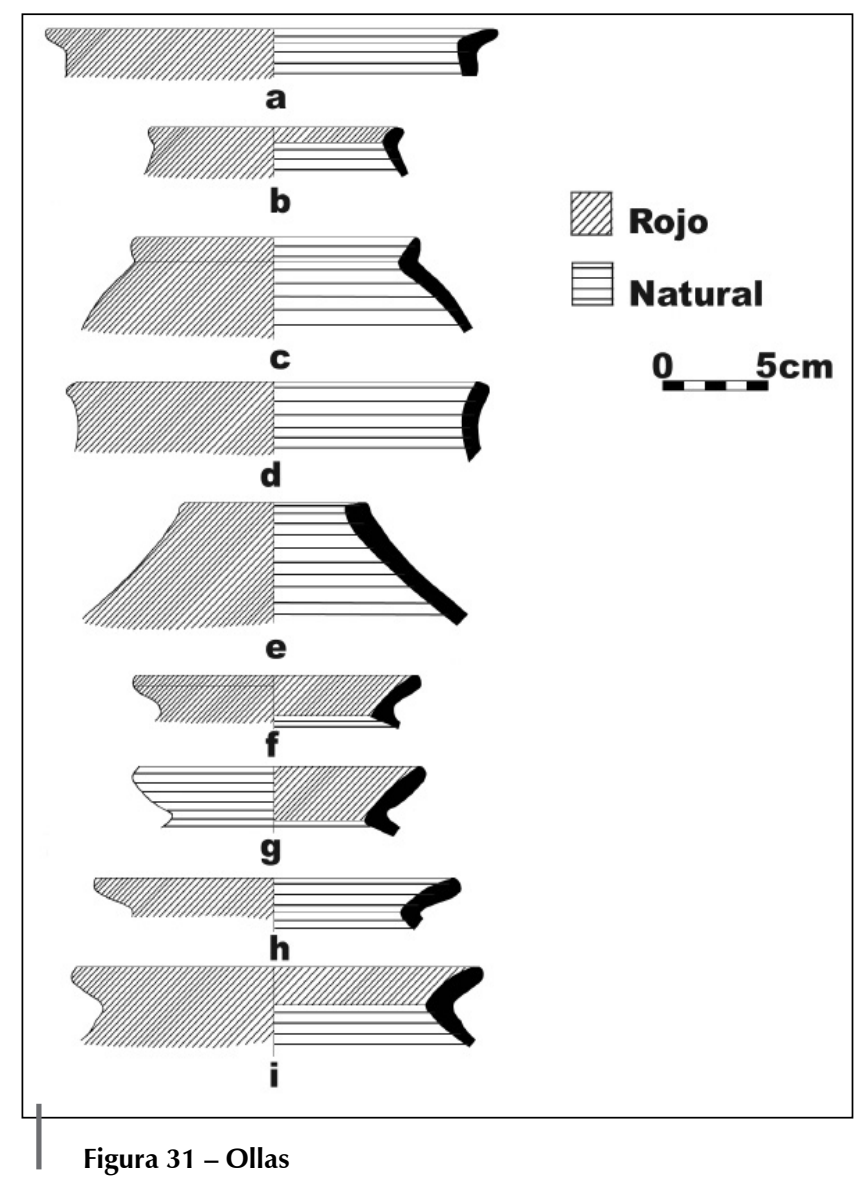


tiestos están alisado de manera uniforme. De manera aislada se aprecian tiestos con pulido mate, aunque muchos están con una superficie interna de apariencia irregular.

Las formas que predominan son:

1. Botella de $3 \mathrm{~cm}$ de diámetro que posee un gollete curvo cóncavo que se abocina de manera pronunciada hacia el exterior cerca del borde. El labio es aguzado con un contorno dentado. No se sabe si es una forma decorativa o es por desgaste (fig. 32a).

2. Cántaro:

Cántaros de cuello divergente de 12 a $18 \mathrm{~cm}$ de diámetro de boca. El labio es aguzado y plano (figs. 32b, 32c, 32d).

Cántaros de cuello cóncavo de $12 \mathrm{~cm}$ de diámetro con labio aguzado (fig. 32e)

3. Olla:

Ollas de cuello compuesto de $14 \mathrm{~cm}$ de diámetro de boca. El labio es redondeado (fig. 32f, 32g).

Ollas de cuello divergente de 14 a $18 \mathrm{~cm}$ de diámetro en la boca. El labio es redondeado y aguzado (fig. 32h, 32i).

Ollas de cuello incipiente (fig. 33a, 33b) y de cuello corto divergente (fig. 33c, 33d). La altura de los cuellos varía de 5 a $11 \mathrm{~mm}$. El labio es aguzado y plano. El diámetro de boca varía de 16 a $20 \mathrm{~cm}$. Presentan como decoración líneas de color negro que se ubican en la cara interna de los cuellos.

4. Cuenco de paredes convergentes de 14 a $18 \mathrm{~cm}$ de diámetro de boca. El labio es redondeado y aguzado. Un tiesto tiene el cuerpo compuesto de donde sobresale un apéndice a manera de asa (fig. 32j, 32k).

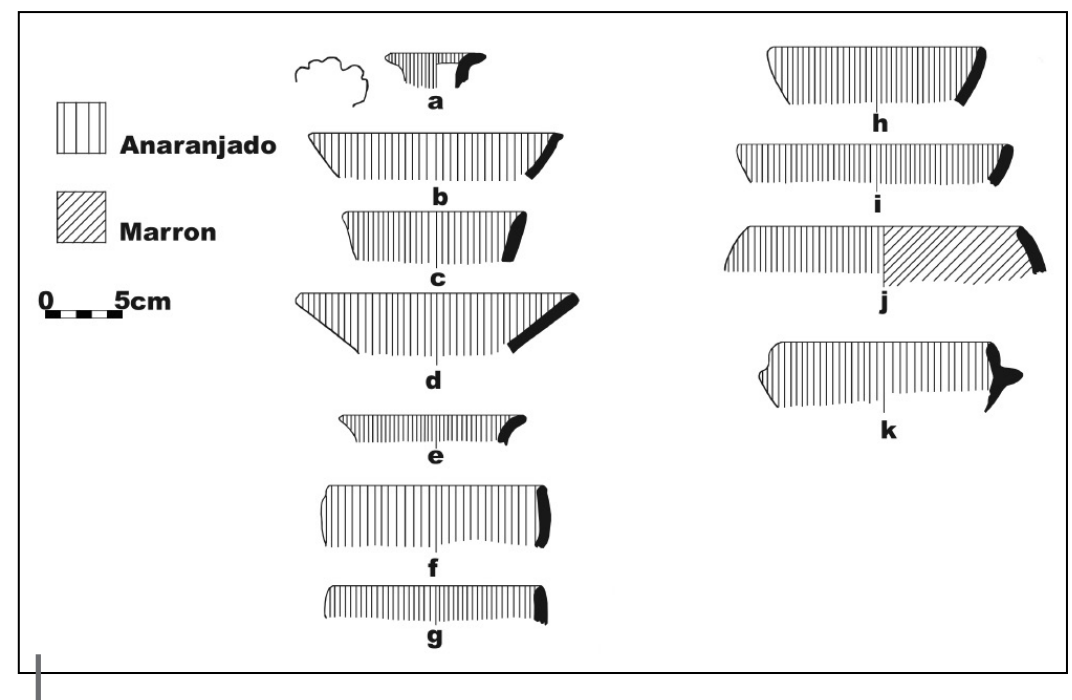

Figura 32 - Botella, cántaro, olla y cuenco

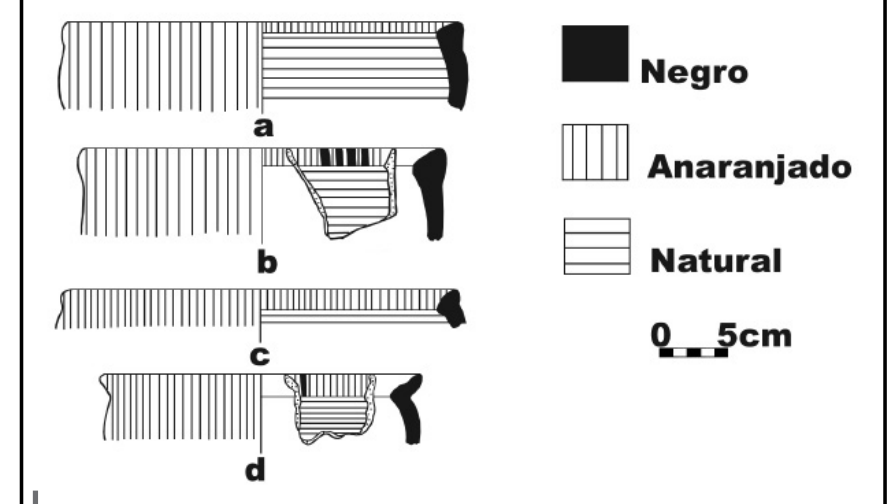

Figura 33 - Ollas de cuello incipiente

Hay 15 fragmentos diagnósticos de este tipo, lo que representa el 1,25 \% del total de la muestra.

\section{2. 8. Pachacamac-Crema sobre Marrón}

Lo conforman las pastas A y B. Las vasijas cerradas se decoran con una banda pintada en el sector superior y exterior del cuello, en el cuerpo y asa. Los diseños son trazados con pintura crema, previamente se aplica engobe marrón. En otros casos alternan el color marrón y crema. Los trazos son bien definidos.

Las formas que predominan son las vasijas cerradas, destacando:

1. Cántaro: según la orientación del cuello se ha dividido en:

Cántaros de cuello convexo. El labio es redondeado. El diámetro de boca es de $10 \mathrm{~cm}$ (fig. 34a).

Cántaros de cuello recto divergente. El labio es redondeado. El diámetro de boca varía de 7 a $16 \mathrm{~cm}$ (fig. 34b, 34c).

2. Olla:

Ollas de cuello alto con inclinación al exterior en el sector del borde. El labio es redondeado. El diámetro de la boca varía entre 16 y $18 \mathrm{~cm}$ (fig. 34d, 34e, 34f).

Ollas de cuello compuesto. El labio es redondeado y aguzado. Las vasijas pueden tener varios tamaños según el diámetro de la boca, que varía entre 7 y $16 \mathrm{~cm}$ (fig. 34g, 34h).

Ollas de cuello incipiente. La altura del cuello (desde el punto de constricción máxima hasta la boca de la vasija) varía de 2 a $8 \mathrm{~mm}$. El labio es plano y aguzado. El diámetro de la boca varía de 14 a $17 \mathrm{~cm}$ (fig. 35a, 35b, 35c).

Ollas de cuello corto expandido. La altura del cuello varía de 5 a $10 \mathrm{~mm}$. El labio es redondeado y aguzado. El diámetro de boca varía de 16 a $22 \mathrm{~cm}$ (figs. 35d, $35 e, 35 f, 35 g, 37 b, 37 c)$. 
Jesús A. Ramos Giraldo, Ponciano Paredes Botoni
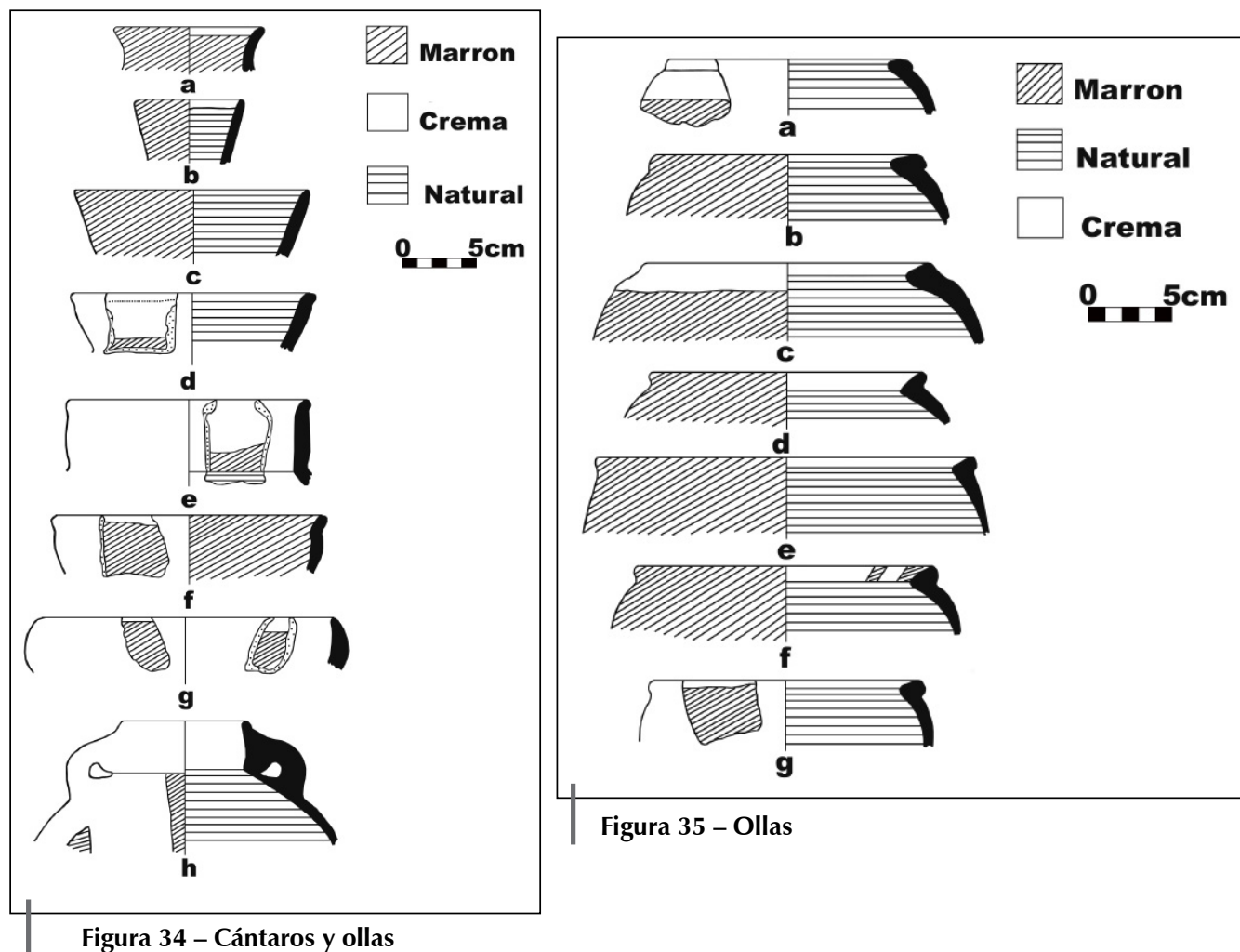

Figura 35 - Ollas
Excavaciones en la segunda muralla-Puente Lurín: estilos cerámicos durante el Horizonte Tardío

Ollas de cuello divergente con ligero doblado al interior en el sector del borde. El labio es redondeado y aguzado. El diámetro de boca varía de 16 a $22 \mathrm{~cm}$ (figs. 36a, 36b, 36c).

Olla de cuello doblado al interior en el sector del borde. El labio es plano y el diámetro de la boca es de $12 \mathrm{~cm}$ (fig. 36d).

Olla de cuello corto y de paredes engrosada. El labio es redondeado y el diámetro de la boca alcanza $14 \mathrm{~cm}$ (fig. 36e).

Ollas de cuello recto. El labio es aguzado y el diámetro de la boca varía de 16 a $18 \mathrm{~cm}$ (fig. 36f, 36g).

Ollas de cuello recto divergente. El labio es redondeado, aguzado y plano. E diámetro de la boca varía de 13 a 22 cm (fig. 36h, 36i, 36j, 36k).

Ollas de cuello divergente engrosado hacia el exterior en el sector del borde. El labio es aguzado y el diámetro de la boca alcanza $10 \mathrm{~cm}$ (fig. 37a).

Entre las vasijas abiertas, destacan los cuencos de paredes curvo convexas, poco profundos y que no son cerrados (fig. $37 \mathrm{~d}$ ) y los cuencos de paredes convergentes y curvatura suave (fig. 37e). A juzgar por los fragmentos de cuerpo, las bases no son marcadas por un punto terminal abrupto, sino que son redondeadas. El labio es aguzado y el diámetro de boca varía de 14 a $16 \mathrm{~cm}$.

Se ha trabajado con 34 fragmentos diagnósticos, lo que representa el 2,83 \% del total de la muestra.
Figura 34 - Cántaros y ollas

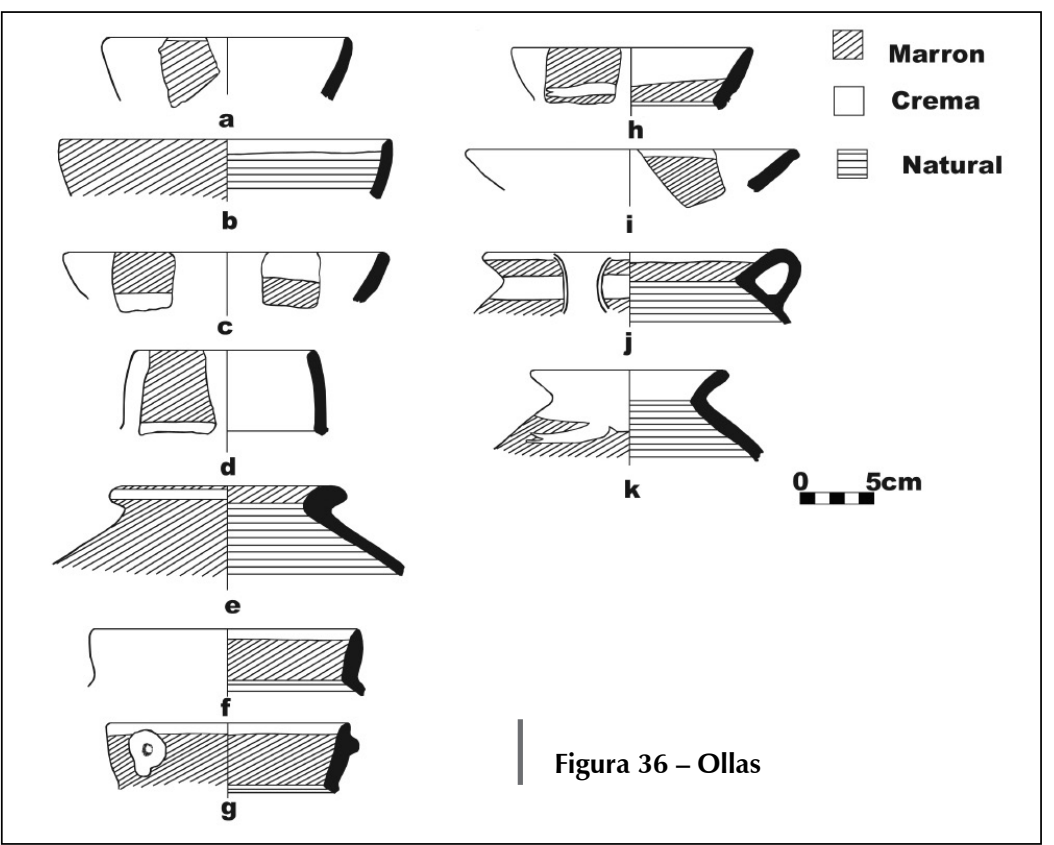

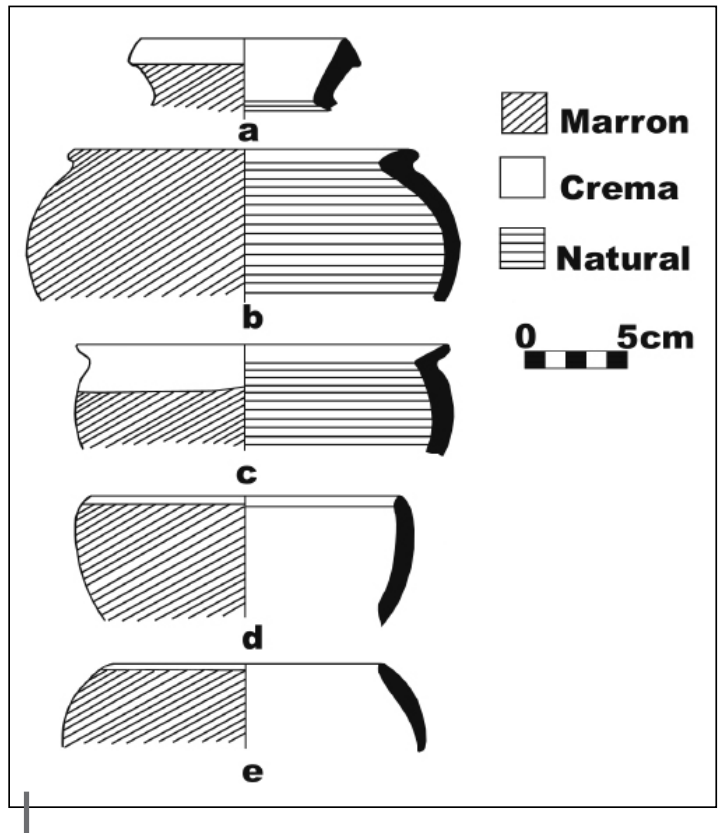

Figura 37 - Ollas y cuencos 


\section{2. 9. Pachacamac-Llano}

Lo conforman las pastas A, B y D. La superficie de los tiestos es tratada en ambos lados con un alisado poco logrado en la mayoría de los casos. Predominan las vasijas cerradas, y destacan las siguientes formas:

\section{Cántaro:}

Cántaros de cuello recto divergente y labio plano. El diámetro de boca varía de 8 a $20 \mathrm{~cm}$ en la boca (fig. 38a, 38b).

Cántaros de cuello recto con ligera inclinación al exterior en el sector del borde. El labio es redondeado y aguzado. El diámetro de boca varía de 12 a $14 \mathrm{~cm}$ (fig. 38c, 38d).

Cántaros de cuello cóncavo y labio aguzado. El diámetro de boca varía de 8 a $20 \mathrm{~cm}$ (fig. 38e, 38f, 38g).

2. Botellas de gollete recto (fig. 39a), de labio redondeado y diámetro de $3 \mathrm{~cm}$ en la boca. Botella de gollete inclinado al exterior en el sector del borde, labio adelgazado y de $8 \mathrm{~cm}$ de diámetro de boca (fig. 39b).

3. Olla:

Ollas de cuello divergente y reforzado al exterior en el sector del borde. El labio

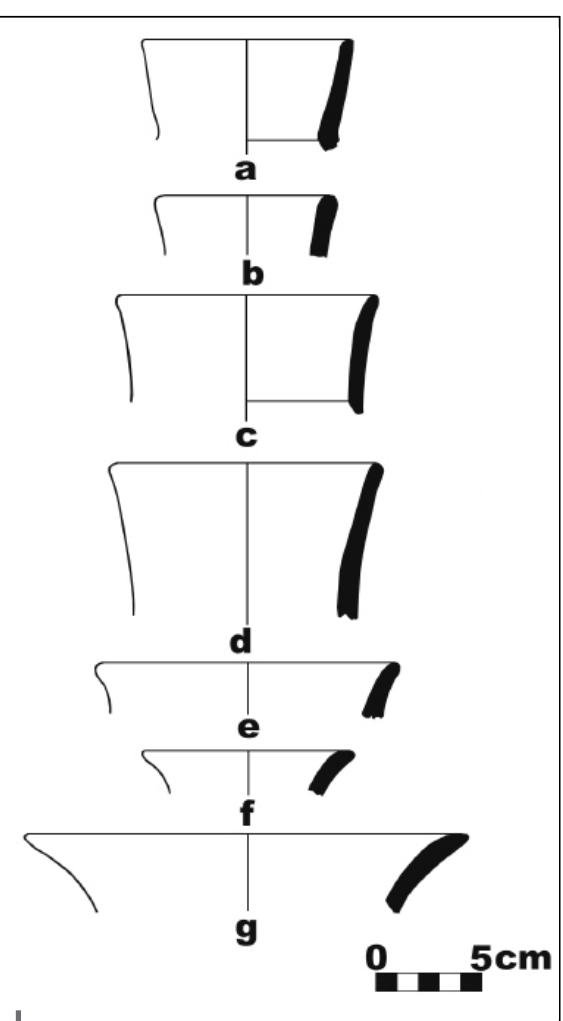

Figura 38 - Cántaros es aguzado. El diámetro de la boca es de 8 a $20 \mathrm{~cm}$ (fig. 39c, 39d, 39e, 39f, 39g, 39h, 39i, 39j, 39k). Ollas sin cuello recto divergente de 12 a $20 \mathrm{~cm}$ de diámetro. El labio es redondeado y aguzado (fig. 40a, 40b, 40c)

Ollas de cuello compuesto de 8 a $18 \mathrm{~cm}$ de diámetro con labio redondeado (fig. 40d, 40e, 40f).

Ollas de cuello corto y divergente. La altura de los cuellos varía de 7 a $16 \mathrm{~mm}$. El labio es redondeado y aguzado. La boca de las vasijas varía de 16 a $20 \mathrm{~cm}$ de diámetro (fig. $40 \mathrm{~g}$ ).

Ollas de cuello incipiente. La altura de los cuellos varía de 4 a $8 \mathrm{~mm}$. El labio es plano y la boca varía de 12 a $16 \mathrm{~cm}$ de diámetro (fig. 40h, 40i).

Ollas de cuello corto reforzado al exterior y labio aguzado. El diámetro de boca varía de 10 a $18 \mathrm{~cm}$.

Ollas de cuello recto de 11 a $20 \mathrm{~cm}$ de diámetro de boca. El labio es plano y redondeado.

Ollas sin cuello de paredes de curvaturas suave $y$ convergentes de 12 a $18 \mathrm{~cm}$ de diámetro. El labio es redondeado y aguzado, la base redondeada y no tiene punto terminal. Generalmente las paredes de las vasijas son delgadas, a excepción de un fragmento que tiene sus paredes engrosadas en el sector del labio. Frecuentemente presentan restos de hollín en el exterior y esto, combinado con su fuerte presencia, sugiere que servían como las vasijas estándar para cocinar.

4. Vasijas abiertas: destaca un tiesto con las paredes inferiores que presentan una marcada convexidad y las paredes superiores casi verticales. El labio se nota adelgazado y el diámetro de boca es de $20 \mathrm{~cm}$ (fig. 41a). Asimismo se han recuperado tiestos de cuencos de paredes curvo convexos que se inclinan al interior en el borde; la base produce una forma ligeramente cerrada. El diámetro de boca va de 14 hasta $18 \mathrm{~cm}$. Por la forma de las paredes, la base tenía que ser redondeada. El labio es redondeado. El tratamiento de ambas superficies fueron pulidos (fig. 41b, 41c, 41d).

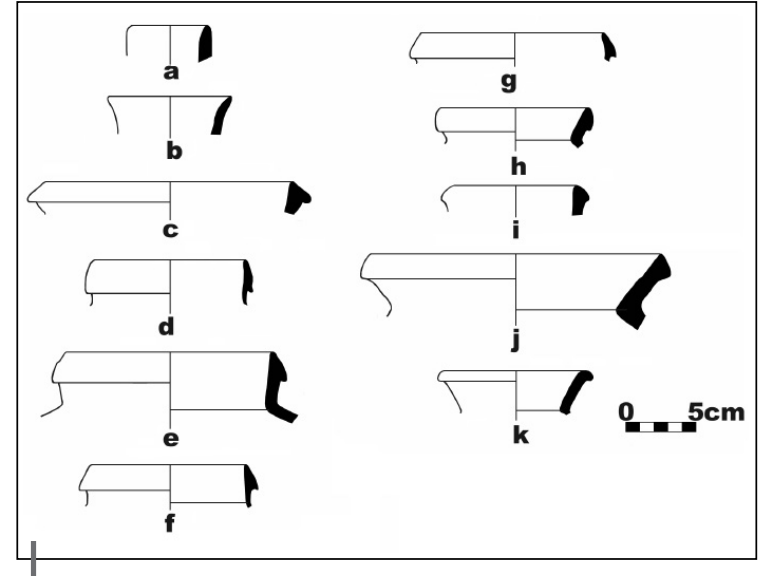

Figura 39 - Botellas y ollas

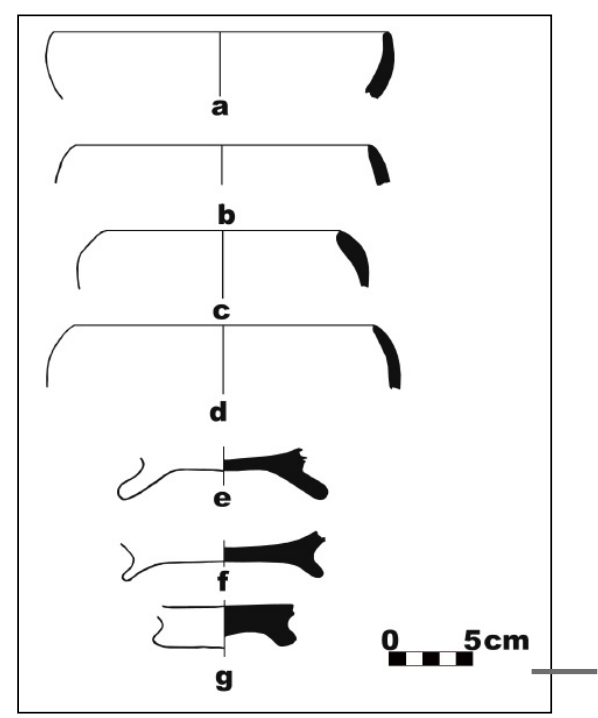

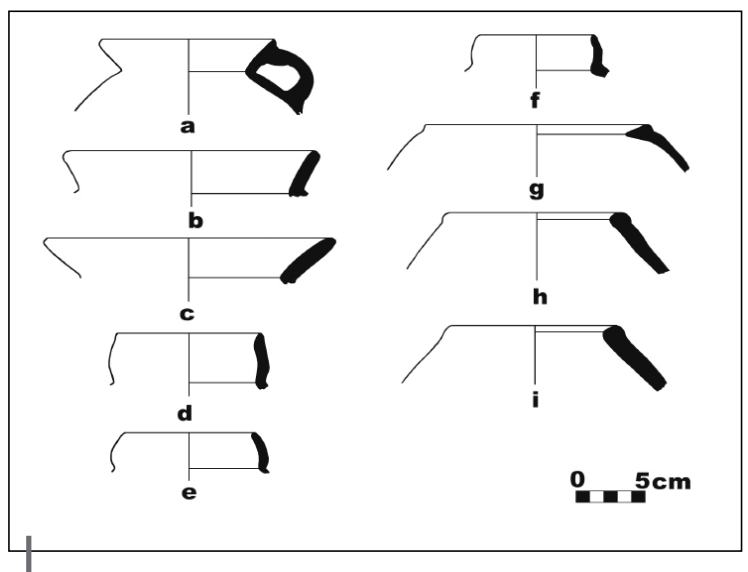

Figura 40 - Ollas 
Jesús A. Ramos Giraldo, Ponciano Paredes Botoni

Se han identificado tres tiestos que corresponden a la parte inferior de las vasijas cerradas con base pedestal. El exterior del pedestal es alisado con un material flexible que deja marcas finas; el interior del pedestal, en cambio, se presenta áspero. El lado superior del pedestal tiene restos de carbón (fig. 41e, 41f, 41g).

Contamos con 120 fragmentos diagnósticos, representando el 9,97 \% del total de la muestra.

\subsection{Pachacamac-Estampado}

Lo conforman las pastas A y B. La decoración se efectúa en la unión del cuello con el cuerpo, engrosando esta sección; en los tiestos de ollas se presenta en la superficie interna de los cuellos, así como en los labios planos reforzado a exterior.

Se ha identificado la siguiente forma:

1. Olla:

Ollas de cuello recto divergente de 14 a $24 \mathrm{~cm}$ de diámetro, con el labio redondeado y plano (fig. 42a, 42b, 42c, 42d, 42e, 42f, 42g).

Ollas de cuello incipiente de 14 a $22 \mathrm{~cm}$ de diámetro de boca y labio redondeado (fig. 43a, 43c)

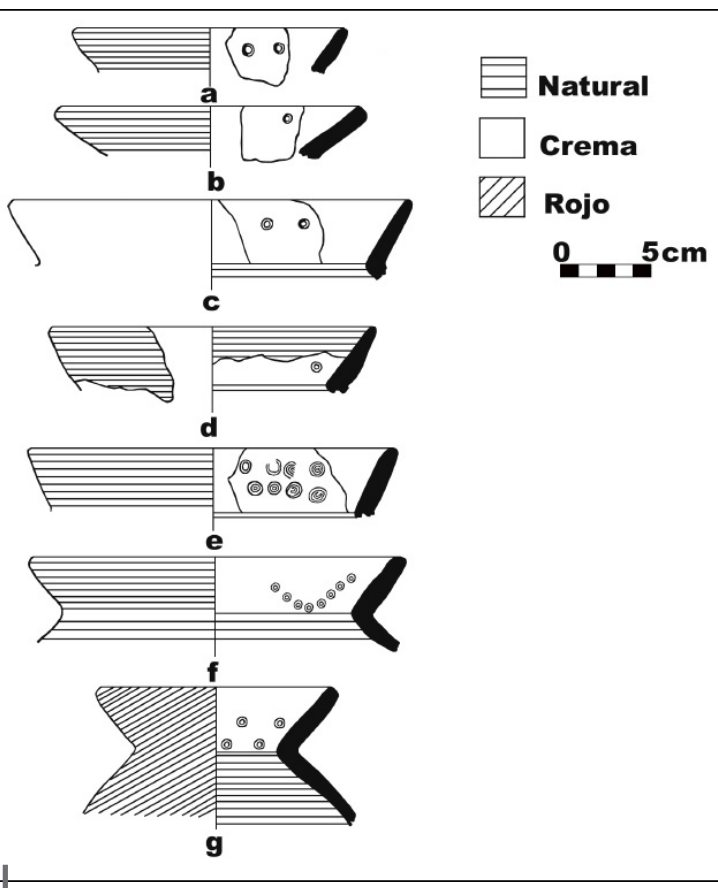

Figura 42 - Ollas
Figura 43 - Ollas y cuellos decorados

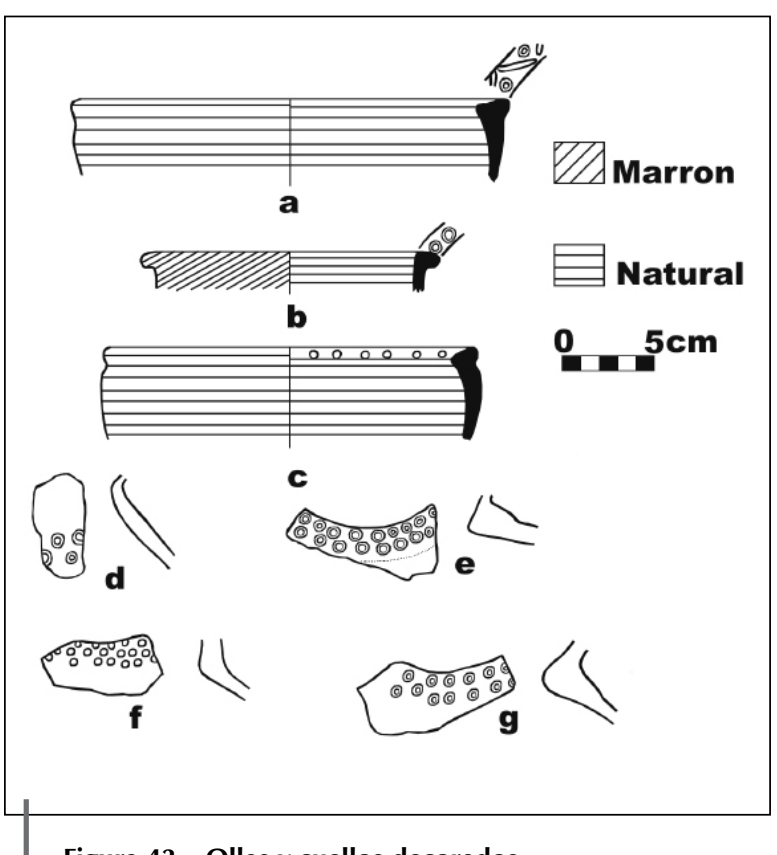

Excavaciones en la segunda muralla-Puente Lurín: estilos cerámicos durante el Horizonte Tardío

Los diseños pertenecen a la técnica del estampado. Es probable que hayan utilizado cañitas que han dejado como huellas los círculos de $10 \mathrm{~mm}$ de diámetro. Estos fueron estampados teniendo las mismas profundidades, con mucho cuidado se colocaron en distancias desiguales y en dos filas distribuidas de modo más o menos regular, uno bajo otro (figs. 42d, 42e, 42f, 42g, 43d, 43e, 43f, 43g).

Existen 14 fragmentos diagnósticos de este tipo, lo que representa el 1,16 \% del total de la muestra.

\section{2. 11. Estilo Puerto Viejo}

Lo conforman las pastas A y B. Los fragmentos tienen la superficie alisada regularmente en el exterior e irregular en el interior. Los diseños son trazados sobre la superficie externa y el labio (extendiéndose en una banda hasta el interior). Se ejecutan los motivos con pintura negra, previamente se cubre con una capa de engobe crema o blanco hasta la parte media del cuerpo.

En este tipo se definen el uso de tres colores: negro que varía de un color negro pálido hasta un marrón oscuro; rojo, que se presenta en variadas tonalidades, desde un rojo encendido hasta un rojo pálido; blanco, que varía desde un blanco bastante definido hasta un crema claro.

Se han identificado las siguientes formas:

1. Cántaro (figs. 44, 45, 46):

Los fragmentos encontrados pertenecen a secciones de cuellos de cántaros. Las paredes son compuestas y divergentes, el labio se presenta recto con un pequeño reborde al exterior o en ambos lados; existen labios subredondeados. Algunos tiestos tienen un aplicado circular ubicado casi en la unión del cuello con el cuerpo. Se trataría de las orejeras de los personajes que se presentan en las vasijas (figs. 45e, 45f, 46a). El diámetro de boca varía entre 12 a $22 \mathrm{~cm}$.

La decoración es pintada y se realiza utilizando los colores negro y crema sobre marrón o rojo, que sirve de fondo; el color crema se utiliza para el rostro, el fondo de los ojos y de otras figuras; el color negro para delinear los ojos y las zonas marrón/rojo y crema. Las facciones se logran mediante la técnica del moldeado y, en algunos casos, con pastillaje.

2. Cuenco:

Cuencos de paredes rectas inclinadas al interior, permitiendo formar un cuerpo de forma carenada o aquillada. El labio es redondeado y adelgazado. El diámetro varía de 14 a $24 \mathrm{~cm}$ en la boca. Ambas superficies están alisadas de manera uniforme; la superficie externa se ha cubierto previamente con engobe crema para luego trazar los diseños; internamente la mayoría de los fragmentos están cubiertos con engobe rojo (fig. 47).

Cuencos de paredes rectas inclinadas al interior y carenadas en el sector medio superior del cuerpo. El labio es redondeado. El diámetro varía de 22 a $28 \mathrm{~cm}$ en la boca. Los tiestos se caracterizan por la aplicación de una capa de engobe crema sobre la superficie externa del cuerpo y el labio. El acabado es alisado áspero al tacto (fig. 48) 

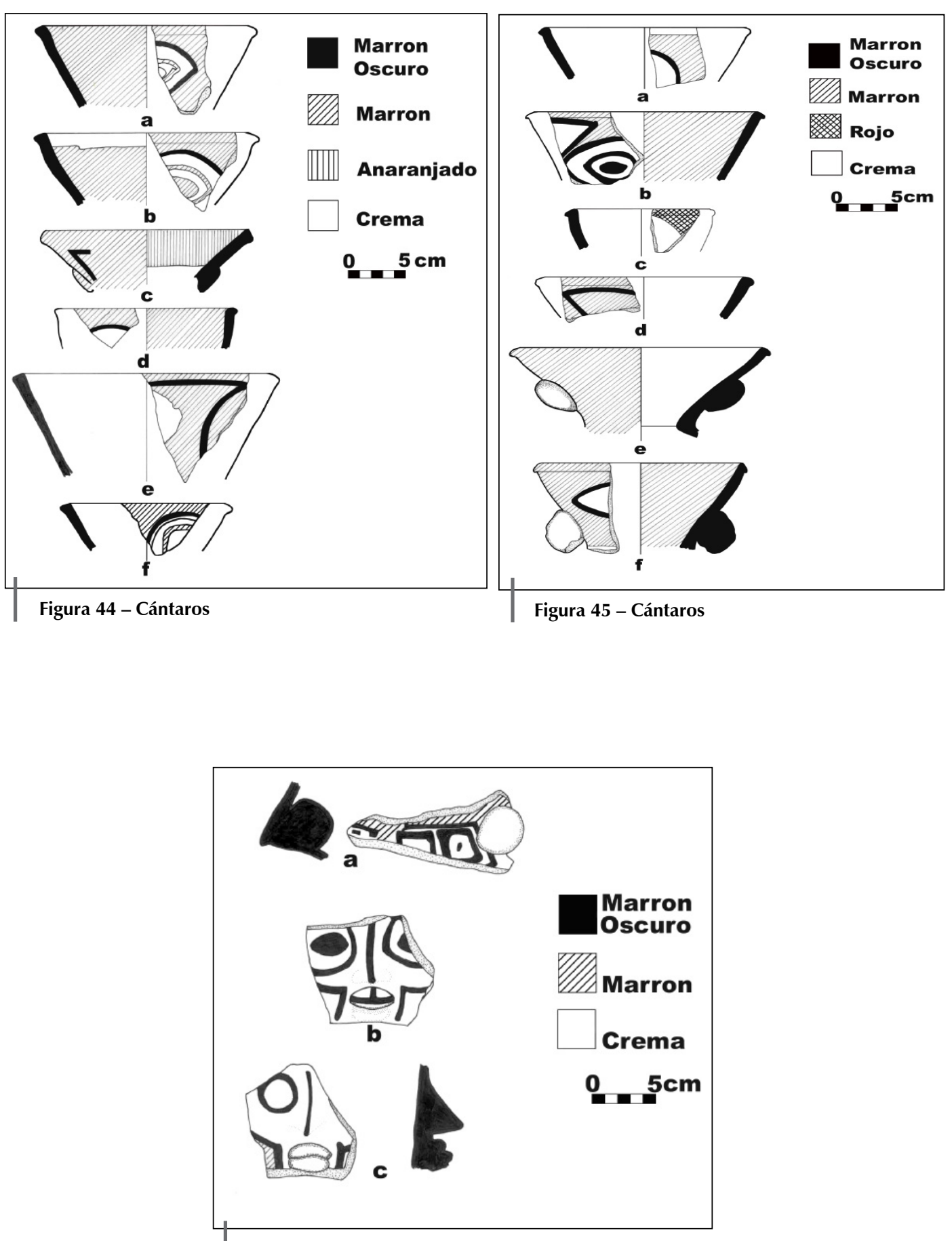

Figura 46 - Fragmentos de cántaros

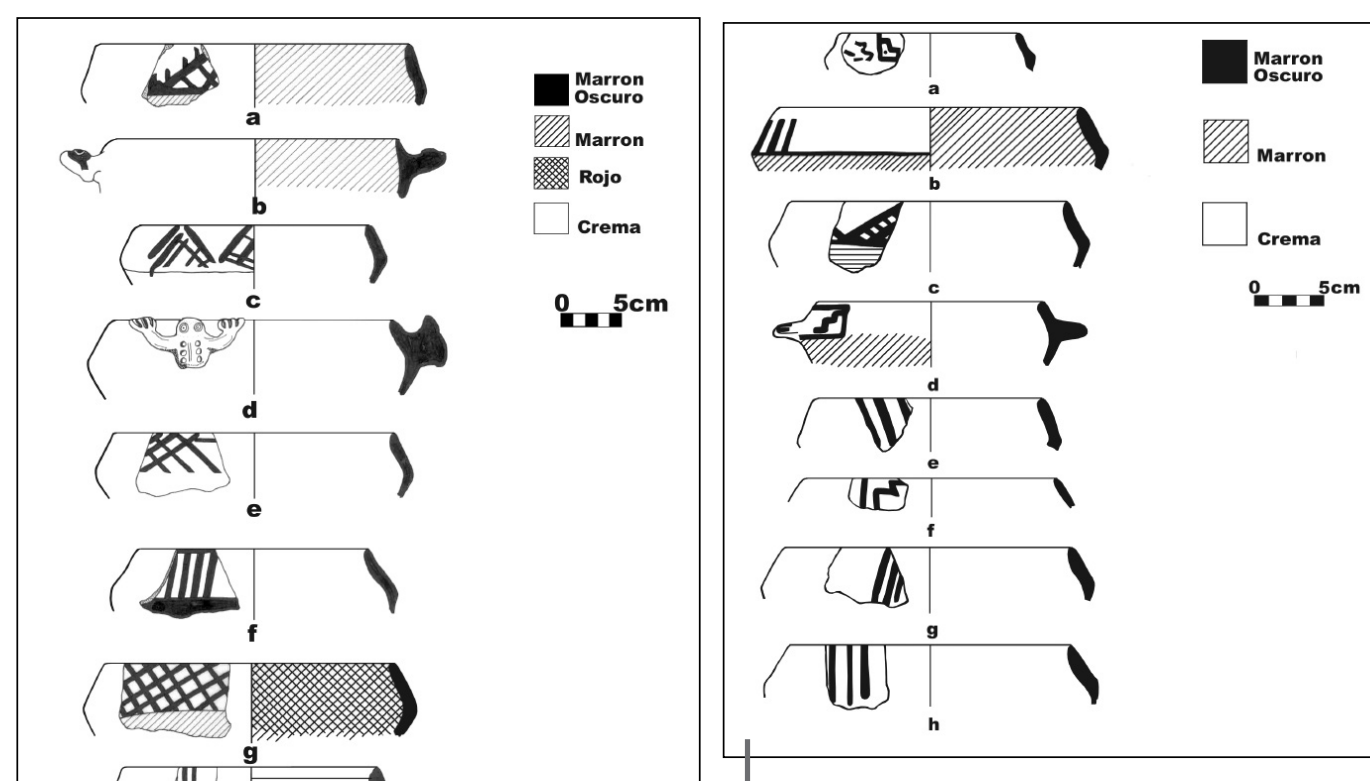

Figura 48 - Cuencos

Cuencos de paredes rectas y carenado en el sector medio superior del cuerpo. El labio es redondeado. Existe una considerable variación en los tamaños, los diámetros de boca pueden tener entre 16 y $24 \mathrm{~cm}$. Los tiestos presentan engobe crema sobre la superficie externa del cuerpo y el labio (fig. 49).

3. Olla:

Ollas de cuello corto que varía entre 17 y $21 \mathrm{~mm}$ de alto, y de cuerpo globular. El labio es redondeado y de bordes doblados hacia el exterior. Existe una considerable variación en los tamaños; los diámetros de boca pueden tener entre 16 y $24 \mathrm{~cm}$. Ambas superficies están alisadas uniformemente; previamente, la externa se ha cubierto con engobe crema. Internamente el engobe es rojo. La decoración consiste en trazos lineales que ocupan la cara interna del cuello (figs. 50, 51, 54).

Ollas de cuerpo carenado o aquillado en su sección media superior, de cuello corto y divergente. La altura del cuello (desde el punto de constricción máxima hasta la boca de la vasija) varía de 8 a $20 \mathrm{~mm}$. El diámetro varía de 14 a $22 \mathrm{~cm}$ en la boca. La superficie externa está alisada hasta alcanzar uniformidad, previamente se ha colocado una capa de engobe crema. La superficie interna está alisada y áspera al tacto, algunos fragmentos poseen engobe marrón. Un fragmento presenta el asa en posición horizontal, la cual une el labio con la sección superior del cuerpo. La decoración consiste en trazos lineales que ocupan la cara interna del cuello y la superficie externa del cuerpo (fig. 52). 


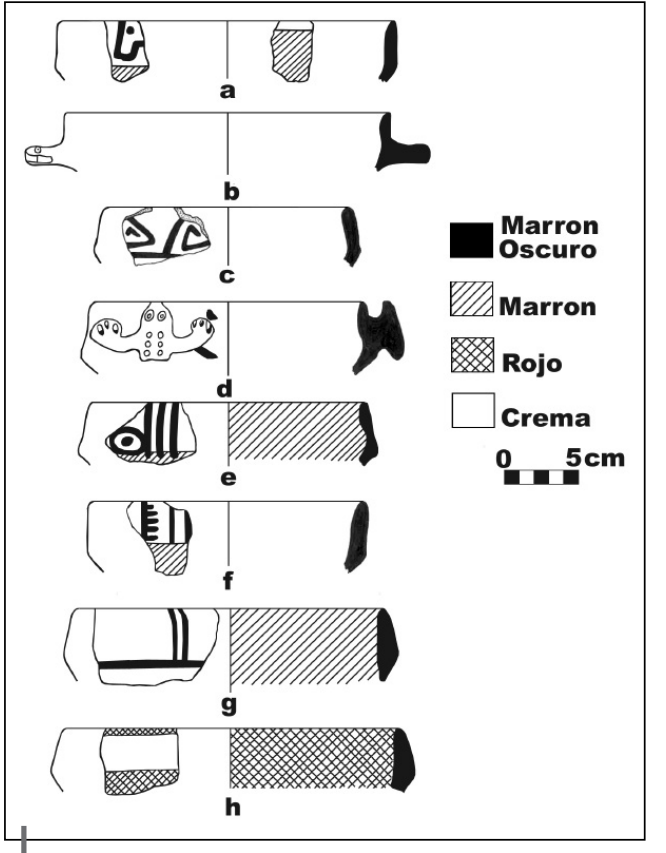

Figura 49 - Cuencos verticales
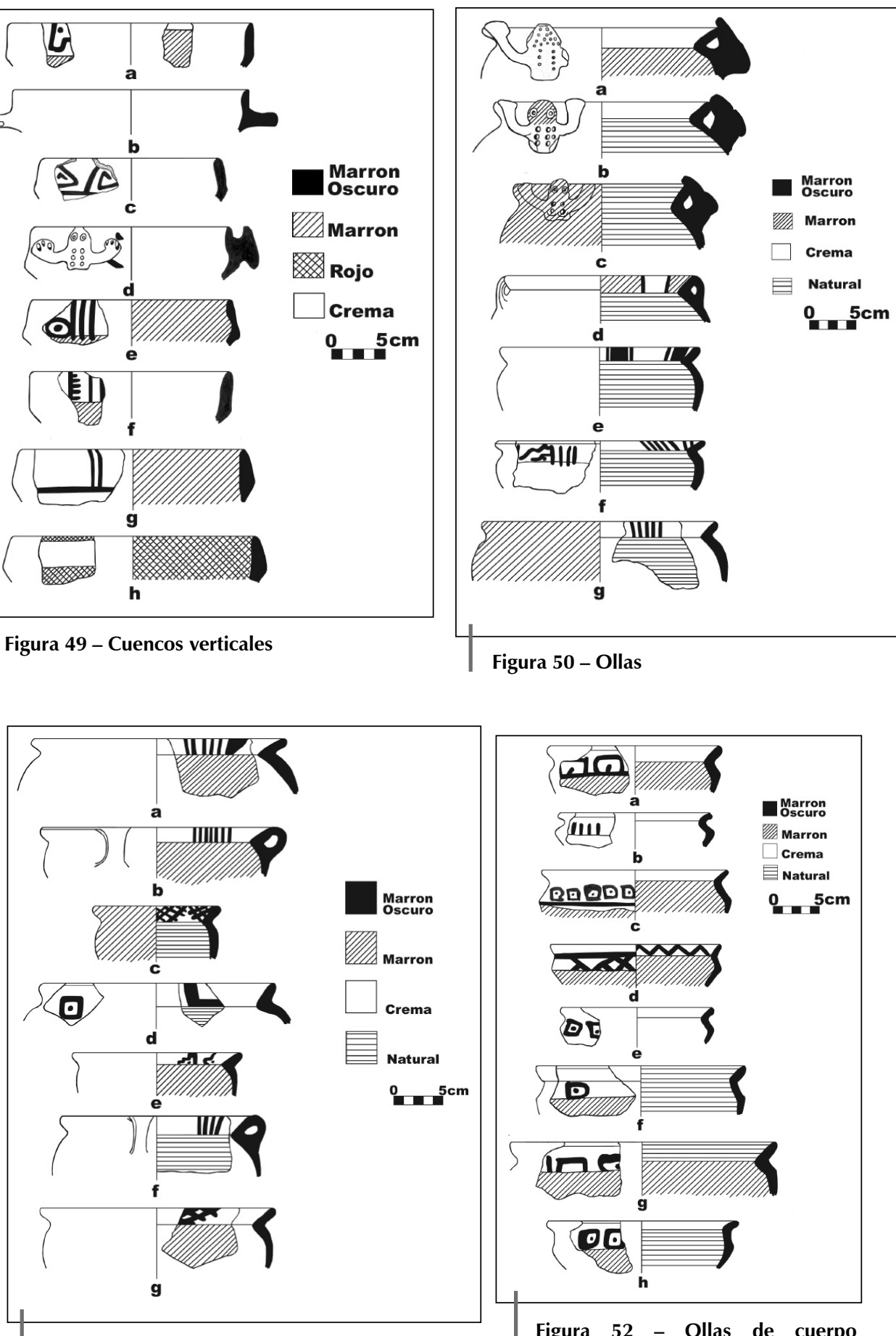

Figura 51 - Ollas

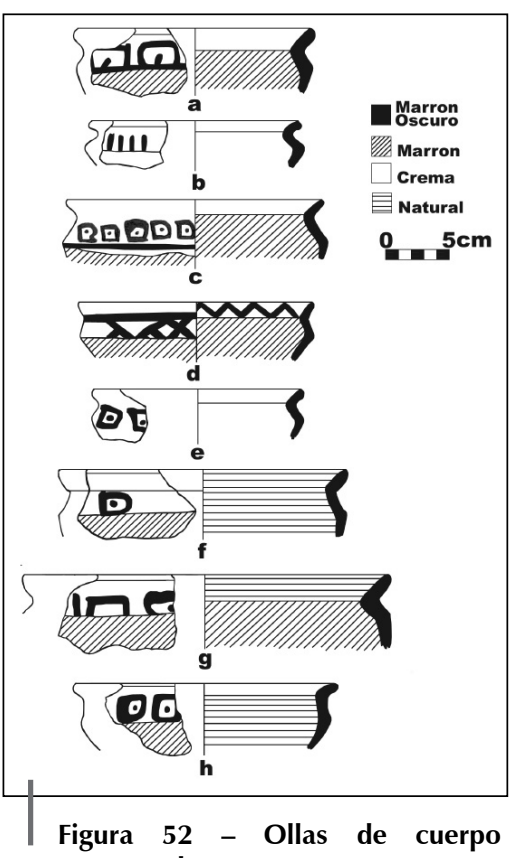

carenado

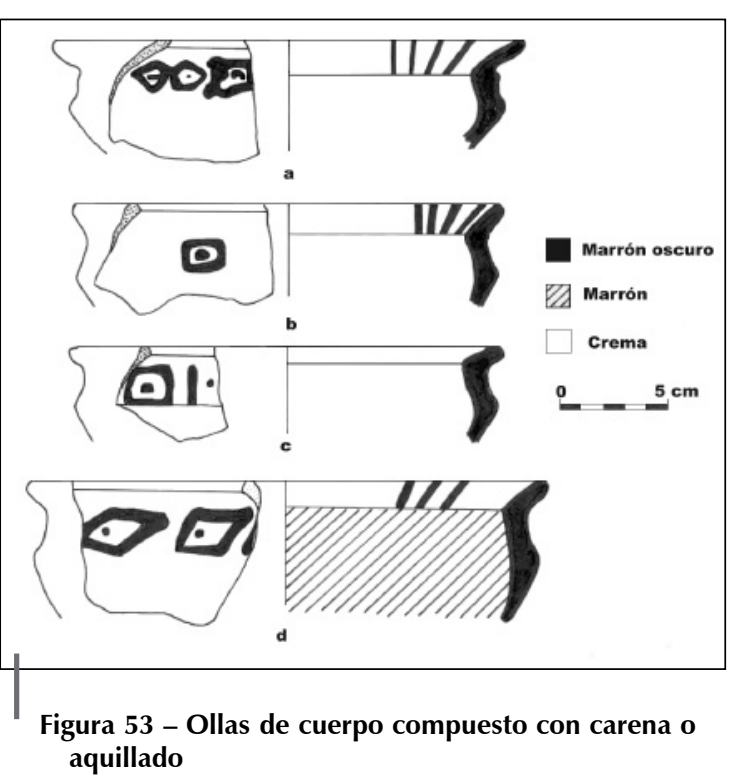

aquillado
3. 3. Ollas que exhiben un cuerpo compuesto y con el aquillado en la parte media. El labio es redondeado y el diámetro de boca oscila entre 20 y $24 \mathrm{~cm}$. La superficie externa está alisada uniformemente pero antes se ha cubierto con engobe crema. La superficie interna está alisada áspero al tacto; pocos tiestos tienen engobe marrón (fig. 53).

Decoración:

La decoración de los fragmentos consiste en trazos lineales que conforman figuras geométricas:

Cuadrados con punto central (figs. 51d, 52a, 52h, 53b).

Motivos escalonados con puntos delimitados por líneas marrones dentro de la franja crema (fig. 51e).

Motivos de peces estilizados (figs. 52e, 53a, 53d).

Motivos en forma de «D» (fig. 52c, 52f)

Varios:

La línea de decoración está en la sección sobre el ecuador de los cuencos y ollas. La forma de las asas de algunos cuencos no se puede precisar aunque en otros casos se presenta como una cabeza de ave. En la decoración escultórica destacan unos sapos colocados en los bordes con sus extremidades delanteras extendidas. Tenemos un total de 462 fragmentos diagnósticos, lo que corresponde al 38,40 \% del total de la muestra. 


\section{2. 12. Estilo Lurín}

Está representado por pasta del tipo C. La arcilla presenta como temperante granos blanco lechoso de tamaño heterogéneo, además de pequeñas partículas transparentes y brillantes (al parecer cuarzo hialino). De manera aislada se observan partículas transparentes de color gris y láminas delgadas doradas. Los tiestos se caracterizan por la aplicación de una capa de engobe rojo (10 R 4/6, 2,5 YR 3/4) sobre la superficie externa del cuerpo, cuello y labio (en algunos casos se extiende en una banda hasta el interior del cuello). En su mayoría, la superficie de los fragmentos es tratada con un alisado no muy bien logrado. En pocos casos se aprecia un alisado uniforme en la superficie interna de los cuellos. Todos los tiestos presentan mica en ambas superficies, a pesar que algunos tienen engobe.

Se han identificado las siguientes formas:

Vasijas cerradas:

\section{Olla:}

Ollas sin cuello de paredes curvas y bordes convergentes. Presentan un reborde proyectado al exterior a manera de «pestaña» y un labio redondeado. Existe una considerable variación en los tamaños, los diámetros de boca tienen entre 16 y $24 \mathrm{~cm}$. La superficie externa presenta evidencia de hollín (fig. 55a, 55b, 55c, $55 d, 55 e, 55 f)$.

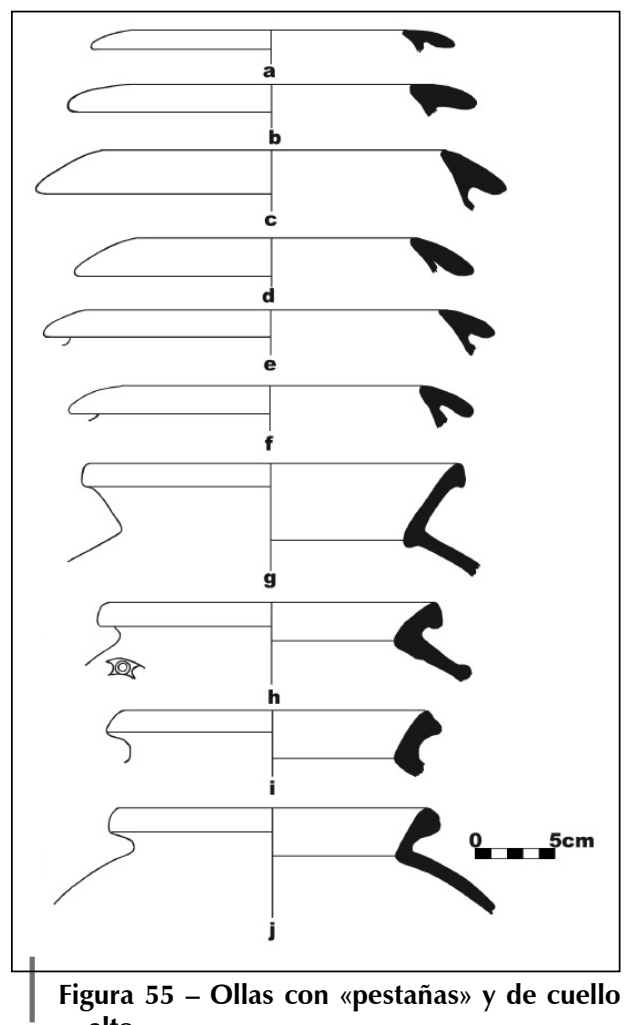

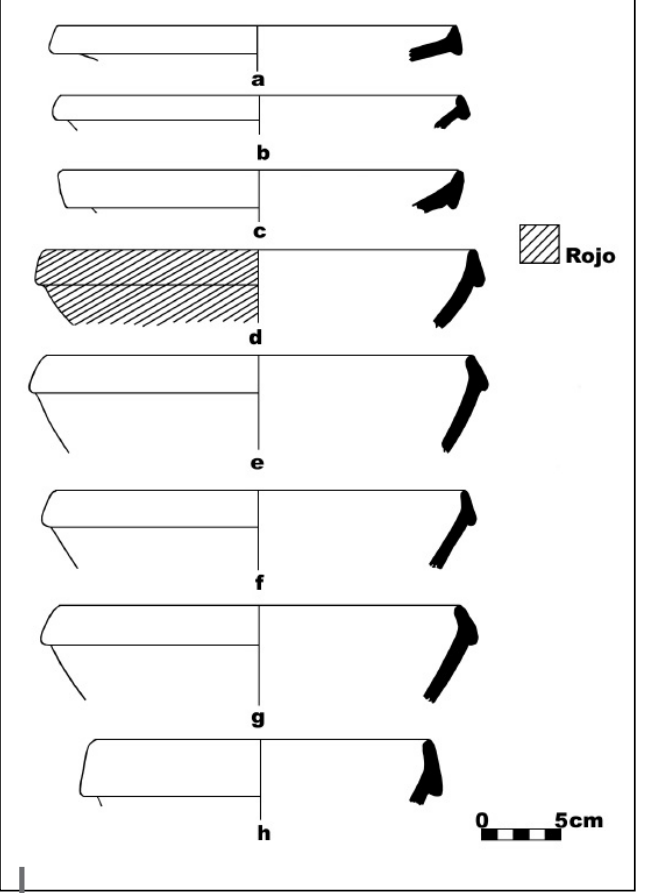

Figura 56 - Ollas de cuello compuesto

Ollas de cuello alto divergente y engrosado hacia el exterior en el sector del borde. Existe una considerable variación en los tamaños, los diámetros de boca varían entre 12 y $28 \mathrm{~cm}$. El labio es adelgazado y plano. La superficie externa está cubierta parcialmente con hollín (fig. 55g, 55h, 55i, 55j).

Ollas de cuello compuesto reforzado al interior y exterior en el sector del borde. El diámetro varía de 16 a $34 \mathrm{~cm}$ en la boca (figs. 56a, 56b, 56c, 56d, 56e, 56f $56 \mathrm{~g}, 56 \mathrm{~h}, 58 \mathrm{~d}, 58 \mathrm{e}, 58 \mathrm{f}, 58 \mathrm{~g}, 58 \mathrm{~h}$ ).

Ollas de cuello compuesto inclinado al interior en el sector del borde. El diámetro de boca varía de 10 a $11 \mathrm{~cm}$ (fig. 57a, 57b, 57c).

Ollas de cuello recto divergente. Presentan el labio plano y redondeado en las esquinas. El diámetro de boca varía de 15 a $34 \mathrm{~cm}$ (figs. 57d, 57e, 57f, 57g, 57h, 59a, 59b, 59c, 61b, 61c, 61d, 61e, 61f, 61g, 61h, 62d). Presentan asa cintada que une la parte superior del cuerpo con el labio.

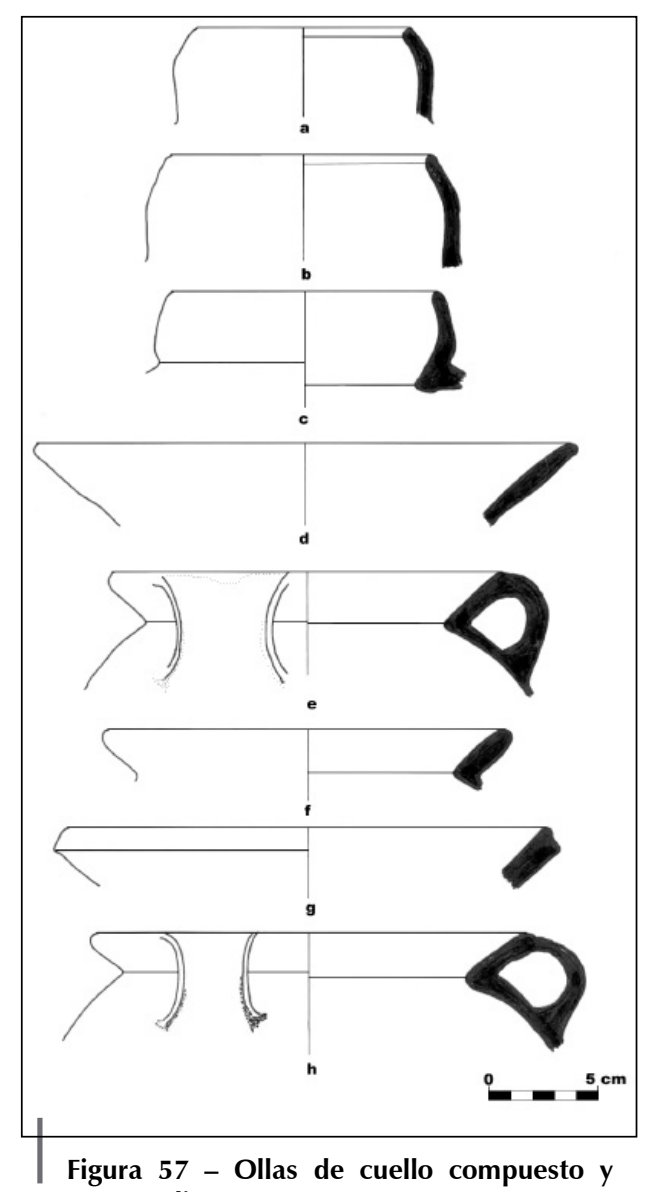

recto divergente

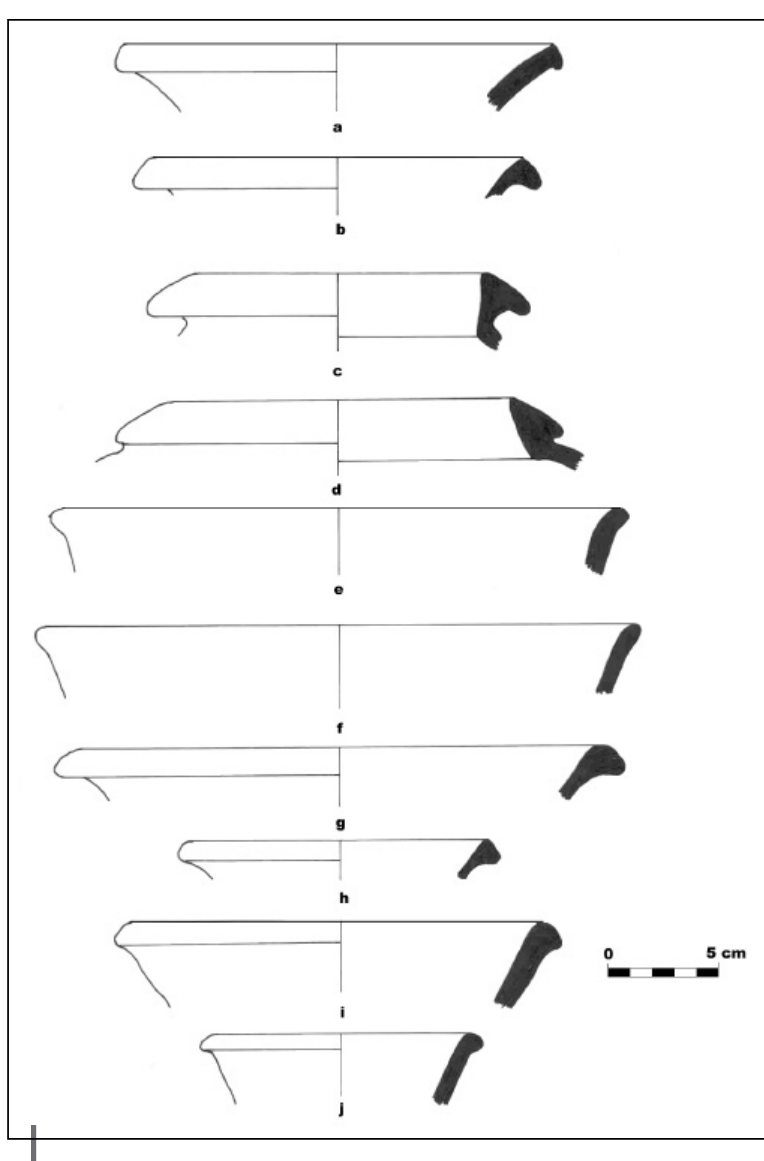

Figura 58 - Ollas de cuello engrosado 
Jesús A. Ramos Giraldo, Ponciano Paredes Botoni

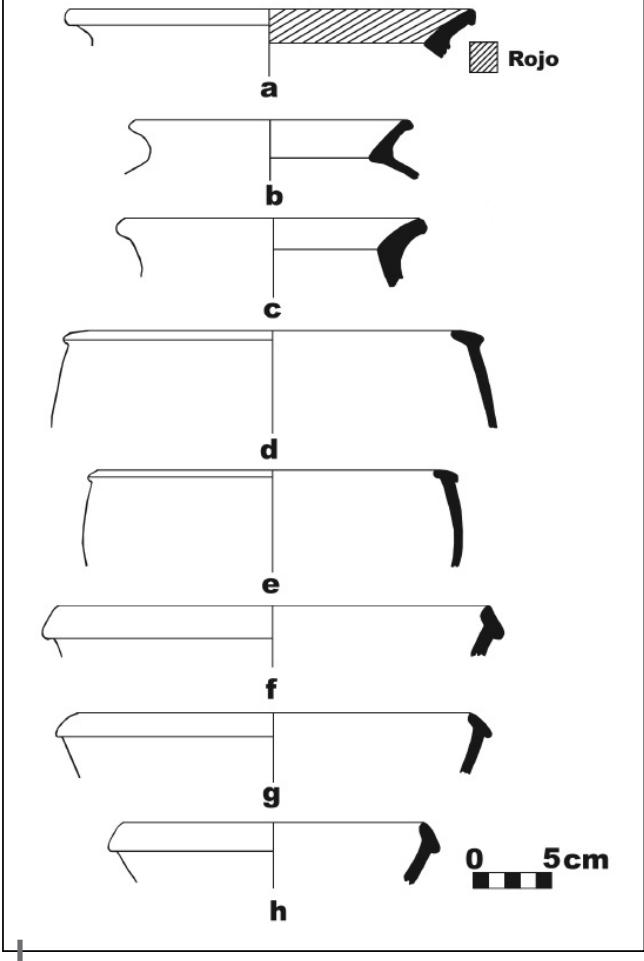

Figura 59 - Ollas de cuello recto divergente y

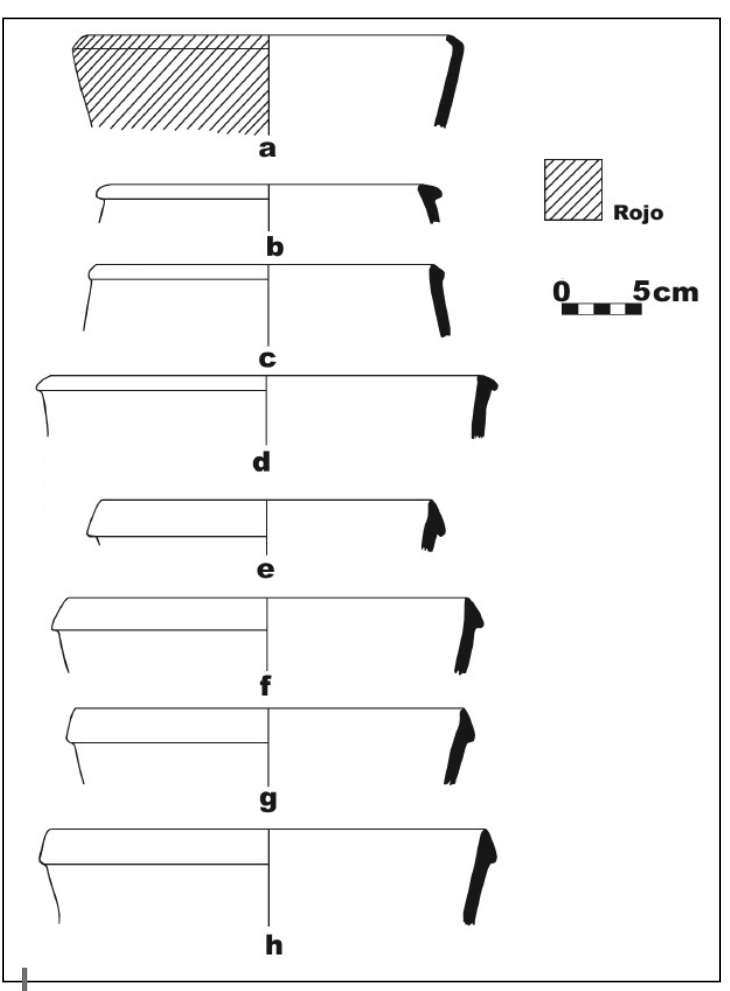

Figura 60 - Ollas con bordes engrosados
Ollas de cuello divergente engrosado en el borde. Los labios son redondeados y planos. El diámetro de boca varía de 14 a $28 \mathrm{~cm}$ (fig. 58).

Ollas de cuello recto de 10 a $28 \mathrm{~cm}$ de diámetro de boca. El labio se presenta adelgazado y subredondeado. Las paredes de la vasija están engrosadas en el sector del borde. Presentan restos de hollín en el exterior, lo que sugiere que servían, como las vasijas estándar, para cocinar (fig. 60).

Olla de cuello recto (fig. 61a) y labio adelgazado. El diámetro de boca es de $26 \mathrm{~cm}$.

Ollas de cuello compuesto, labio redondeado y plano. Existe una considerable variación en los tamaños, los diámetros de boca varían entre 10 y $28 \mathrm{~cm}$ (fig. $62 \mathrm{a}, 62 \mathrm{~b}, 62 \mathrm{e}, 62 \mathrm{f}, 62 \mathrm{~g}, 62 \mathrm{~h}$ ).

Olla sin cuello de paredes de curvaturas suaves y convergentes de $12 \mathrm{~cm}$ de diámetro. Presenta un labio redondeado, igual que la base. Las paredes de la vasija están engrosadas en el sector del labio. Presenta restos de hollín en el exterior lo que sugiere que servían, como las vasijas estándar, para cocinar (fig. 62c).

Ollas de cuello divergente y labio plano engrosado hacia el exterior. El diámetro de boca va entre 14 y $28 \mathrm{~cm}$.
Excavaciones en la segunda muralla-Puente Lurín: estilos cerámicos durante el Horizonte Tardío

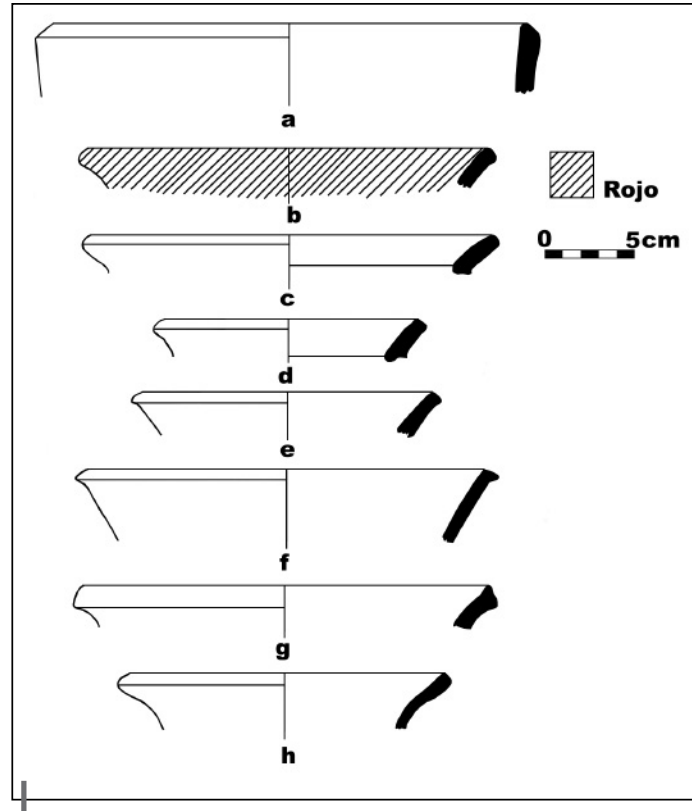

Figura 61 - Ollas de cuello recto

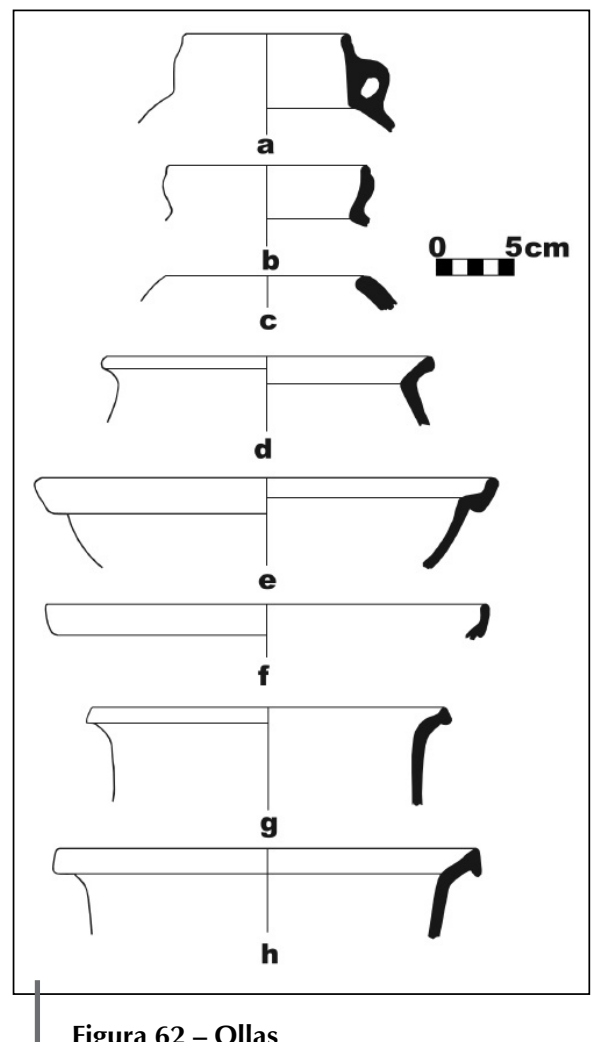

Figura 62 - Ollas

Olla de cuello convergente reforzado al exterior y labio adelgazado. El diámetro de boca es de $16 \mathrm{~cm}$

2. Bases: se han identificado 2 fragmentos de base plana que corresponden a las ollas. Exteriormente está alisado y presenta engobe rojo; interiormente el fondo presenta restos carbonizados (fig. 63c).

3. Asas cinta: están cubiertas con engobe rojo. En la superficie superior de asa se ven las huellas del instrumento utilizado para bruñir, mientras que el lado inferior queda áspero, sin pulir e irregular. Por lo general, son planas en sección transversal y de lados redondeados con $10 \mathrm{~mm}$ de grosor; su ancho es de $40 \mathrm{~mm}$. No presentan decoración y provienen de las ollas; se ubican en la sección media del cuerpo en posición horizontal (fig. 63c).

4. Cuerpos decorados: sobre la superficie externa de la vasija se ha aplicado una tira de arcilla en forma ondulante, en cuya superficie media se han aplicado los diseños que pertenecen a la técnica del estampado. Es probable que hayan utilizado cañitas que han dejado como huellas los círculos de $10 \mathrm{~mm}$ de diámetro. Estos fueron estampados teniendo las mismas profundidades, con mucho cuidado se colocaron en distancias desiguales y en unas filas distribuidos 
de modo más o menos regular. Esta decoración representa una serpiente (figs. 55h, 63d, 63e, 63f, 63g).

Tenemos 175 fragmentos diagnósticos, lo que corresponde al 14,55 \% del total de la muestra.

\section{2. 13. Estilo Inca Local}

Conformado por la pasta D. Con este término, se abarca toda la cerámica estilísticamente incaica o de influencia incaica, pero elaborada fuera del Cusco.

1. Aríbalo: se han agrupado aquí los fragmentos de vasijas de cuello angosto y con borde fuertemente evertido. Están divididos en dos grupos, los que están pintados (en totalidad o parte) y los que no.

Aríbalo pintado: corresponde al borde pintado con engobe rojo. Presenta una franja de 10 a $20 \mathrm{~mm}$ en la parte interna del cuello. El espesor del borde es de $6 \mathrm{~mm}$. El diámetro varía de 18 a $20 \mathrm{~cm}$ en la boca. El labio es semirrecto y recto (fig. 64a, 64b).

Aríbalo sin pintura, conformado por dos fragmentos de bordes. El grosor de los bordes varía de 5 a $7 \mathrm{~mm}$ y el diámetro de 14 a $18 \mathrm{~cm}$. El labio es recto (fig. 64c, 64d)
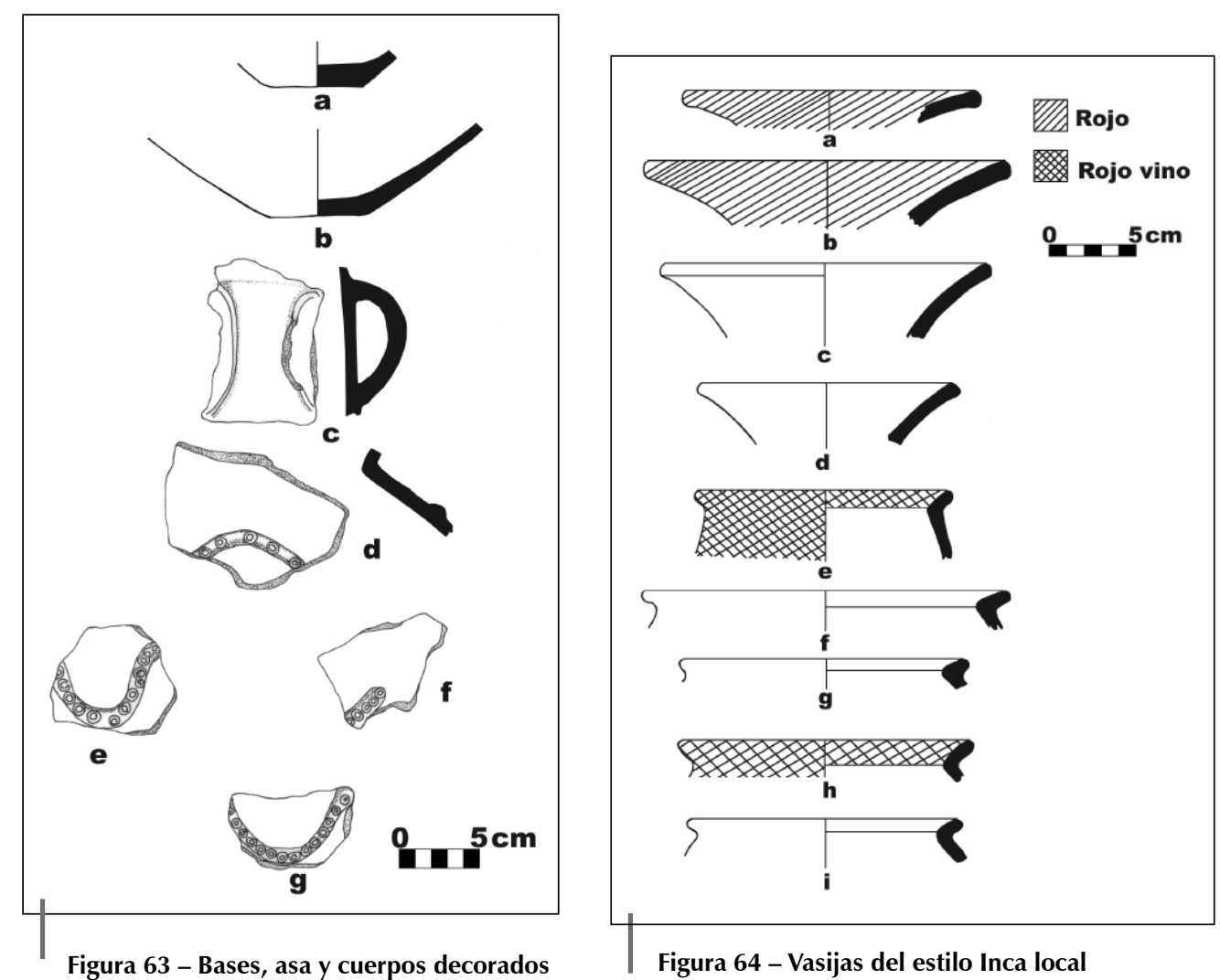

Figura 64 - Vasijas del estilo Inca local
2. Olla: según el ángulo del doblado, existen dos grupos.

Olla con el borde ligeramente doblado hacia fuera, no muy fuerte, de forma casi redondeada. El labio es redondeado, el cuello corto y el borde evertido. La parte interna del borde, el labio y el cuerpo están pintados con color crema. El borde es engrosado en relación a las paredes del cuerpo. El diámetro de boca va de 13 a $20 \mathrm{~cm}$ (fig. 64f, 64h, 64i).

Olla con un fuerte doblado del borde hacia fuera y en ángulo agudo. El doblado se ubica muy cerca de la boca, casi a $1 \mathrm{~cm}$ de ella. El borde es engrosado en relación a las paredes del cuerpo. Dos fragmentos presentan la parte interna del borde, labio y el cuerpo pintados de color rojo a rojo vino. El labio es redondeado y subredondeado y el diámetro de boca es de $16 \mathrm{~cm}$ (fig. 64e, 64g).

De esta muestra se han agrupado un total de 08 fragmentos diagnósticos que representan el $0,66 \%$ del total de la muestra.

\section{3. Comparaciones morfológicas y discusión}

El análisis de los materiales cerámicos excavados en la segunda muralla-Puente Lurín ha permitido la identificación de una ocupación tardía definida a partir de la presencia de alfares procedentes de las capas arqueológicas intactas de la excavación IV (cuadro 1). Estos estratos se acumularon durante un período relativamente corto.

Los tiestos de fácil identificación corresponden a los estilos Inca-Local y Puerto Viejo; además existe un grupo de cerámica llamado Lurín, por haber sido estudiada en este valle. Por el momento notamos la presencia del estilo Lurín en otros sitios de los mismos períodos en las partes media y baja del valle de Lurín. Por ahora ha sido reportado también en el sitio «Armatambo».

Es siempre muy difícil identificar la cerámica local, pues Pachacamac y sus áreas periféricas aún carecen del estudio comparativo de colecciones alfareras provenientes de excavaciones en área. Este grupo se caracteriza por reunir 10 tipos de cerámica. Su asociación con los estilos ya descritos permitirá una mayor aproximación a la determinación de la cronología de la segunda muralla-Puente Lurín.

El primer tipo identificado pertenece al Crema sobre Rojo, poco presente, puesto que representa el $1,83 \%$ del total de la muestra. Su mayor presencia se ve en los niveles bajos y en los bolsones 2, 6 y 7 . Las formas predominantes son ollas y, en menor proporción, los cántaros; asimismo entre los tiestos se identifica un borde de cuenco de $14 \mathrm{~cm}$ de diámetro de boca (fig. 10c).

Lo primero que resalta en este tipo es una olla sin cuello, de paredes curvas y bordes convergentes que presenta un reborde corto proyectado al exterior a manera de «pestaña», recuperada en el bolsón 6. Esta forma de vasija corresponde a lo que se denomina «pepino», y hasta ahora no ha sido identificado en los diversos trabajos realizados en Pachacamac. Uhle (1903: 63, Fig. 66) reporta la presencia de la forma conocida como «pepino», asignándola al período Inca; pero el «pepino» descrito por Uhle tiene cuello recto o algo convexo y tiene el interior del borde rebajado. 
Cuadro 1 - Relación de los tipos de cerámica con los tipos de pastas

\begin{tabular}{|c|c|c|c|c|c|c|}
\hline \multirow{2}{*}{ CERÁMICA } & \multicolumn{6}{|c|}{ PASTA } \\
\hline & $\mathrm{A}$ & B & $\mathrm{C}$ & $\mathrm{D}$ & $\mathrm{E}$ & $\mathrm{F}$ \\
\hline INCA LOCAL & & & & $x$ & & \\
\hline LURÍN & & & $x$ & & & \\
\hline PUERTO VIEJO & $x$ & $x$ & & & & \\
\hline ENGOBE ROJO & $x$ & $x$ & & $x$ & & \\
\hline ENGOBE MARRÓN & $x$ & $x$ & & $x$ & & \\
\hline NARANJA PULIDO & $x$ & $x$ & & $x$ & & \\
\hline CREMA SOBRE NARANJA & & $x$ & & $x$ & & \\
\hline NEGRO PULIDO & & $x$ & & & $x$ & \\
\hline CREMA SOBRE MARRÓN & & $x$ & & & & \\
\hline LLANO & $x$ & $x$ & & $x$ & & \\
\hline ROJO SOBRE CREMA & $\mathrm{x}$ & $\mathrm{x}$ & & $\mathrm{x}$ & & $\mathrm{X}$ \\
\hline BANDA CREMA & $x$ & $x$ & & $x$ & & $x$ \\
\hline ESTAMPADO & $x$ & $x$ & & & & \\
\hline
\end{tabular}

Hasta ahora, los trabajos realizados en la periferia de Pachacamac tampoco han permitido identificar esta forma (Paredes \& Ramos, 1994; Aramburu \& Machacuay, 1996). Utilizando materiales procedentes de varios sitios arqueológicos provenientes del valle de Lurín, Feltham (1983) también identifica la variante de cuello recto del «pepino»; relata que las muestras proceden de Pachacamac, Panquilma, Molle, Anchucaya y las describe como tipo Orange Ware, Form. XVI (Feltham, 1983: 931).

Al comparar con los materiales procedentes del valle del Rímac, vemos que en este valle sí se ha identificado la forma de «pepino» de paredes curvas y bordes convergentes con reborde corto. En base al material procedente de la zona Huachipa-Jicamarca, Silva (1992: 61) define los estilos alfareros del valle. Entre las formas del Horizonte Tardío identifica unas ollas con refuerzo exterior y pestaña. La Fig. 105 (Silva, 1992: 68) es similar a la figura 7a de nuestro trabajo.

En el archivo del museo de sitio de Pachacamac se encuentra el diario de campo n. ${ }^{\circ} 7$, donde se describe la cerámica recuperada en Huaycán de Pariachi; lamentablemente no tiene autoría. Las diferentes formas se identifican gracias a la estratigrafía. De esta manera logran definir que un sector de Huaycán de Pariachi había estado ocupado desde el Intermedio Tardío hasta el Horizonte Tardío; precisamente al describir la cerámica que denominan «Tipo pepino decorado», identifican dos variantes: «pepino» de cuello recto o algo convexo con el interior del borde rebajado y «pepino» sin cuello, de paredes curvas y bordes convergentes que presenta un reborde corto proyectado al exterior. Lo asignan al período Intermedio Tardío; para la última etapa del desarrollo cultural, es decir para el Horizonte Tardío, solo identifican el «pepino» de cuello recto.

Hasta la fecha, los trabajos realizados en Armatambo solo han identificado los «pepinos» de cuello recto (Bazán, 1990; Hyslop \& Mujica, 1992, Fig. 19; Vallejo, 2004: 636).

También destacan las ollas con rebordes al exterior (fig. 7b, 7c, 7d). Esta forma ha sido recuperada igualmennte en la Plaza III de la «Pirámide con Rampa» n. ${ }^{\circ} 3$ (Feltham \& Eeckhout, 2004: 663). Los autores lo llaman «la media flecha» y casi siempre está cubierta con una capa de pintura blanca sobre el interior y exterior del cuello encima de un engobe rojo; cronológicamente lo asignan al Ishmay tardío del incanato.

Para la «Pirámide con Rampa» n. ${ }^{\circ} 2$ y la periferia de Pachacamac, no se han reportado formas de este tipo (Franco, 1993; 1998; Paredes \& Ramos, 1994; Aramburu \& Machacuay, 1996).

Revisando el material procedente del valle de Lurín, se aprecian las ollas con reborde al exterior identificadas desde el sitio de Panquilma hasta Chuchusurco; algunas están pintadas de rojo con bandas blancas en el exterior (Feltham, 1983).

Para el valle del Rímac, Silva (1992: Fig. 92 y 118) identifica también esta forma y la describe como jarras de paredes divergentes y de paredes rectas a veces con borde reforzado en el exterior. Cronológicamente menciona que la alfarería local y foránea o Inca aparece asociada a contextos domésticos. También destacan las ollas de cuello corto (fig. 9a, 9b, 9c) que muestran semejanzas con el tipo Engobe Rojo Decorado recuperado en el Sector III del Proyecto Arqueológico Pachacamac (Aramburu \& Machacuay, 1996: Fig. 46) asociados con la cerámica Inca.

El tipo Banda Crema presenta un porcentaje considerable; está presente en los niveles 1, 11, 12, 16, 17, 18 19, 38, 43 y bolsones 2, 4, 6 y 7 . Dicho tipo abarca los cántaros, ollas, botella y cuencos. Se observa cierta relación morfológica entre las vasijas Crema sobre Rojo y Banda Crema que se puede apreciar entre las formas 7a, 9a, 9b, 9c con las formas 13, 15 del tipo Banda Crema.

La forma 3A descrita por Díaz \& Vallejo (2002: 60) como botella de cuello compuesto, decorada con pintura blanco-cremosa en toda la superficie exterior, podría estar emparentada con nuestra figura 14b, pero lamentablemente solo tenemos la sección superior del cuello o gollete, lo que dificulta nuestra comparación. Los autores sugieren que la forma $3 \mathrm{~A}$ pertenece al período Intermedio Tardío (Díaz \& Vallejo, 2002: 71).

Para Pachacamac, Bandelier recupera unas vasijas de cuello abombado que tiene la forma de un pequeño barril o copa colocada sobre el cuerpo de la vasija. A decir de Feltham \& Eeckhout (2004: 662, Fig. 26), correspondería cronológicamente al Ishmay Medio, es decir al período Intermedio Tardío. La forma descrita por Feltham \& Eeckhout estaría muy emparentada con nuestra figura 14b. 
Dentro del tipo Banda Crema existen también ollas de cuello recto divergente y cuello compuesto que presentan asas cintadas verticales ubicadas a la mitad del cuello y que terminan en el hombro superior de la vasija (figs. 11g, 16b) y ollas con asas que unen el labio mismo con la parte superior del cuerpo (fig. 16a, 16b).

El tipo Engobe Marrón, ha sido identificado en poca proporción. Tiestos de este tipo han sido recuperados en los niveles 17, 18, 35, 43, 49, 54 y bolsones 6 y 7 . Las vasijas se caracterizan por una aplicación de engobe de color marrón sobre la superficie exterior y el labio (que se extiende en una banda hasta el interior). Los cántaros tienen engrosado el exterior en el sector de la boca; algunos tiestos (fig. 18e, 18g) están decorados con el rostro de un personaje mediante la técnica del aplicado, los ojos son almendrados y la nariz respingada, la boca aparece en relieve con incisión.

$\mathrm{Si}$ hacemos comparaciones con otros sectores de Pachacamac, no podemos observar algún parecido con nuestro material, los investigadores presentan las vasijas cántaro-efigie hechas en bulto presionados desde el interior (Franco, 1993; 1998; Aramburu \& Machacuay, 1996; Feltham \& Eeckhout, 2004). Las ollas identificadas son de cuerpo globular y tienen el exterior engrosado en el sector de la boca, de forma definida como «la media flecha». También se ha identificado un tiesto de cuello perteneciente a una botella decorada con el rostro de un personaje (fig. 19a), los ojos son aplicados en forma de granos de café y la boca consiste en una incisión en forma de media luna.

El tipo Crema sobre Naranja, se recupera en los niveles 11, 20, 22, 38, 43 y en los bolsones 3, 6 y 7. Los cántaros, recuperados en los bolsones, son de cuello expandido (fig. 20) y se caracterizan por tener casi siempre un engobe de color naranja en la superficie exterior y el labio pintado de crema (extendiéndose en una banda hasta el interior y/o exterior). En otros tiestos se alternan los colores crema y naranja para darle la decoración deseada. Entre las ollas destacan 2 formas: de cuello divergente y de cuello corto.

El tipo Negro Pulido constituye un segundo grupo recuperado en grandes cantidades en los niveles 7, 17, 19, 20, 32, 37, 38, 39, 40, 43, 45, 46, 51, 62 y en los bolsones 2, 6 y 7 . Los tiestos han sido elaborados utilizando las pastas B y E. Sobre la superficie se ha agregado una capa de engobe de color negro, donde la superficie exterior ha sido pulida uniformemente hasta alcanzar brillantez. Las vasijas abiertas han sido pulidas internamente.

Destacan las ollas de cuellos divergentes, variando en la forma del cuerpo. Están decoradas con un batracio ubicado sobre el diámetro mayor del cuerpo, de ta forma que apoya sus extremidades anteriores sobre el labio de las ollas. El batracio presente en la figura $23 \mathrm{f}$ está menos tratado que los de las figuras $22 \mathrm{~d}$ y $23 \mathrm{e}$. En este grupo se identifica una mayor presencia de tiestos de botellas de gollete divergente y gollete recto inclinado al exterior en el sector de la boca. Al realizar la comparación de los cántaros, se aprecia una similitud con los cántaros de tipo Engobe Marrón, sobre todo con los que se ven en la figura 18 en cuanto al engrosamiento exterior de las paredes en el sector de la boca.
Fuera de Pachacamac, se puede apreciar que la cerámica del tipo Negro recuperado por Bazán en Armatambo, presenta también similitud con las figuras $25 a, 25 b$ y $25 c$ de nuestro material, en lo que respecta al engrosamiento en el sector del borde (Bazán, 1990: Lám. 8a, Lám. 22). Entre las vasijas abiertas se han podido identificar platos y cuencos, siendo esta última forma la de mayor presencia. Destacan los cuencos de paredes rectas y convergentes con carena en el ecuador (fig. 26d, 26e, 26f, 26g) y que llevan como motivo decorativo la representación de un batracio (fig. 26d) y de un ave (fig. 26g). Esta forma es muy similar a los cuencos del estilo Puerto Viejo. Si se compara con la cerámica de Ica, se aprecia que la forma de la figura $26 \mathrm{~d}$ es muy similar a los platos de Ica 9 (Menzel, 1976: Pl. 19. Fig. 226 y 227); hay similitud en las paredes rectas con la carena en el ecuador. La diferencia con nuestro material está en la base que es redondeada y más profunda.

La cerámica agrupada como tipo Engobe Rojo muestra persistencia en los niveles superiores 17, 18, 21, 22, 23, 24, 25, para luego disminuir en los niveles 33, 34, $38,40,48$ y en los bolsones 2, 3, 6 y 7 . Se caracteriza por ser una cerámica con temperantes blanco lechoso predominante y pasta de color claro. Las formas con mayor presencia son ollas de cuello divergentes, paredes convergentes y cuello recto y corto cubierto por una capa de engobe rojo.

Cuando llevamos a cabo comparaciones con los materiales procedentes de Pachacamac, vemos que las referencias son escasas. A pesar de que las muestras de la «Pirámide con Rampa» n. ${ }^{\circ} 2$ son abundantes, no se reportan formas de este tipo (Franco, 1993; 1998). Asimismo, al realizar comparaciones con otros sitios investigados, se puede apreciar que existe la cerámica con engobe rojo pero las formas son diferentes a las que estamos presentando (Silva, 1992; Aramburu \& Machacuay, 1996; Guerrero, 2004).

Los lotes de muestras de cerámica asociados a los niveles $1,13,37,38,43$ y a los bolsones 1, 2 y 6 han sido identificados como tipo Naranja Pulido. De acuerdo a las comparaciones hechas, la botella de la figura 33a es similar a la descrita por Feltham \& Eeckhout (2004: Fig. 41), donde el labio es plano y presenta engobe naranja. Se sugiere que el tipo Naranja Pulido forma parte de la cerámica introducida por los incas en Pachacamac.

Se identifica poca cerámica de estilo Inca, lo que indica la influencia de ese estilo pero es cerámica fabricada en la región y con materias primas locales, razón por la cual lo estamos denominando Inca-Local. Formas de esta cerámica son, en general, los aríbalos y ollas. Entre los aríbalos se distinguen dos grupos: pintados y sin pintar. Los pintados se caracterizan por estar engobados totalmente de rojo: tienen un acabado más esmerado y las formas presentan una mayor regularidad. Los aríbalos sin pintar tienen formas desproporcionadas, lo que a veces hace que sean semejantes a las vasijas locales. Un segundo tipo difundido en la fase IncaLocal son las llamadas ollas de probable base anular y con tapas. En este caso también se presentan ollas pintadas y sin pintar.

La presencia de tiestos Inca-Local se encuentran en los niveles 2, 3, 13, 17, 18 (bolsón 1), 21, 25 (bolsón 4) y 43. Definimos como bolsones, a las roturas que 
fueron realizadas para colocar desechos de material cultural (cerámica, moluscos, artefactos líticos, óseos de animal, entre otros), producto de actividades dentro de Pachacamac o en el Templo, desaparecido hoy, ubicado en el PP. JJ. «Julio C. Tello», e indicado en el plano de Uhle realizado en 1896.

La cerámica del estilo Puerto Viejo es la más numerosa y representa el 38,40 \% del total de la muestra. Hay cántaros, cuencos y ollas. Los cántaros son vasijas que representan personajes, pero durante nuestra excavación solo se han recuperado los fragmentos de cuello con representación del rostro de los personajes, denominados, por esta razón, «Cara-Gollete». Tienen aplicaciones de negro y crema sobre marrón o rojo; el crema se utiliza para el rostro, el fondo de los ojos y de otras figuras; el negro para delinear los ojos y las zonas marrón/rojo y crema. Las facciones se logran mediante la técnica del moldeado y en algunos casos con pastillajes.

Los cuencos y ollas se caracterizan por presentar la superficie alisada regular en el exterior e irregular en el interior. Los diseños están trazados sobre la superficie exterior y el labio (extendiéndose en una banda hasta el interior). Los motivos son hechos con pintura negra, previamente cubierta por una capa de engobe crema o blanco hasta la parte media del cuerpo. Se identifica el uso de tres colores: negro variando hasta un marrón oscuro; rojo (desde un encendido hasta un pálido) y blanco (desde blanco a crema claro).

Durante nuestra clasificación solo identificamos como estilo Puerto Viejo a la cerámica que emplea el uso de tres colores (negro, rojo y crema). Sin embargo, después de realizar comparaciones morfológicas, consideramos que la cerámica con los colores marrón sobre crema también forma parte del estilo Puerto Viejo, aunque muchos investigadores lo identifican como propia del «estilo Ishmay». En tal sentido, los tipos Ichimay cara-gollete e Ichimay negro sobre blanco (Bueno, 1982) o Ichma Bícromo (Paredes \& Franco, 1987-1988) no son parte de la cerámica local pre Tawantinsuyo, tal como lo propone Bueno (1982).

Las excavaciones realizadas en las «Pirámides con Rampa», también han permitido recuperar tiestos del estilo Puerto Viejo. Lamentablemente, el poco control en el registro estratigráfico está creando más confusión que aportes. Por ejemplo el material recuperado en la «Pirámide con Rampa» n. ${ }^{\circ} 1$ fue analizado y reporta un fuerte porcentaje de cerámica del estilo Puerto Viejo (Ramos \& Paredes, 2002).

Se identifica también el estilo «Puerto Viejo» en la «Pirámide con Rampa» $n .^{\circ} 2$. Franco identifica los tipos Marrón Oscuro/Amarillo Pálido y Negro, Amarillo Pálido o Blanco sobre Engobe Rojo, y los considera como parte de su segunda fase. Lo describe como cántaros cara-gollete pintados en colores marrón oscuro sobre cerradas con cuerpo aquillado pintadas de color amarillo pálido o blanco en el tercio superior y rojo oscuro en el cuerpo inferior (Franco, 1993). Asociados a estos tipos, Franco también identifica fragmentos de ollas de uso doméstico trabajadas en cerámica negra con elementos decorativos en relieve de serpientes con incisos, círculos impresos y una cara-gollete alta, de lados divergentes con tratamiento inciso y ojos alados, que según el autor, tiene profunda influencia Lambayeque.

En tal sentido, si se compara con la cerámica, Franco $(1993 ;$ 1998) considera su segunda fase como correspondiente al período Intermedio Tardío. Sin embargo creemos que hay que afinar esta segunda fase, toda vez que existen tiestos con elementos decorativos que nos estarían indicando todo lo contrario. Franco reporta serpientes con incisos y círculos impresos. Según comparaciones la presencia de la serpiente es introducida por los incas a su llegada a la costa central.

Para la «Pirámide con Rampa» $\mathrm{n}^{\circ}$ 3, el análisis del material cerámico también nos aporta datos muy interesantes. Feltham \& Eeckhout (2004), tomando solo como criterio la descripción morfológica, tratan de definir el estilo Ishmay Tardío. Manifiestan que los cuencos son bastantes frecuentes en las plazas de las «pirámides», y que la forma más frecuente durante el Ishmay Tardío son los cuencos carenados que suelen llevar un engobe rojo y luego una capa de pintura blanca en la parte superior y, sobre esta capa, un diseño de pequeños rectángulos con un punto dentro, o de triángulos, o de peces. Otra de las formas correspondería a las jarras con cara-gollete producidas antes de la llegada de los incas al Santuario. Más tarde, durante el Incanato, fabrican otras formas de cuencos además de los cuencos carenados (Feltham \& Eeckhout, 2004: 657-658).

Tratando de sintetizar lo expuesto, los autores citados sostienen que el Ishmay Tardío tiene dos fases antes de la llegada de los incas a fines del siglo XIV y continúan con el Incanato. Felthan \& Eeckhout (2004: 656) plantean también que las raíces del Ishmay Tardío se encuentran en el Intermedio Tardío, por los diseños en blanco y negro sobre rojo. Según nuestra comparación, pensamos que los cuencos carenados y las jarras cara-gollete decorados con los colores marrón, blanco y rojo, forman parte del estilo «Puerto Viejo» y no del estilo «lshmay Tardío».

Los trabajos realizados en los alrededores de la tercera muralla reportan el subgrupo «Cara-Gollete» en el grupo Inca Asociado (Aramburu \& Machacuay, 1996: 50). La cerámica «Cara-Gollete» correspondería al estilo «Puerto Viejo». Lamentablemente los autores no lo ubican en el tiempo, a pesar de que estratigráficamente identifican dos ocupaciones (Aramburu \& Machacuay, 1996: 26-27).

Fuera de Pachacamac, la cerámica Puerto Viejo también es identificada con un fuerte predominio en dirección al sur chico. En los valles de Chilca y Mala existen los cántaros efigies con la misma idea del rostro y el cuerpo de las vasijas; presentan las manos recogidas. Duccio Bonavia estudió un lote de cerámica recolectado en el sitio de Puerto Viejo (Bonavia, 1959:137). Él piensa que la cerámica Puerto Viejo representa un estilo local pre Inca y que muy bien puede ser definido de «estilo» (Bonavia, 1959:166). Definió los tipos «Cara-Gollete» y «Negro sobre Blanco».

Existen algunas diferencias entre los cántaros efigie de Puerto Viejo y los de Pachacamac, pero no debemos olvidar que el material trabajado por Bonavia es de superficie y el tipo Cara-Gollete se define en base a 72 fragmentos; entonces, tendría que existir diferencias en los rostros. Pero un estilo no se diferencia solo por el rostro; para llegar a definir un estilo, se tiene que ver la forma de la cerámica, la decoración y la pasta. Al menos entre la cerámica «Cara-Gollete» de Puerto Viejo y las de Pachacamac existen semejanzas en la forma y la decoración, lo que nos permite afirmar que son cerámicas del mismo sitio.

En el sitio «El Salitre» del valle de Mala, también se encuentran cerámicas cántaros efigie que, según Howard Goldfried (1969), no se distinguen de las de Puerto 
Viejo. Otro sitio arqueológico identificado en el valle de Mala, corresponde a «Cerro Salazar». Para el período Intermedio Tardío también se identifica el tipo Cara-Gollete. Gabe (2000: 59) manifiesta que no se conoce sus antecedentes inmediatos en el «Cerro Salazar», por lo que su presencia debe obedecer más bien a una influencia foránea del sitio arqueológico. Asimismo, Gabe (2000: 50) señala que los valles de Chilca, Mala y Asia comparten muchos rasgos culturales, registrados en la cerámica, y espera que con mayores investigaciones se pueda definir una cultura local para esta zona sureña.

Además del sur chico, el estilo Puerto Viejo también se reporta en la isla San Lorenzo (Isla, 1995: 88) y otros sitios del valle del Rímac (Guerrero, 2004) Vallejo (2004) utilizando como base los materiales recuperados en Armatambo, publica un artículo donde elabora la secuencia cerámica Ychsma, definiendo las características generales para cada fase. Lamentablemente, en su afán de poner un nuevo nombre a un estilo ya identificado como Puerto Viejo, refiere que las vasijas «Cara-Gollete» corresponden a la forma más típica del estilo Ychsma (Vallejo, 2004: 619) y lo asigna a las fases Ychsma Tardío A y B del Horizonte Tardío (Vallejo, 2004: 621).

Al interior del valle de Lurín, recientemente han encontrado tiestos de este estilo en el sitio Pueblo Viejo-Pucará, ubicado en las quebradas laterales que atraviesan las primeras estribaciones de los Andes en la margen izquierda del río Lurín (Makowski \& Vega Centeno, 2004: 689). Con las excavaciones definen dos fases dentro del Horizonte Tardío. Lamentablemente, la cerámica es presentada en forma general, sin tratar de definir a que fase corresponde cada estilo identificado. Cuando tratan de explicar la presencia del estilo «Puerto Viejo» en el sitio, sugieren que es un tributo a la administración imperial (Makowski \& Vega Centeno, 2004: 710).

Por lo expuesto en el sur chico, se estima que el estilo «Puerto Viejo» está surgiendo en el período Intermedio Tardío y perdura hasta el Horizonte Tardío, ya con el amplio dominio de los incas. Para Pachacamac, las excavaciones reportan el ingreso del estilo Puerto Viejo antes de la presencia Inca, probablemente a finales del período Intermedio Tardío, por lo cual se propone que está ingresando a Pachacamac a través de intercambio de grupos culturales. Producida la conquista Inca, puede haber sido utilizado como ofrenda, toda vez que en el valle de Mala se encontraba uno de los hijos de Pachacamac (Santillán, 1968 [1563]). Sin embargo, su abundante presencia, tanto en Pachacamac como en Armatambo, nos puede indicar la existencia de mitmas trasladados por los incas desde Mala, encargados de fabricar esta cerámica ritual o de un culto relacionado con la representación de este personaje.

Dentro de otro grupo de cerámica que está ingresando a Pachacamac existe uno muy peculiar, que denominamos Estilo Lurín. Hasta ahora este estilo tiene un área limitada de distribución y un carácter local desde el punto de vista morfológico y tecnológico. Considerando el hecho de su mejor reconocimiento en el Santuario de Pachacamac y en otros sitios del valle de Lurín se decide dar el nombre de Estilo Lurín a los complejos cerámicos que aquí se presentan. Como criterio decisivo se toma la producción de la cerámica en la cuenca, es decir, de las materias primas accesibles en el mismo valle bajo, tal como se ha planteado.
Desde un punto de vista tecnológico, la arcilla de la cerámica del Estilo Lurín presenta un temperante hecho de granos blanco-lechoso de tamaño heterogéneo, además de partículas transparentes, brillantes y pequeñas (al parecer cuarzo hialino). Se observan en forma aislada partículas de color gris y láminas delgadas doradas. Los tiestos se caracterizan por la aplicación de una capa de engobe rojo (10 R 4/6, 2,5 YR 3/4) sobre la superficie externa del cuerpo, cuello y el labio (en algunos casos se extiende en una banda hasta el interior del cuello). En su mayoría, la superficie de los fragmentos es tratada con un alisado no muy bien logrado; aisladamente se aprecia un alisado uniforme en la superficie interna de los cuellos. Todos los tiestos presentan mica en ambas superficies, a pesar que algunos tienen engobe.

Las ollas son vasijas características de este estilo. Se explica por la presencia, en su cuerpo, de una aplicación en forma de «S» representando una serpiente que lleva círculos estampados. Destacan también las ollas con «pestaña», las ollas de cuello compuesto doblado al exterior en el sector de la boca y las ollas de cuello compuesto reforzado al interior y exterior en el sector del labio.

Formas del estilo Lurín se reportan en la «Pirámide con Rampa» n. ${ }^{\circ} 1$ y en varias excavaciones dentro de Pachacamac, así como en el perímetro del pueblo Puente Lurín y en todo el valle de Lurín, siempre asociadas con materiales del Horizonte Tardío (Feltham, 1983; Paredes \& Ramos, 1994: 347; Eeckhout \& Ramos, 1995; Eeckhout, 1999a: 40; Ramos, 1999). Los trabajos realizados en las «Pirámides con Rampa» n. ${ }^{\circ} 2$ y 3 permiten también su identificación bajo los nombres de Engobe Rojizo Bruñido y Sin Bruñir, Lurín Brun Lisse (Franco, 1998: 47; Eeckhout 1999b: 56). En el sitio 26 de la Pampa de San Bartolo se identifican formas de esta tradición con cerámica Inca, pero junto a ellas se recuperan restos de textiles coloniales (Ramos \& Paredes, 2002: 50). Eso estaría indicando que la cerámica del estilo Lurín es utilizada hasta en los primeros años de la Conquista.

Para el sitio Pucará-Pueblo Viejo, Makowski \& Vega Centeno (2004) definen varios estilos: Ychsma local del valle bajo, la cerámica marrón del valle alto, Puerto Viejo de la costa, estilo influenciado por la Costa Norte, incluyendo el ChimúInca y el Inca Provincial. Cuando describen la cerámica marrón mencionan que por el alfar parece corresponder a la tradición serrana, así como por las formas características (cántaros con labios reforzados interna y externamente, cántaros con cuello compuesto, ollas, pequeñas botellas, platos, etc.) y el acabado marrón llano. Su única decoración es una pintura roja poscocción y en algunos casos, unas serpientes aplicadas (Makowski \& Vega Centeno, 2004: 700). Este grupo de cerámica formaría parte del estilo Lurín identificado en Pachacamac.

Los inicios de este estilo se identifican en el sector «Las Palmas»-Pachacamac correspondientes a las primeras fases del Intermedio Tardío; las formas identificadas son vasijas utilitarias (Ramos \& Paredes, 2006: 53). En tal sentido, esta tradición alfarera debió constituir las vajillas de los peregrinos procedentes del interior de valle y que ingresaban al Santuario Pachacamac. Eso muestra, por lo tanto, una larga duración que abarca el Intermedio Tardío, el Horizonte Tardío y los primeros años de la Conquista. 
Realizando comparaciones de las ollas con «pestañas» con otros valles, se aprecia que su asociación al Horizonte Tardío es señalada por investigadores como Guffroy (1977: 56), quien menciona que es una vasija resultante de la influencia Inca en la región, de acuerdo a su material recuperado en el valle medio del Chillón Pérez \& Arce (1989: 35) denominan Inca Local (Chocas) a las vasijas de bordes con «pestañas» recuperadas en el sitio de Chocas, valle medio del Chillón. Para el Rímac, Silva (1992: 67-68) logra identificar en el sitio de Huaca Trujillo 1 y 2 ollas con «pestañas» asociadas a materiales del Horizonte Tardío.

En los sitios de Armatambo y Pedreros, Bazán (1990: 183) identifica el tipo «Marrón» con formas exclusivas como ollas con pestaña prominente, ollas de cuello recto, algunas con reborde, etc.; encuentra este tipo de cerámica en estratos Inca. Inexplicablemente, refiere que este tipo tiene mucha semejanza morfológica con la cerámica rústica del litoral de Mala, poniendo como ejemplo al sitio Las Totoritas. La forma más destacada es la olla con pestaña. Bazán señala haberlo registrado en los sitios de Armatambo, Santa Catalina, Cerro Pedreros, Huaca Trujillo y Huaca Aramburu, en las secciones baja y media del valle de Lima; Pachacamac en Lurín y en el valle del Chillón, en el sitio de Chocas (Bazán, 1990: 187). Llega a manifestar que existe una gran uniformidad, un solo alfar, lo que le hace suponer la existencia de una sola cantera proveedora de arcilla.

Durante nuestra investigación, hemos confrontado la información etnográfica y encontramos que la pasta presente en las vasijas modernas de Santo Domingo de los Olleros y algunas formas son similares a las del Estilo Lurín (Ramón, 1999). Todo eso se correlaciona mejor con la utilización de canteras similares de donde procede la misma materia prima de los alfares en diversos períodos, y tal como ya se ha propuesto se encuentra en afloramientos metamorfizados del batolito de la costa que afloran en todos los valles de la costa central del Perú. Pero en el caso del valle de Lurín, el Estilo Lurín del Intermedio Tardío y Horizonte Tardío y el etnográfico actual de Santo Domingo de los Olleros se ensamblan con el Estilo Lurín del horizonte blanco sobre rojo conformando en realidad una tradición alfarera de casi dos mil años de continuidad.

\section{Referencias citadas}

ARAMBURÚ C., R. \& MACHACUAY, M., 1996 - Talleres Inca de Producción No Agrícola en Pachacamac, 79 pp.; Lima: U. N. M. S. M. Trabajo de Investigación de PreBachillerato. Escuela Profesional de Arqueología.

BAZÁN DEL CAMPO, J., 1990 - Arqueología y Etnohistoria de los períodos prehispánicos tardíos de la costa central del Perú, 259 pp.; Lima: U. N. M. S. M. Tesis para optar el título en Licenciatura, escuela Profesional de Arqueología.

BONAVIA, D., 1959 - Cerámica de Puerto Viejo (Chilca). In: Actas y Trabajos del II Congreso Nacional de Historia del Perú, Vol. 1: 137-168; Lima.

BUENO MENDOZA, A., 1982 - El Antiguo valle de Pachacamac: Espacio, Tiempo y Cultura. Boletín de Lima, n. ${ }^{\circ}$ 24: 55 pp.; Lima: Editorial Los Pinos. Separata.
CORNEJO G., M. A., 2000 - La Nación Ischma y la provincia inka de Pachacamac. Arqueológicas, n. ${ }^{\circ}$ 24: 149-173; Lima.

DIARIO DE CAMPO, S/f - Anónimo. n. ${ }^{\circ} 7$. Archivo el Museo de Sitio de Pachacamac.

DÍAZ A., L. \& VALLEJO, F., 2002 - Identificación de Contextos Ichma en Armatambo. Arqueología y Sociedad, n. ${ }^{\circ}$ 14: 47-75; Lima.

EECKHOUT, P., 1999a - Pirámide con Rampa № III, Pachacamac. Nuevos datos, nuevas perspectivas. Bulletin de I'Institut Francais d'Études Andines, 28 (2): 169214; Lima.

EECKHOUT, P., 1999b - Pachacamac durant I'Intermédiare récent. Étude d'un site monumental préhispanique de la Côte centrales du Pérou, 503 pp.; Londres: BAR Internacional Series.

EECKHOUT, P. \& RAMOS G., J., 1995 - Proyecto Pachacamac: Informe Final de la Temporada 1993-1994. Anexo III: Prospecciones y Levantamientos Topográficos en el Valle de Lurín. Cerámica. Informe presentado al Instituto Nacional de Cultura.

FELTHAM, J., 1983 - The Lurin valley Peru, A. D. 1000-1532; Londres: Universidad de Londres. Tesis presentada para obtener el grado de Doctor en Folosofía.

FELTHAM, J. \& EECKHOUT, P., 2004 - Hacia una definición del estilo Ychsma: aportes preliminares sobre la cerámica Ychsma Tardía de la Pirámide III de Pachacamac. Bulletin de l'Institut Francais d'Études Andines, 33 (3): 643-679; Lima.

FORD, J., 1962 - Método cuantitativo para establecer cronologías culturales, 63 pp.; Washington D.C.: American Museum of Natural History. Unión Panamericana, Secretaría General O. E. A.

FRANCO J., R., 1993 - Excavaciones en la Pirámide con Rampa n. ํ2, Pachacamac; Lima: U. N. M. S. M. Tesis de Licenciatura.

FRANCO J., R., 1998 - La Pirámide con Rampa n. ㅇ 2 de Pachacamac. Excavaciones y Nuevas Interpretaciones, 105 pp.; Trujillo, Perú: Inka Natura Travel (auspiciador).

GABE B., C., 2000 - Investigaciones arqueológicas en el cerro Salazar-Mala, 64 pp.; Lima: Corporación Hotelera Bujama Resort SAC (auspiciador). Serie de Investigaciones CEAMA, n. ${ }^{\circ} 1$.

GOLDFRIED, H., 1969 - El Salitre, un centro religioso en el valle de Mala. In: Mesa redonda de Ciencias Prehistóricas y Antropológicas, Tomo II: 201-217; Lima: PUCP, Instituto Riva Agüero. Seminario de Antropología.

GUERRERO, D., 2004 - Cronología cerámica y patrones funerarios del valle del Rímac: una aproximación a los períodos tardíos. In: Puruchuco y la Sociedad de Lima: Un homenaje a Arturo Jiménez Borja: 157-177; Lima: Concytec.

GUFFROY, J., 1977 - Recherches archéologiques dans la moyenne vallée du Chillón. Bulletin de l'Institut Francais d'Études Andines, 6 (1-2): 25-62; Lima.

HYSLOP, J. \& MUJICA, E., 1992 - Investigaciones de A. Bandelier en Armatambo (Surco) en 1892. Gaceta Arqueológica Andina, n. $^{\circ}$ 22: 63-86; Lima.

ISLA C., J., 1995 - Materiales recuperados por Max Uhle (1906-1907) en la Isla San Lorenzo, Costa Central del Perú. Gaceta Arqueológica Andina, n. ${ }^{\circ}$ 24: 73-91; Lima.

KROEBER, A., 1926 - The Uhle Pottery Collections from Chancay. University of California Publications in American Archaeology and Ethnology, 21 (7): 265-304; Berkeley.

LUMBRERAS S., L. G., 1981 - La Arqueología como ciencia social, 192 pp.; Lima: Ediciones PEISA.

LUMBRERAS S., L. G., 1983 - El concepto de tipo en arqueología (II). Gaceta Arqueológica Andina, $\mathbf{n} .^{\circ}$ 7: 3; Lima. 
MAKOWSKI, K. \& VEGA CENTENO, M., 2004 - Estilos Regionales en la Costa Central en el Horizonte Tardío. Una aproximación desde el valle del Lurín. Bulletin de l'Institut Français d'Études Andines, 33 (3): 681-714; Lima.

MENZEL, D., 1976 - Pottery Style and Society in Ancient Peru, 275 pp.; Berkeley and Los Angeles, California: University of California Press.

PAREDES B., P., 1988 - Pachacamac-Pirámide con Rampa n. ${ }^{\circ}$ 2. Boletín de Lima, n. ${ }^{\circ} \mathbf{5 5}$ : 41-58; Lima.

PAREDES B., P., 1991a - Pachacamac. Los Incas y el Antiguo Perú. In: 3000 años de Historia: 364-383; Bruselas: Centro Cultural de la Villa de Madrid.

PAREDES B., P., 1991b - Pachacamac: murallas y caminos epimurales. Boletín de Lima, n. ${ }^{\circ}$ 74: 85-95; Lima.

PAREDES B., P. \& FRANCO J., R., 1987-1988 - Excavaciones en el Templo Viejo de Pachacamac. Willay, n. ${ }^{\circ}$ 27-28: 25-27; Cambridge.

PAREDES B., P. \& RAMOS G., J., 1994 - Excavaciones arqueológicas en el sector Las PalmasPachacamac. Boletín de Lima, Vol. XVI, n. ${ }^{\circ}$ 91-96: 313-349; Lima.

PÉREZ Z., M. \& ARCE T., S., 1989 - Chocas: asentamientos prehispánicos tardíos en el valle bajo del Chillón, 42 pp.; Lima: Consejo Nacional de Ciencia y Tecnología.

RAMÓN J., G., 1999 - Producción alfarera en Santo Domingo de los Olleros (HuarochiríLima). Bulletin de l'Institut Français d'Études Andines, 28 (2): 215-248; Lima.

RAMOS G., J., 1999 - Investigaciones Arqueológicas, Conservación y Restauración de la Pirámide con Rampa n..$^{\circ}$-Pachacamac. $6^{\circ}$ y $7^{\circ}$ Informe de Campo. Presentado al Instituto Nacional de Cultura. Ms.

RAMOS G., J. \& PAREDES B., P., 2002 - Trabajos Arqueológicos en la Pampa San Bartolo, Lurín-Lima. Boletín de Lima, . $^{\circ}$ 127: 29-53; Lima.

RAMOS G., J. \& PAREDES B., P., en prensa - Excavaciones en la Pirámide con Rampa n. ${ }^{\circ} 1$.

SANTILLÁN de, H., 1968 [1563] - Relación del origen, descendencia, política y gobierno de los Incas;Madrid: Ediciones Atlas. Biblioteca de Autores Españoles, Tomo CCIX.

SHIMADA, I., 1991 - Pachacamac Archaeology: Retrospect and Prospect. In: Pachacamac a reprint of the 1903 (M. Uhle, ed.): LXVIII pp.; Philadelphia: The University Museum of Archaeology and Anthropology University of Pennsylvania.

SILVA S., J. E., 1992 - Ocupaciones PostFormativas en el valle del Rímac: HuachipaJicamarca. Pachacamac, Vol. 1, n. ${ }^{\circ}$ 1: 49-74; Lima.

STRONG, W., 1925 - The Uhle Pottery Collections from Ancon. University of California Publications in American Archaeology an Ethnology, 21 (4): 135-190; Berkeley.

STRONG, W., WILLEY, G. \& CORBETT, J., 1943 - A ceramic sequence at Pachacamac. Archaeological Studies in Peru, 1941-1942. Columbia Studies in Archaeology and Ethnology, 1 (3): 27-122; New York.

UHLE, M., 1903 - Pachacamac. Report of the William Paper M. D. D. L. Peruvian Expedition of 1896, 103 pp.; Philadelphia: University of Pennsylvania.

VALLEJO B., F., 2004 - El estilo Ychsma: características generales, secuencia y distribución geográfica. Bulletin de I'Institut Français d'Études Andines, 33 (3): 595-642; Lima. 